$\mathrm{DOE} / \mathrm{ID} / 12691--2$

DE92 013692

\title{
ON-LINE CHEMICAL COMPOSITION \\ ANALYZER DEVELOPMENT
}

\section{Phase II}

Final Report

February 1992

Work Performed Under Contract No. DE-FC07-881D12691

\author{
Prepared for the \\ J.S. Department of Energy \\ Under DOE Idaho Field Office \\ Sponsored by the Office of the Assistant Secretary \\ for Conservation and Renewable Energy \\ office of Industrial Technologies \\ Washington, D.C. \\ Prepared by \\ Measurement \& Control Engineering Center \\ University of Tennessee \\ Knoxville, Tennessee
}




\begin{abstract}
The energy consumed in distillation processes in the United States represents nearly three percent of the total national energy consumption. If effective control of distillation columns can be accomplished, it has been estimated that it would result in a reduction in the national energy consumption of $0.3 \%(1)$. Real-time control based on mixture composition could achieve these savings. However, the major distillation processes represent diverse applications and at present there does not exist a proven on-line chemical composition sensor technology which can be used to control these diverse processes in real-time.

This report presents a summary of the findings of the second phase of a three phase elfort undertaken to develop an on-line real-time measurement and control system utilizing Raman spectroscopy. A prototype instrument system has been constructed utllizing a Perkin Elmer 1700 Spectrometer, a diode pumped YAG laser, two three axis positioning systems, a process sample cell and a personal computer. This system has been successfully tested using industrially supplied process samples to establish its performance. Also, continued application development was undertaken during this Phase of the program using both the spontaneous Raman and Surface-enhanced Raman modes of operation.

The study was performed for the U.S. Department of Energy, Office of Industrial Technologies, whose mission is to conduct cost-shared R\&D for new high-risk, high-payoff industrial energy conservation technologies. Although this document contains references to individual manufacturers and their products, the opinions expressed on the products reported do not necessarlly reflect the position of the Department of Energy.
\end{abstract}




\section{EXECUTIVE SUMMARY}

Direct on-line measurement of chemical composition is important for optimal control of distlllation columns which consume $3 \%$ of the energy used in the United States.

During Phase I of this effort it was shown that Raman spectroscopy could identify a group of chemical compounds which were important to the chemical processing industry. Also during this earlier phase candidate measurement system configurations were identified and measurement system accuracy and the time required to make an accurate measurement were established.

During the Phase II effort of the project a multiple point measurement system was constructed and tested. This was accomplished by routing the excitation light from a diode pumped YAG laser to the measurement points with optical fibers and returning the Rarnan scattered light to the spectrometer with optical fibers. An optical multiplexer was designed to time-share the light in both paths. The excitation light wavelength was in the near infrared range, thereby reducing the possible fluorescence of the samples to be analyzed.

The spectrum of the Raman-scattered light was measured by use of an interferometerbased spectrometer (Perkdn-Elmer 1700). The entire system is controlled by an IBM compatible computer. The computer initiates a scan of the spectrum of the chemical stream, gathers the spectral data from the spectrometer and estimates the composition of the constituents. The calibration of the system is done by a "training" process in which multiple samples with different typical concentrations of the constituents of the chemical stream are analyzed and their spectra stored. Next, the unique set of orthogonal functions making up the experimental data are found. Finally an empirical mathematical model of the relation between spectral features and composition is formed based on multiple linear regression of the weights of the orthogonal functions against the known concentrations of the constituents. The accuracy goal of the project was a measurement of composition of each constituent of a process 
chemical stream within 3 minutes with a root-mean-square (rms) uncertainty of less than $2 \%$. (This is an absolute error. That is, if the actual concentration is $10 \%$ the reading may lie within $8 \%$ and $12 \%$ with a probability of 0.68 , plus or minus one standard deviation on a Gaussian distribution. If the actual concentration is $50 \%$ the estimate of concentration would lie between $48 \%$ and $52 \%$ with the same probability.) The final system achleved an error of about $1 \%$ rms in 3 minutes for the constituents composing the chemical stream in the first field trial test site, Tennessee Eastman Corporation of Kingsport. Tennessee. 


\section{TABLE OF CONTENTS}

Abstract 1

Executive Summary

Table of Contents $\quad$ iv

List of Figures $\quad v$

List of Tables $\quad$ vi

I. Introduction 1

II. Background 3

III. Phase I Concept Development 4

IV. Major Tasks Included in the Phase II Prototype Chemlcal 5

V. System Design and Operation 6

VI. System Testing $\quad 15$

VII. Economic Analysis of Industrial Use of the Sensor System 22

VIII. Continued Applications Development 43

IX. Surface-Enhanced Raman Spectroscopy 48

X. Commercial System Design 64

XI. Documentation and Technology Transfer Presentations 67

XII. Project Review Meetings $\quad 69$

$\begin{array}{lll}\text { XIII. Conclusions and Future Work } & 70\end{array}$

Appendix A - Progress Report - Chemometric Data Analysis A-1 Using Artificial Neural Networks

Appendix B - A Literature Search of Near Infrared B-1 Surface-Enhanced Raman Scattering Research

Appendix C - Raman Spectroscopy for On-Line, $\quad$ C-1 Real-Time, Multi-Point Industria! Chemical Analysis

Appendix D - 1991 Pittsburgh Conference Presentation Abstract D-1

Appendix E - Blbllography E-1 


\section{LIST OF FIGURES}

Figure 1. $\quad$ Block Diagram of the Mult1-point Chemical 6

Figure 2. Arrangement of Excitation and Collection Fibers in 8

Figure 3. Sample Cell Construction $\quad 9$

Figure 4. Isopropanol Raman Spectrum with Silica Raman Interference 17

Figure 5. Close View of End of Fiber Probe Inside Quartz Sheath 18

Figure 6. Isopropanol Spectrum with New Probe-in-Sheath 19

Figure 7. TEC Fleld Test Columin 23

Figure 8. Composition Profiles in the TEC Azeo Column 25

Figure 9. $\quad$ Energy Costs of Distlllation $\quad 27$

Figure 10. Cost of Variation in Product Purity 28

Figure 11. Production Loss Due to Variation 29

Figure 12. Energy Requirements vs. Product Purity for the 30

Figure 13. Present Control System Dual-Ended Temperature Control 32

Figure 14. A Proposed Composition Based Control 33

Figure 15a. Variation in Product Purity vs. Feed Composition 35

Figure 15b. Variation in Product Purity vs. Feed Composition (magnifled) 36

Figure 16. Potential Energy Savings Using Composition Control 37

Figure 17a. Acetic Acid Composition Sensitivity vs. Tray Location 39

Figure 17b. Water Composition Sensitivity vs. Tray Location 40

Figure 17c. Solvent Composition Sensitivity vs. Tray Location 41

Figure 18. $\quad$ Transformation of Variation in Composition at Tray $9 \quad 42$

Figure 19. Spectrum of High Concentration Lactic Acid 46

Figure 20. $\quad$ Spectra of a Series of Resins with Differing 47

Figure 21. Spectrum of Gasoline \#6 49

Figure 22. Spectrum of Gasoline \#10 50

Figure 23. Electrochemical Cell Plating Apparatus $\quad 52$

Figure 24. Near Infrared FT-SERS Experimental Apparatus 53

Figure 25. Neat Pyridine $\quad 54$

Figure 26. $\quad$ SERS of 5 ppm Aqueous Pyridine $\quad 55$

$\begin{array}{lll}\text { Figure 27. } & \text { Vacuum Deposition Apparatus } & 57\end{array}$

Figure 28. SERS/Reg. Raman Comparison - Pyridine 60

Figure 29. SERS/Reg. Raman Comparison - Benzene 61

Figure 30. Electroplating Apparatus $\quad 63$

Figure 31. SERS Tests of 5 ppm Aqueous Pyridine 65 


\section{LIST OF TABLES}

Table 1. Estimated Cost of Interferometer and Dispersive

Table 2.

List of Technology Transfer Presentations

69 


\section{INTRODUCTION}

Distillation is one of the most imporiant unit operations found in the chemical and the petrochemical industries today. It is the primary means used to separate mixtures of chemicals into useful cornponents. Distillation columns are extremely energy intenslve and notoriously difficult to control in the complex and ever changing environment in which they typically operate. The successful operation and control of these systems are quite often fundamental to the overall economics, product quality and to the productivity of a plant or a refinery. The limiting factor on how well this can be done depends on accurate and rapid measurement of composition at key points in the column. Off-line laboratory measurements have been used extensively in the past. These are accurate and reliable, but they are generally far too slow to be used effectively in the minute by minute control of a column. Process chromatographs have been used on-line for many years, but they also tend to be very slow. At present process control systems utilize on-line indirect composition measurement estimated from temperature and pressure. These measurements are inexpensive and fast, but they tend to perform poorly in most industrial situations and often lead to incorrect control actions.

Some laboratory optical spectroscopic techniques are being developed for industrial process control. The most popular of these is probably near infrared absorption spectroscopy. It is a good general-purpose technique but can have problems in aqueous solutions because of the strong absorption of light by water in the near infrared. Generally speaking, laboratory analytical instrumentation is very accurate and versatile but also expensive and delicate. Therefore, if it is to be applied industrially the cost per measurement must be minimized and the instrument must be either ruggedized or otherwise protected from any harsh operating conditions. One way to bring down the cost per measurement is to share the cost of the instrumentation among several measurements. Since the measurement points may be at some considerable distance from each other this means either bringing chemical sample streams to the instrument with the attendant installation costs, time delay and maintenance problems or somehow physically extending the instrument capabilities to the measurement locations. Optical analytical methods lend themselves to extension of the instrument to the 
measurement points because of the avallabllity of low-loss optical fibers. Another advantige of this technique is that the expensive, delicate instrumesitation can be located in a relatively benign environment (such as a control room) and only the optical fibers and some relatively simple sampling equipment need to be at the measurement point. There are installation costs for the fiber but they should be lower than costs for piping the process streams to the Instrument and the maintenance cost should be stgnificantly lower. Since light propagatlon through the fibers is practically instantaneous there is no transport lag to slow the system response, except in any local sampling system at the measurement point.

Of the three common optical spectroscopic methods in use today, fluorescence spectroscopy, absorption spectroscopy, and Raman spectroscopy, we chose Raman because of its narrow, distinct spectral features and relative insensitivity to the presence of water in the sample. 


\section{BACKGROUND}

The control of industrial distillation columns has received much attention in recent years. The high cost of energy and new integrated plant designs have resulted in industry reconsidering the approach of column over-design and operation at high steam and reflux rates. It has been estimated that distillation processes consume three percent of the energy produced in the United States. This large energy usage has been attributed in large part to inefficiencies of currently used process control methods.

Optimal control of the energy usage in a distlliation column can be eflected by monitoring composition at several points in the column. An appropriate composition controller must be able to determine concentrations of multiple components at levels of $3 \%$ to $99 \%$ with accuracy $\pm 2 \%$ of true value. The required reproducibility or precision must be better than $2 \%$. The components present must be correctly identified by the composition controller and the composition measurements must be appropriately manipulated to provide a "realtime" signal for the controller in order that it be able to control the process.

An essential characteristic of an appropriate composition controller is its suitabillty to the industrial environment in general, and the column probe durability in the chemically hostule environment of the column. Temperatures of up to 600 degrees $F$ and pressure of 0.5 to 600 psia must not damage the composition probe or force the probe to generate incorrect information.

Varlous composition analysis methods have been considered, in the past, for use in column process control. Many of these have been utllized with varying degrees of success due 10 Inherent limitations in these techniques. A critical concern in determining potential energy savings utiltzing composition control is the universality of the on-line analyzer. Raman spectroscopy was chosen for this development effort as the most appropriate for the control of a broad range of distlllation separations.

The development of an advanced sensor system based on Raman spectroscopy for online, real-time data acquisition for distllation control has been divicied into three phases. 
The flrst phase effort was funded by the Department of Energy (DOE) In March, 1988 under contract DE-FC07-88ID 12691. This effort consisted of a feaslbility study to determine if Raman spectroscopy had broad application potential to distlllation control and the selection of the best detection system for its application to sensing and control.

This report summarizes the results of the second Phase Prototype On-Line Sensor Development effort. Following the successful completion of this effort the third Phase On-Line Field Trial and Demonstration of Column Control will be undertaken at the Ternessee Eastman plant in Kingsport, Tennessee.

\section{PHASE I CONCEPT DEVELOPMENT}

During the first phase of this contract experimental studies were successfully carried out demonstrating the feasibility of using Raman spectroscopy to analyze the chemical components within a distillation column (2). Experiments performed also established that a varlety of instrument systems, 1.e. FT or Dlode/CCD Arrays, could be constructed for column sensing and control. Also, the signal averaging time required for the necessary composition determinations was established for each detection system using test mixtures of appropriate chemicals prepared in-house or acquired from several industrial companies with an interest in the application of the technique to their processes. The time required for data acquisition and chemometric analysis was compared with the closed-loop cycle time required for control of typical industrial chemical processes. The important conclusions from Phase I are summarized below:

1. Raman spectroscopy is a good choice for analysis of important industrial chemicals.

2. Fiber optic probes can be used to multiplex the excitation and Raman scattered light.

3. The excitation wavelength should be between about $750 \mathrm{~nm}$ and $1.064 \mu \mathrm{m}$.

4. A spectroscopic resolution of about $2 \mathrm{~cm}^{-1}$ is required to resolve the spectral features of the three chosen chemical mixtures. 
5. An interferometer-based analysis system with $1.064 \mu \mathrm{m}$ excitation provides sufficient range, resolution and signal-to-noise ratio to make estimates of chemical component concentrations accurate to within about $2 \%$ in three minutes. Also, this performance is adequate for control of the chemical processes shosen for field trials.

Following a series of meetings with industrial chemical manufacturers and instrument suppliers, two distillation applications were selected for in-depth study during the Phase I effort and as candidates for sensor system design and testing during the Phase II and Phase III ef.orts of this project. The applications chosen were based on: (1) their industrial importance and total national energy consumption represented by these and related processes, and (2) their avallability as industrial test sites during the Phase III effort.

\section{MAJOR TASKS INCLUDED IN THE PHASE II PROTOTYPE CHEMICAL COMPOSITION DESIGN, CONSTRUCTION, AND TEST EFFORT}

The results of the major tasks undertaken as part of the Phase II effort can be found in the sections of this report given below:

1. Sample-cell design and fabrication

2. Optical system development

3. Software development

4. System Assembly and checkout

5. Prototype testing

6. Continued application development

7. Commercial system design

8. Economic analysis of industrial use of the sensor system

9. Documentation and technology transfer

10. Project reviews

11. Surface Enhanced Raman evaluation (added during Phase II) - Section IX
- Section V

- Section V

- Section V

- Section V

- Section VI

- Section VIII

- Section X

- Section VII

- Section XI

- Section XII 


\section{SYSTEM DESIGN AND OPERATION}

\section{System Design}

In October of 1989 a design review meeting was held at the University of Tennessee with representatives of DOE. Tennessee Eastman Corporation (TEC) and other interested partles. The basic structure of the proposed system design was presented at that time and approved by those present.

A diagram of the multi-point chemical composition measurement system is shown in Fig. 1.

\section{On-Line Chemical Composition Measurement System}

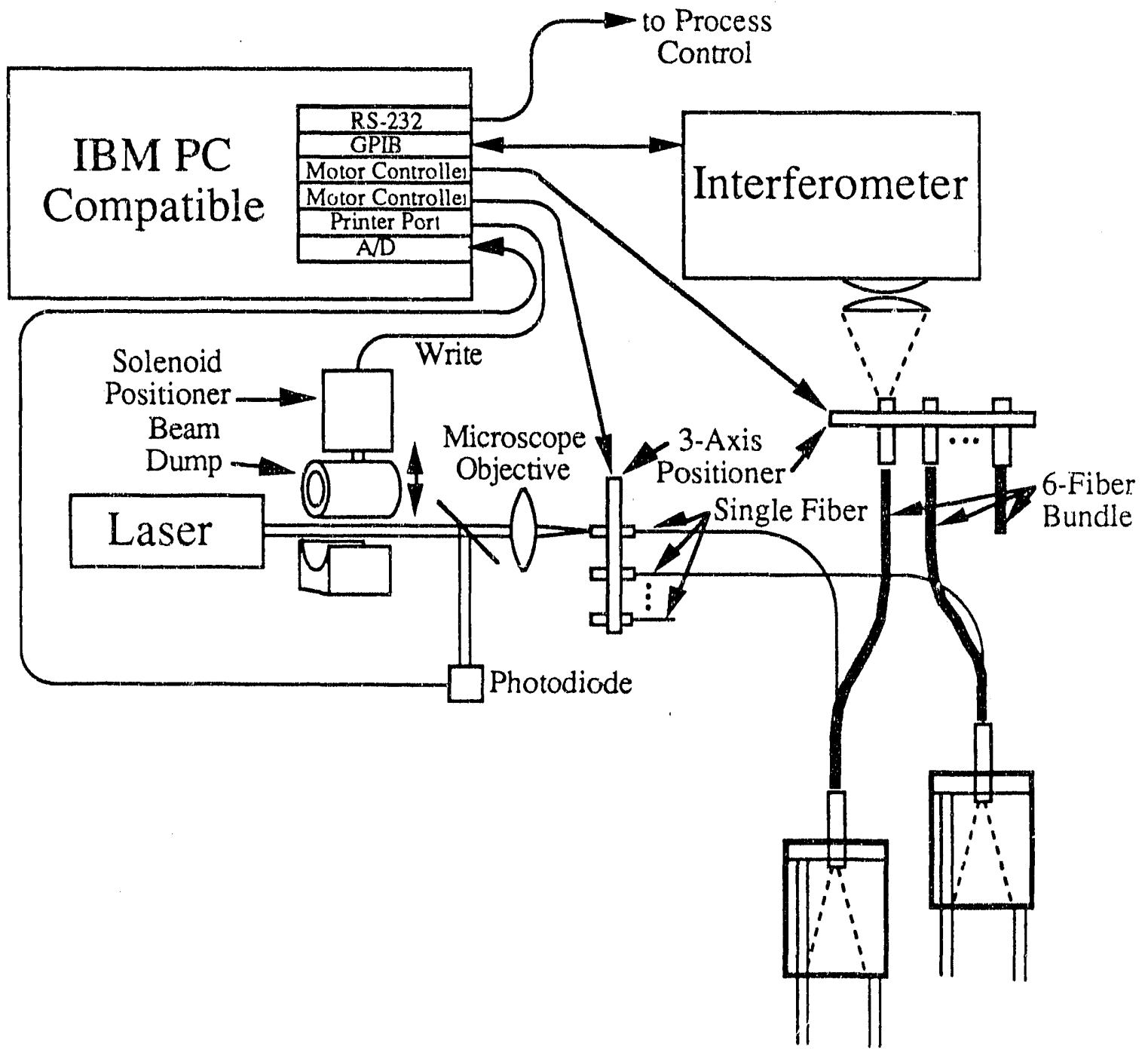

Figure 1. Block diagram of the multi-point chemical composition measurement system 
The system is controlled by an IBM compatible computer which sequences the operations and also does the chemometric estimates based on the acquired spectra. The excitation light is generated by a Neodymium-doped Yttrium-Aluminum-Garnet (YAG) laser whose free-space wavelength is $1.064 \mu \mathrm{m}$. This excitation light source was chosen because for all but a few chemical mixtures there is no significant fluorescence with that excitation wavelength and YAG lasers are avallable at power levels of hundreds of milliwatts to several watts. The laser light is focused by a microscope objective onto the core of an excitation fiber winch carries the excitation light to the chemical sample. Any of seve wa excitation fibers leading to different sample cells can be used and the one used is chosen by a 3-axis positioner which acts as the input multiplexer. During the time of switching between excitation fibers, the beam dump is interposed between the laser and the input multiplexer to avoid damage to the excitation fiber connectors or other structures by the excitation light.

The excitation light exits the excitation fiber in the sample cell. There it spreads in a conical pattern causing the Raman scattering effect as the light passes through the liquid. The cone is defined by the numerical aperture of the excitation fiber. At any point in this cone the excitation light is both Rayleigh and Raman scattered uniformly in all directions. Arrayed around the excitation fiber in the sample cell are six (6) collection fibers (Figure 2). 


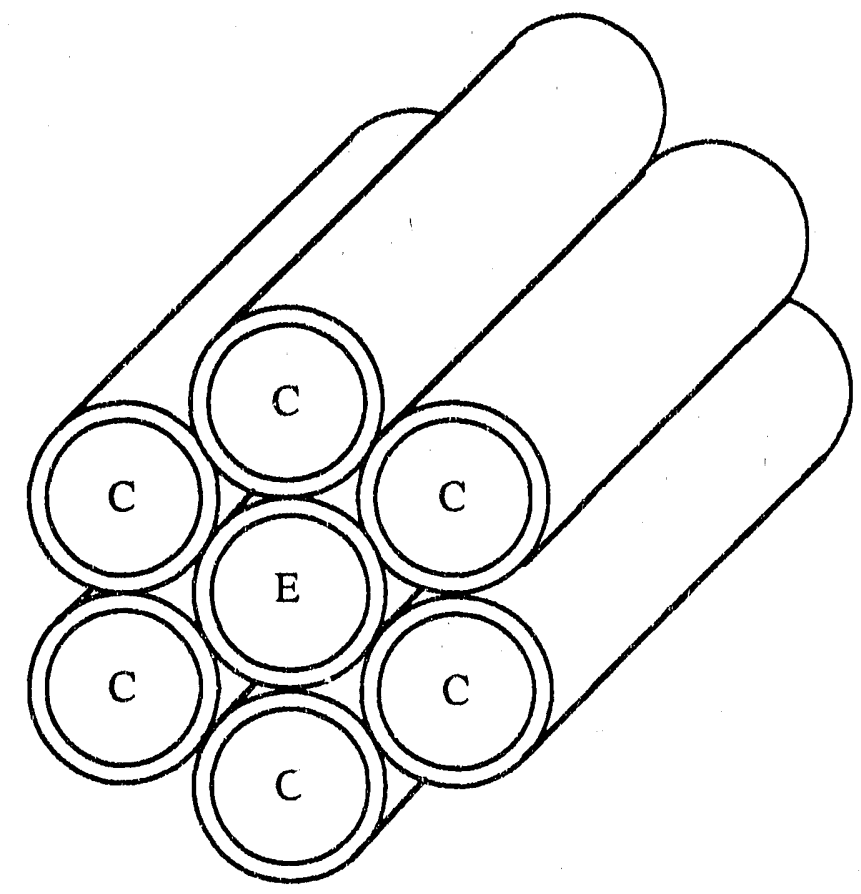

Figure 2. Arrangernent of excitation and collection fibers in the fiber optic probe. (E for excitation and $C$ for collection)

These fibers view the cone of excitation light, each from its own perspective, and collect any light Rayleigh or Raman scattered within the excitation cone which strikes the ends of the collection fibers at an angle within each fiber's numerical aperture. The bundle ai excitation and collection fibers entering the sample cell is referred to as the "fiber optic probe". Basically, the amount of light collected depends on the amount of overlap between the excitation cone and each of the "reception cones" of the collection fibers. The power of the collected light depends on both the volume of overlap and the intensity of the excitation light in that volume. It has been shown both theoretically and experimentally that the collection efficiency of the probe can be optimized by setting the collection fibers at a small angle with respect to the excitation fiber (3).

The sample cell is designed to optimize the collection efficiency of the fiber optic probe (Figure 3). 


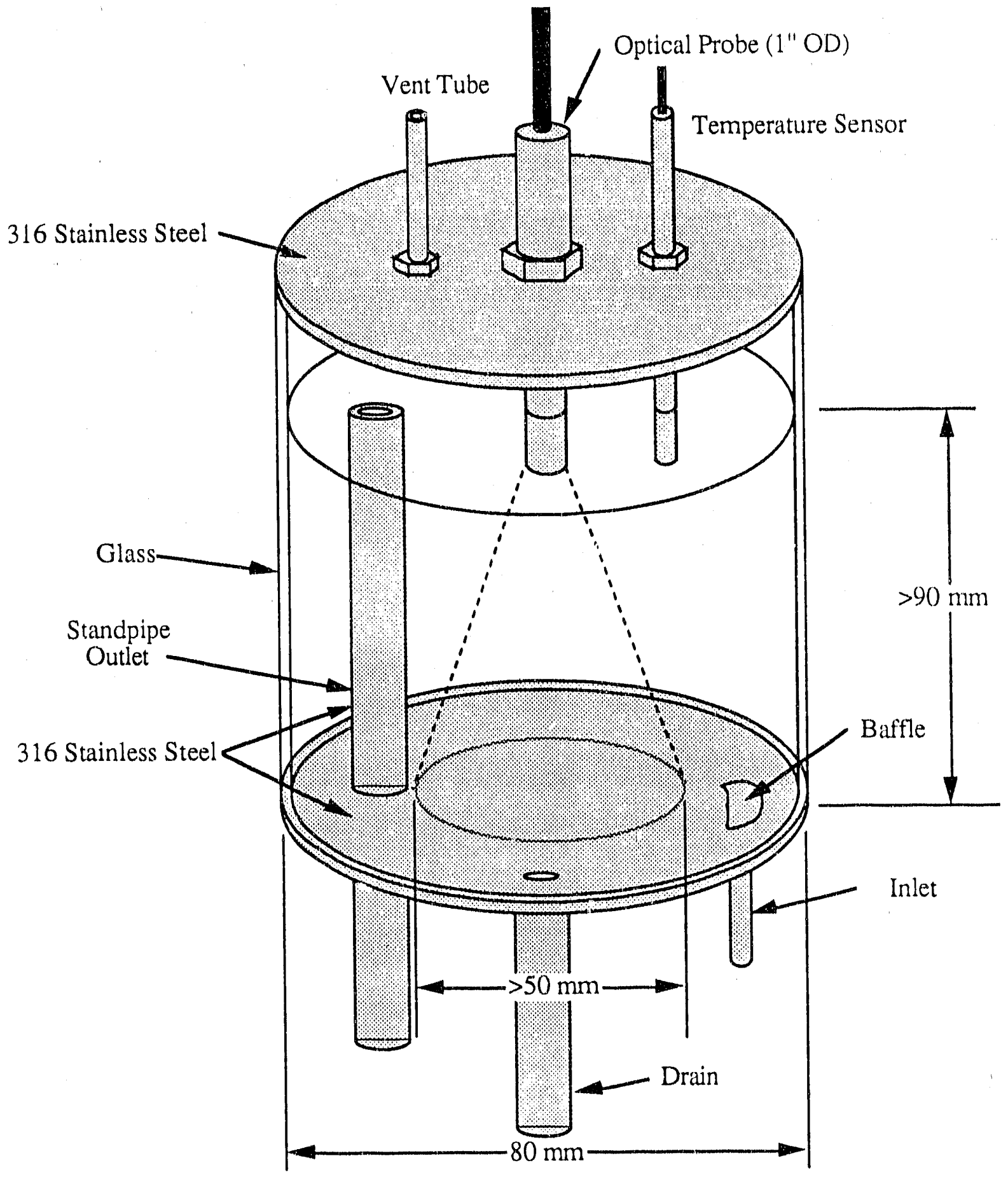

Figure 3. Sample cell construction.

It was shown in Phase I that the depth of field should be at least $90 \mathrm{~mm}$ to gather practically all of the avallable light. Therefore the cell is more than $90 \mathrm{~mm}$ deep and wide enough to accommodate the entire excitation cone to a $90 \mathrm{~mm}$ depth without obstruction. The 
chemical to be analyzed enters the sample cell at the bottom through a bafle which promotes mixing through turbulence. The chemical exits the sample cell through a standplpe which sets the upper level of the liquid in the sample cell. Obviously this level should be above the end of the probe. The fiber optic probe is inside a quartz "sheath" which prevents direct contact between the chemical sample and the end of the probe. This is necessary because in Phase I it was discuvered that the TEC chemical stream will attack the epoxy which holds the flbers In place, allowing them to move, and sertously degrading their collection efficlency. The quart $z$ sheath is itself inside a protective stainless steel tube which is fastened in place by a one (1) Inch Swagelock fitting. In the top of the sample cell there are also Swagelock fittings to hold a thermocouple and a vent tube. There is also a drain in the bottom of the sample cell to emply it for cleaning.

The collected Rayleigh- and Raman-scattered light travels back to the spectrometer through the collection fibers. The light exiting the collection fibers is coupled to the spectrometer by a lens arrangement which maximizes the amount of light which ultimately strikes the detector in the spectrometer (4). This is very important because signal-to-noise ratio is of critical importance in this measurement. After passing through the input lenses the light is filtered by a Rayleigh-rejection filter which partially removes that part of the excitation light which was Rayleigh scattered into the collection fibers (or directly reflected from the sample cell or Mie scattered from any particulates in the chemical). This is important because the Rayleigh-scattered light can be several orders of magnitude more powerful than the Raman scattered and could saturate the detector and/or cause excess shot noise if it is not removed. Next the light traverses the interferometer which generates the interferogram.

Upon exdting the interferometer the light is again filtered by a Rayleigh-rejection filter to further reduce the power at the excitation wavelength. Then the remaining light is focused onto an Indium-Gallium-Arsenide (InGaAs) photodiode and its power is converted to electrical current. The electrical current from the pholodiode is converted to voltage and is sampled at 
evenly spaced intervals of interferometer mirror postion and stored in computer memory. This data sequence of voltages forms the interferogram. Multiple interferograms are taken and averaged and stored in memory. The Fourter transform of the averaged interferogram is calculated by the spectrometer's computer, forming the power spectrum of the collected light. and that spectrum is then avallable for acquisition by the system's control computer.

The sequence of events is controlled by the system control computer. It Initiates the taking of data by sending a command to the spectrometer. The system computer then continuously polls the spectrometer computer, checking to see whether it is ready with the spectral data. When the spectrometer is ready the control computer commands it to transie: the data over the IEEE-488 data bus. When the transfer is complete the control computer analyzes the acquired spectrum and estimates the chemical composition of the contents of the sample cell.

\section{Chemometric Modeling}

The estimation of chemical composition is based on an empirical model. The model is formed during a calibration process. The callbration consists of a training phase and a verfication phase. In the training phase multiple chemical mixtures representative of the range of chemical compositions expected in the actual process are introduced into the sample cell one at a time. A spectrum is taken of each one and stored. After all spectra have been acquired most of them are used in the training process but a few are reserved for the verification phase. The training spectra are analyzed along with the known conceritrations of each constituent of the training chemical mixtures. The analysis corsists of findirig the socalled "elgenspectra" of the traindrig spectra. The elgenspectra are the orthogonal eigenfunctions of the set of training spectra and therefore any of the individual training spectra (and any other spectrum of the same length) could be formed by a weighted sum of the eigenspectra. The model is a multiple linear regression of each of the chemical concentrations against the weights on the elgenspectra used to form each training spectrum. A new spectrum can be broken down into its sum of welghted eigenspectra and its weights can be used to 
estimate the concentrations of its components. After the model is formed it is used to compare the estimates of concentrations of components in the verification samples with the actual concentrations as a final check on the valldity of the model. The rms error between the actual and estimated concentrations of the vertfication samples is the estimated measurement error of the instrument, for that range of concentrations, and for those components.

\section{New Model for Chemometric Estimates of Concentrations}

A concern in the process of estimation of concentrations from spectra is the effect of vartations of the net excitation power delivered to the sample. The laser power itself can, and does, fluctuate by a small percentage on a short term basis (over hours) and will gradually decay on a longer term basis (over weeks). The coupling into the excitation fiber or between fibers at connectors can change over time or with maintenance. The window which protects the probe from the sample can change optical characteristics due to a bulld-up of contaminants over time. The effective power to a mixture can be affected by particulates in the mixture. Any of these effects, If not measured and known accurately can strongly affect the accuracy of chemometric estimates. During the summer of 1991 various techniques were tested to compensate for possible changes in effective excitation power, resulting in the development of a model which uses ratios of spectral peak areas for estimation purposes. Since all spectral peak areas are affected by the same factor when the effective excitation power changes, the ratios of spectral peak areas are not affected. All tests of the model were performed using the acid-solvent water (ASW) mixture present in the Phase II field trial column.

The model is based on the following observations. There are three signilicant peaks in the spectrum of ASW mixtures. The area of the first peak varies most strongly with acid concentration although it is slightly affected by the solvent concentration. This one will be referred to as the acid peak. The area of the next peak is due entirely to solvent concentration and will be referred to as the solvent peak. The third one is in another region of the spectrum known as the "CH stretching" regton, referred to as the $\mathrm{CH}$ peak. It area is allected by' both acid and solvent. In addition, all the peaks are affected in another way by all three 
components. The Raman-scattered light on 1 t $s$ way back to the reception fibers is attenuated by the components. The attenuations are strong functions of wavelength so each peak is alfected differently by the different components. The effect of attenuation is described by Beer's law in which th a. nount of light transnulted is a negative exponential function of the concentration of the component ( as well as its attenuation cross section and the path length). Based on these observations the following model was developed:

$$
\begin{aligned}
& A_{a}=P_{L}\left(\sigma_{a c} C_{a}+\sigma_{s a} C_{s}\right) e^{-a_{\infty} C_{a}} e^{-a_{s} C_{s}} e^{-a_{w a} C_{w}} \\
& A_{s}=P_{L} \sigma_{s s} C_{s} e^{-a_{s} C_{a}} e^{-a_{s} C_{s}} e^{-a_{w s} C_{w}} \\
& A_{c h}=P_{L}\left(\sigma_{a c h} C_{a}+\sigma_{s c h} C_{s}\right) e^{-a_{a c h} C_{a}} e^{-a_{s c h} C_{s}} e^{-a_{w c h} C_{w}}
\end{aligned}
$$

where

$A_{a}$ is the area of the acid peak

$A_{S}$ is the area of the solvent peak

$A_{c h}$ is the area of the $\mathrm{CH}$ peak

$P_{L}$ is the effective excitation power

$\mathrm{C}_{\mathrm{a}}$ is the concentration of acid

$\mathrm{C}_{\mathrm{S}}$ is the concentration of solvent

$\mathrm{C}_{\mathrm{W}}$ is the concentration of water

$\mathrm{s}_{\mathrm{aa}}$ is the effective Raman cross section for acid at the acid peak location

$\mathrm{s}_{\mathrm{sa}}$ is the effective Raman cross section for solvent at the acid peak location

$\mathrm{s}_{\mathrm{SS}}$ is the effective Raman cross section for solvent at the solvent peak location

sach is the effective Raman cross section for acid at the CH peak location

$\mathrm{s}_{\mathrm{sch}}$ is the effective Raman cross section for solvent at the $\mathrm{CH}$ peak location

$\mathrm{a}_{\mathrm{aa}}$ is a coefficient for absorption of acid at the acid peak location

$a_{\text {sa }}$ is a coefficient for absorption of solvent at the acid peak location

$a_{w a}$ is a coefficient for absorption of water at the acid peak location

$a_{a s}$ is a coefficient for absorption of acid at the solvent peak location

$a_{s s}$ is a coefficient for absorption of solvent at the solvent peak location

$a_{w s}$ is a coefficient for absorption of water at the solvent peak location

$a_{a c h}$ is a coefficient for absorption of acid at the $\mathrm{CH}$ peak location

$\mathrm{a}_{\mathrm{sch}}$ is a coefficient for absorption of solvent at the $\mathrm{CH}$ peak location

$\mathrm{a}_{\text {wch }}$ is a coefficient for absorption of water at the $\mathrm{CH}$ peak location

Only area ratios area used in the calibration and estimation processes. The area ratios used are

$\frac{A_{a}}{A_{a}+A_{s}+A_{c h}}, \frac{A_{s}}{A_{a}+A_{s}+A_{c h}}$ and $\frac{A_{c h}}{A_{a}+A_{s}+A_{c h}}$ 
Callbration spectral data are used to find the best values of these parameters to minlmize the error between estimates of concentrations and actual concentrations. Then the model is frozen and is used to estimate concentrations from new spectral data. The model is non-linear. Therefore an iterative technique has been developed to search for the best concentration estimates based on a minimization of the ms error between the area ratios computed by model and the actual area ratios. With this model the rms estimation errors are about $0.8 \%$ for solvent, $1.7 \%$ for acid and $1.3 \%$ for water.

\section{Temperature Effects on Measurement of Acid solvent and Water concentrations}

Several systematic tests were conducted to determine whether temperature has a significant effect on the estimates of concentrations in ASW mixtures. The tests consisted of placing a known sample in a large test tube which was thermostated and controlled at a constant temperature and gathering spectral data for 15 mixtures at 4 temperatures each. The mixtures ranged from $100 \%$ acid to $100 \%$ solvent to $100 \%$ water with most of the mixtures being in the normal range of concentrations expected in operation of the Tennessee Eastman distlllation column. The four temperatures were $30^{\circ} \mathrm{C}, 40^{\circ} \mathrm{C}, 50^{\circ} \mathrm{C}$ and $60^{\circ} \mathrm{C}$. The spectral data were reduced by the chemometric estimation algorithm. Models were butlt for the four temperature cases. The models were different, but only slightly. At a single temperature the estimates of concentration scatter arourid the actual concentrations because of system nolse. This inherent uncertainty with an rms error between $0.8 \%$ and $1.8 \%$ was significantly greater than the errors due to the small differences in the models. Therefore it is not statistically possible to conclude whether there are actual differences due to temperature, but it is possible to conclude that, if there are differences, their effects are insignificant compared to the uncertainty due to system noise.

\section{Effects of Suspended Particulntes on Measurement of Acid. Solvent and Water Concentrations}

Two tests were conducted to determine the effects of suspended particulates on concentrations in ASW mixtures. In each test a sample of $100 \%$ acid was contaminated with 
successively higher concentrations of particulates. Two types of particulates were usedi talcum powder and iron oxtde particles.

In the talcum powder tests the effects on the spectrum were almost unmeasurable until $\therefore$ i.

the concentration was so high the suspension was milky white and completely opaque. We belleve this test to be much worse than anything we could expect in actual operation at Tennessee Eastman and therefore conclude that particles of this size should not be a problem.

In the iron oxide tests the effects on the spectrum were much more significant. Agaln we tested to concentrations much higher than we expect at Tennessee Eastman. We found that two major effects occurred: 1) the baseline of the spectrum rose and 2) the peaks above the baseline got smaller. The rising of the baseline might be due to Raman scattering from the particles or, more likely, backscattering of the Raman of the optical fiber itself. The peaks due to acid and solvent were diminished because of the masking effect of the tron oxide particles making the mixture murky, In these tests, the chemometric estimates were greatly affected by the iron oxide particles. Therefore although we do .not anticipate particles at anywhere near the concentrations we used, we have recommended to Tennessee Eastman that the input sample stream be filtered to reduce the concentration of particles of this size to near zero.

\section{SYSTEM TESTING}

In August of 1990 the system components were all on hand and the system was assembled. During and after the system assembly a series of tests of increasing complexity was performed to check all aspects of system operation. A test plan for these tests was submitted to DOE for approval. The tests were grouped into four types:

1. Single-cell, static-sample tests.

2. Multiple-cell, static-sample tests.

3. Single-cell and multiple-cell flowing-sample tests.

4. Time response tests.

In the first three types of tests runs were done over a 3-day pertod taking data and estimating concentrations continuously over that time. 
The first single-cell, static-sample tests revealed some problems. The probe design had a protective quartz window covering the probe end to avold chemical attack on the epoxy holding the fibers. The quartz window was held in place by an arrangement of a metal retalning ring and O-rings to seal out the chemical. First, because the window was not flush against the fiber ends; there was some reflection of the light from the excitation flber Into the collection flbers before the excitation light entered the chemical sample. This reflection caused some excitation. light to be collected. This was not a major problem since the Rayleigh-rejection filters effectively removed that light.

The more serlous problem was due to the following effect: While traversing the fiber path from the laser to the sample cell the excitation light caused Raman scattering in the excitation fiber. This scattering went in all directions including down the fiber toward the sample cell. When it exited the excitation fiber it, along with the light at the excitation wavelength, was partially reflected into the collection fibers. Even though Ranian scattering in the sllica fiber is a relatively weak effect the long path provided a Raman signal of significant power compared to the Raman scattering from the chemical sample. This formed a rather broad Interfering background on the desired Raman spectrum rom the chemical sample (Figure 4). 


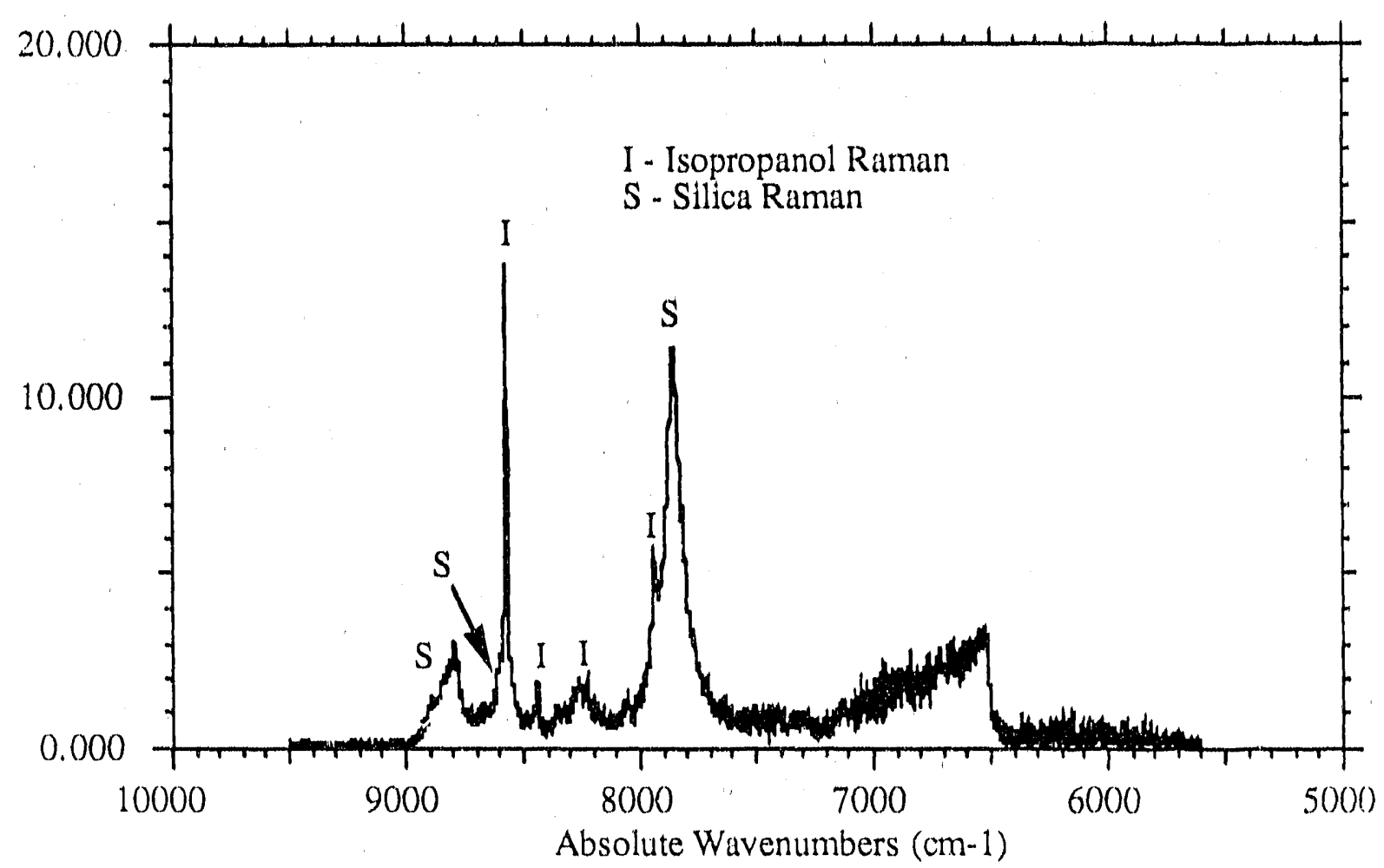

Figure 4. Isopropanol Raman spectrum with silica Raman interference

If this background had been a constant in all samples regardless of their cuncentration it could have been removed by direct subtraction or simply in the chemometric model-forming process. Unfortunately it was not constant because the slightest mechanical disturbance or thermal change caused the spacing between the protective window and the fiber ends to change, thereby changing the intensity of this "sillca Raman".

Another problem with this probe design was that the O-ring seals intended to keep the chemical out did not. Both problems were solved by changing the probe design. An all quartz sheath extending up and out of the chemlcal sample was designed. The probefits into the sheath and flush against the flat end of the sheath which serves as a window (Figure 5). 


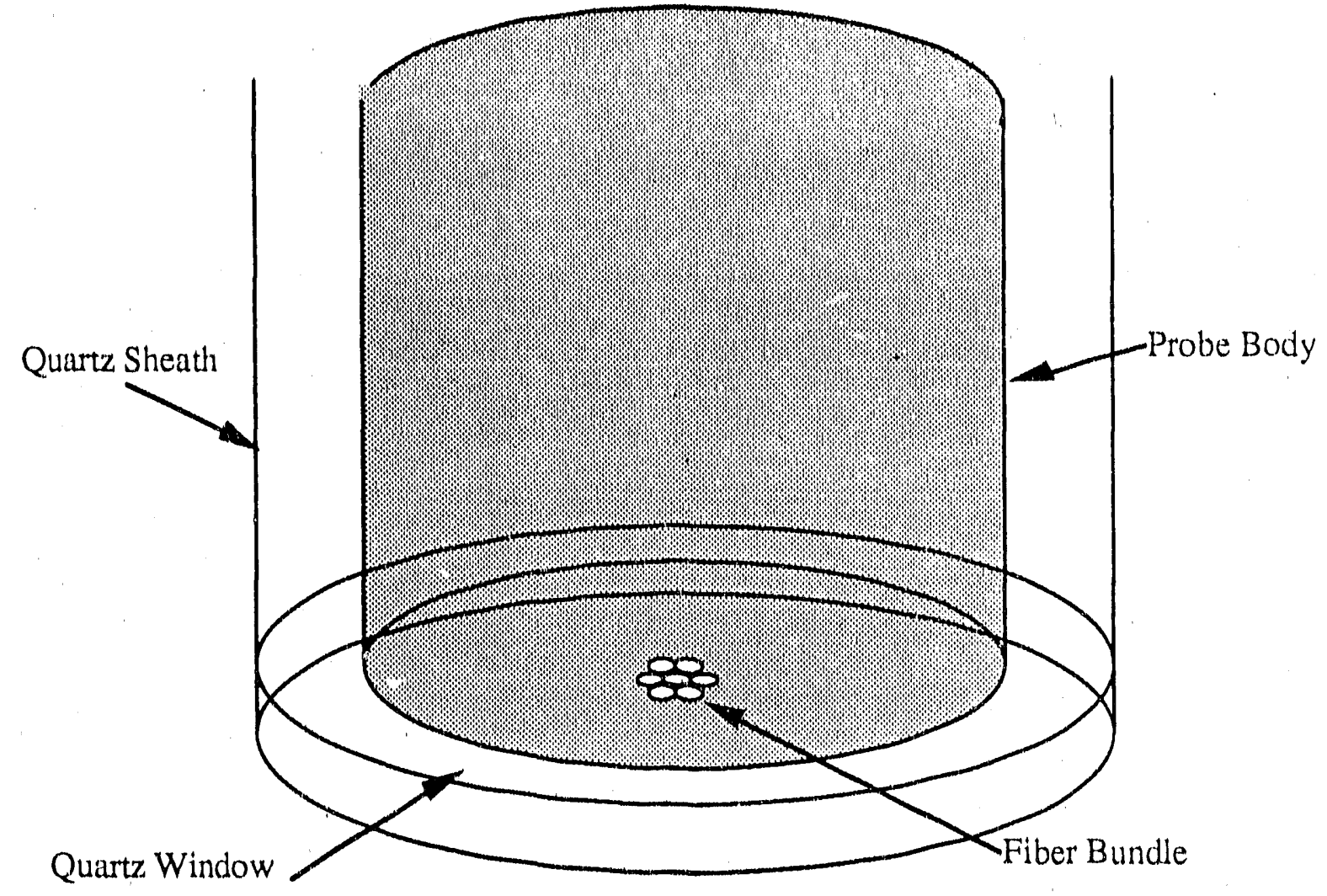

Figure 5. Close view of end of flber probe inside quartz sheath

To ensure that reflections do not occur, index matching gel is placed between the window anf the fiber ends. This new probe design effectively eliminated the leakage and silica Raman probleins (Figure 5). The spectrum in Figure 6 was taken with the new detector and laser as well as the new probe design. Notice the improved signal-to-nolse ratio and the extra feature in the absolute waverumber range from 6350 to 6600 . 


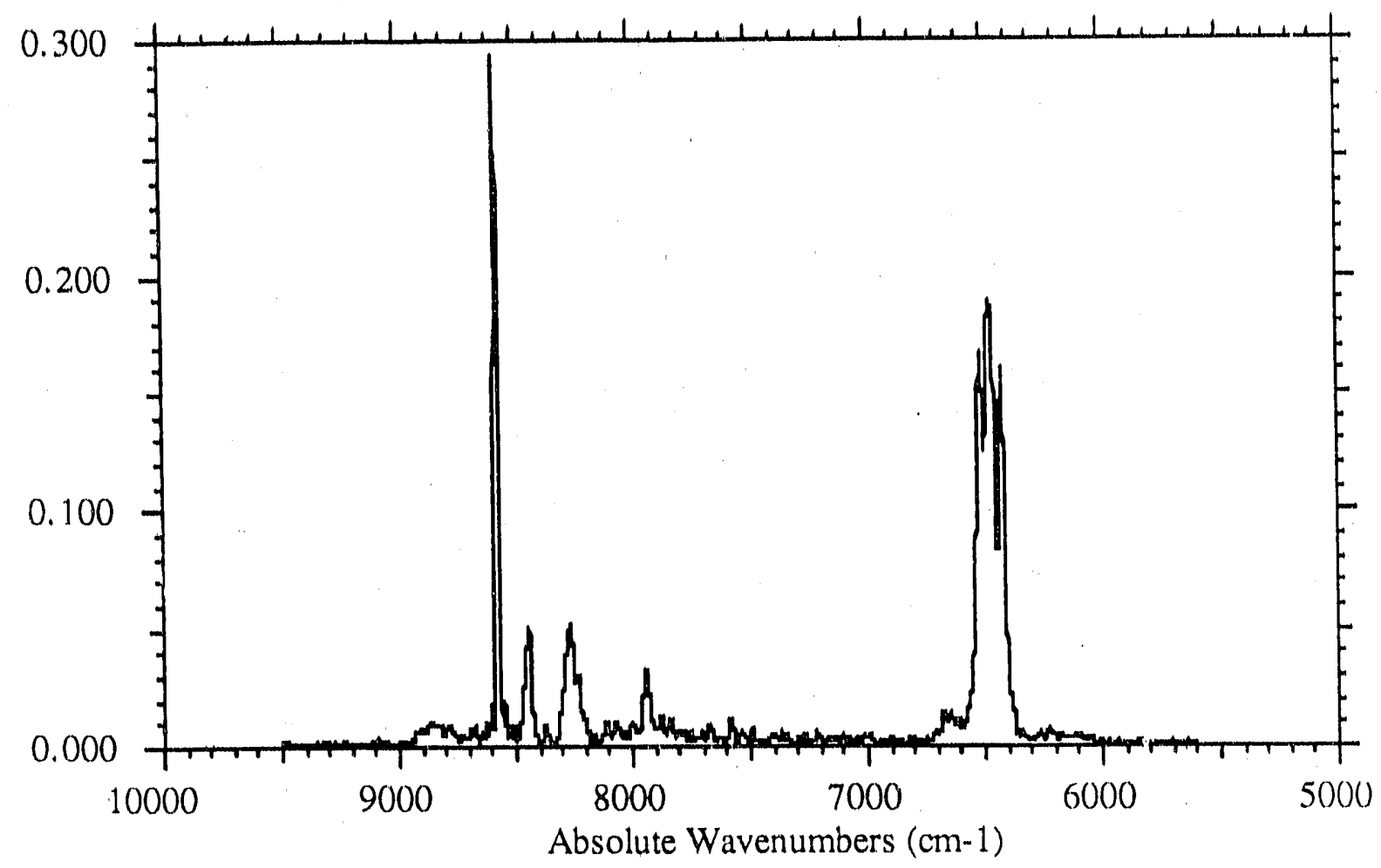

Figure 6. Isopropanol spectrum with new probe-In-sheath design showing almost no silica Raman interference

Another major problem revealed in the first single-cell, static-sample tests was poor signal-to-nolse ratio. Based on Phase I work it was clear that the addition of long extension libers with couplers would reduce both the excitation power at the sample and the returned Raman power and that to achieve the accuracy goal more laser power or less detector noise or a combination of both would be needed. More powerful YAG lasers were avallable but were very expensive and unreliable and required high electrical power and water cooling. None of these attributes was appropriate for an industrial application where economy and rellabllity are paramount. The development of dlode-pumped YAG lasers was about to bring them to market at the power levels required and the market in diode-pumped YAG lasers was maturing. In September a diode-pumped YAG was ordered with the stipulation that it was to be delivered by the end of October in a condition that met specifications of up to $2 \mathrm{~W}$ of output power. After some delays the laser finally arrived in late November. A field engineer came with it and aligned it. Its maximum power capability at that time was about $1.1 \mathrm{~W}$. The vendor prumised to furnish new pump diodes in the near future that would allow it to meet the specifications. 
During about a month of experimentation with the new diode-pumped YAG its power gradually diminished. After consultations with the vendor it was decided that the new diodes would not be forthcoming in the foreseeable future. The laser was returned and another laser from another vendor was ordered. This cne arrived in early March and met specifications. During this time of receiving and testing diode-pumped YAG lasers many of the tests were run with poor signal-to-noise ratio exercising the system and llustrating problems but never achieving the desired accuracy.

In the two-cell, static-sample tests the multiplexer was added to the system and during the 3-day tests two excitation fibers were constantly moved in and out of the laser beam. The 3axis translational stages performed very reliably during the three days, once they were started right. On some occasions at start-up one of the positioners would go to the wrong position and the test would have to be restarted. Once the two positions were successfully found, however, the positioner never falled to find them for three days without error.

The third set of tests involved flowing samples. A cart was built with tanks and a pump to allow pumping a chemical sample in a continuous loop to observe any possible flow effects on the measurement. In the first tests of the flowing sample copious bubble formation was observed. These bubbles would then flow around the loop and appear in the sarnple cell. This caused a considerable loss in sensitivity of the measurement because of the scattering of the excitation light by the bubbles. It was discovered that this bubble formation was caused by the sucking of air into the standpipe. When all the liquid in the sample cell above the standpipe was pumped out the pump pulled air in. The problem was solved by lowering the standpipe slightly to allow a greater flow of liquid into the standpipe. Occasionally some bubbles from various sources, especially on start-up, would enter the cell but by adjusting the flow rate and allowing some pressure rellef at the top of the sample cell it was possible to establish a steady flow with no bubbles.

An imoortant question is "If the input flow suddenly changes from one composition to another, how long is it before the cell contents reflect this new composit:on:?" Obriously the 
changeover time involves the flow rate and the cell size. The cell size is about one quart and the flow rates were approximately one gallon per minute $(1 \mathrm{gpm})$. If all the old sample were pushed out in simple transport by the new composition the changeover would take place in about 15 seconds, well within the effectlve time between measurements of about 3 minutes. However the changeover involves mixing and the old composition will not simply be pushed out by the new. To determine this time two tests were done:

1. Water with red food coloring was put into one tank and clear water into another. Flow was established with the clear water and the flow was switched suddenly to the red water. The transition and the changeover seemed to take place in about 30 seconds. Upon switching back, however, to the clear water, the transition seemed to take much longer, on the order of 2 minutes. This is apparently due to an optical illusion. When red water mixes with clear water the color change to red seems to happen quickly and when clear water is mixed with red the water seems to stay "red" for a long time. The human eye and brain seem to interpret almost any red color at all as being completely "red" and cannot distinguish very well between slightly "red" and very "red".

2. Pure isopropanol was put into one tank and a mixture of $70 \%$ isopropanol and $30 \%$ water in another. Flow was established with pure isopropanol and then suddenly switched to the mixture. Since there is no visual indication of the changeover, spectra were taken at 3 minute intervals before, during and after the switchover. From the estimates of concentration it appeared that the changeover occurred completely within one 3 minute Interval.

The conclusion from these tests is that the instrument measurement time of 3 minutes is the dominant time constant in the system and the changeover time in the cell does not cause any significant additional delay in the measurement.

In early 1991 it was decided to get a thermoelectrically-cooled detector to use in the industrial prototype instead of the liquild nitrogen $\left(\mathrm{LN}_{2}\right)$ cooled detector that had been used up until that time. The noise level was expected to be somewhat higher because the thermoelectric 
cooling can only take the detector down to about $233 \mathrm{~K}$ as opposed to the $77 \mathrm{~K}$ of the $\mathrm{LN}_{2}$ cooling but it was considered important for an industrial instrument not to use $\mathrm{LN}_{2}$. Surprisingly, the new detector, even at room temperature, had much lower noise than the old detector. The vendor attributes this improvernent in performance to the great improvements in the process of makdng InGaAs diodes in the past year. The new detector in combination with the new, more powerful laser greatly increased the signal-to-noise ratio. In late March a new calibration of isopropanol-water mixtures was done with the new detector and laser. Even with the losses in the extension fibers and couplers the rms measurement uncertainty in the verification samples was about $1.1 \%$. This compares very favorably with the rms error of about $10 \%$ with the old detector and laser.

\section{ECONOMIC ANALYSIS OF INDUSTRIAL USE OF THE SENSOR SYSTEM}

\section{Introduction}

During Phase II, a preliminary study estimated the energy savings potential of an analyzer based, column control system. The study used a computer simulation of the column selected for the Phase III field test of the Raman analyzer. The column is a Tennessee Eastman Company azeotropic distllation column (TEC azeo column) that uses a solvent mixture to break the heterogeneous azeotrope formed between water and acetic acid. It is the final unit operation in a plant that recovers commercial grade anhydrous acetic acid from a weak mixture of acetic acid and water.

\section{Description of the Column}

The column is shown in Figure 7. It is a 52 stage column with a reboiler, condenser, and decanter. Energy is supplied to the column at the reboller and removed at the condenser. The boiling liquid in the reboller (mostly acetic acid) provides vapor flow for the tray section of the column. In the condenser, vapors in the overhead (mostly solvent and water) are condensed and fed to the decanter. The decanter removes the water and pumps the solvent back to the column as liquld reflux for the tray section. The tray section is a series of contacting units in 


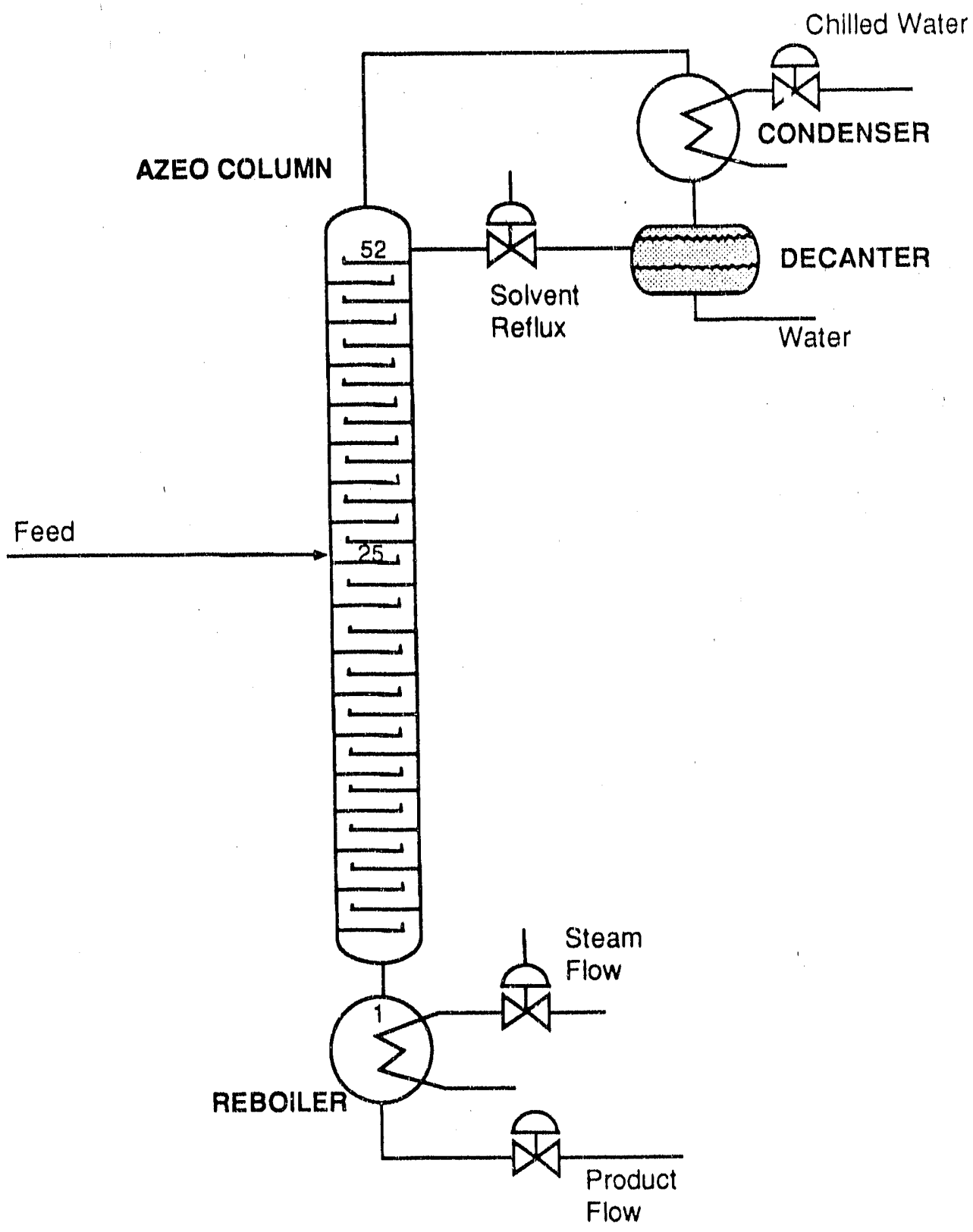

Figure 7

TEC Field Test Column 
which the more volatile components move up and the less volatile components move down. The composition profile which develops from tray-to-tray is one in which the low volatile(s) or components collect in the bottom of the tower and the more highly volatile components collect in the top. Figure 8 shows the composition profile that develops during the normal base case operation of the azeo column.

\section{Energy Efficiency and Utilization in Distillation}

Before presenting the economic analysis of the proposed composition based control of the TEC azeo column, a more general discussion of the energy efficlency and utllization in distillation processes would be helpful. Distillation processes are very common in virtually all manufacturing operations that produce or use liquid materials. It is the most general and in many cases, the only unit operation avallable for separating homogeneous liquid mixtures Into their components. Because it requires the vaporization of large quantities of liquid. distillation is extremely energy intensive. The energy requirement depends on: (1) the relative volatility of each component, (2) the number of trays in the column, (3) the desired purity of the separation, and (4) the variation in the operating environment of the column.

Relotive volatility The relative volatility (as well as other physical properties) of a given mixture is thermodynamically fixed; however, it can be modified by adding other components. In Tennessee Eastman's case, the relative volatilities of acetic acid and water are the same at the azeotrope composition. This phenomena makes it impossible to separate the two components without the addition of a solvent. The selection of solvent influences the energy usage or demand and thus, the solvent identity is typically held in close proprietary confidence.

Number of trays. The number and efficiency of the trays also influences the energy required for a separation. In general, the more trays present and/or the greater tray efficiency, the less energy required for the separation. There is, however, a point of diminishing return. In the column design, the cost of capital equipment is typically balanced against the cost of operations. 


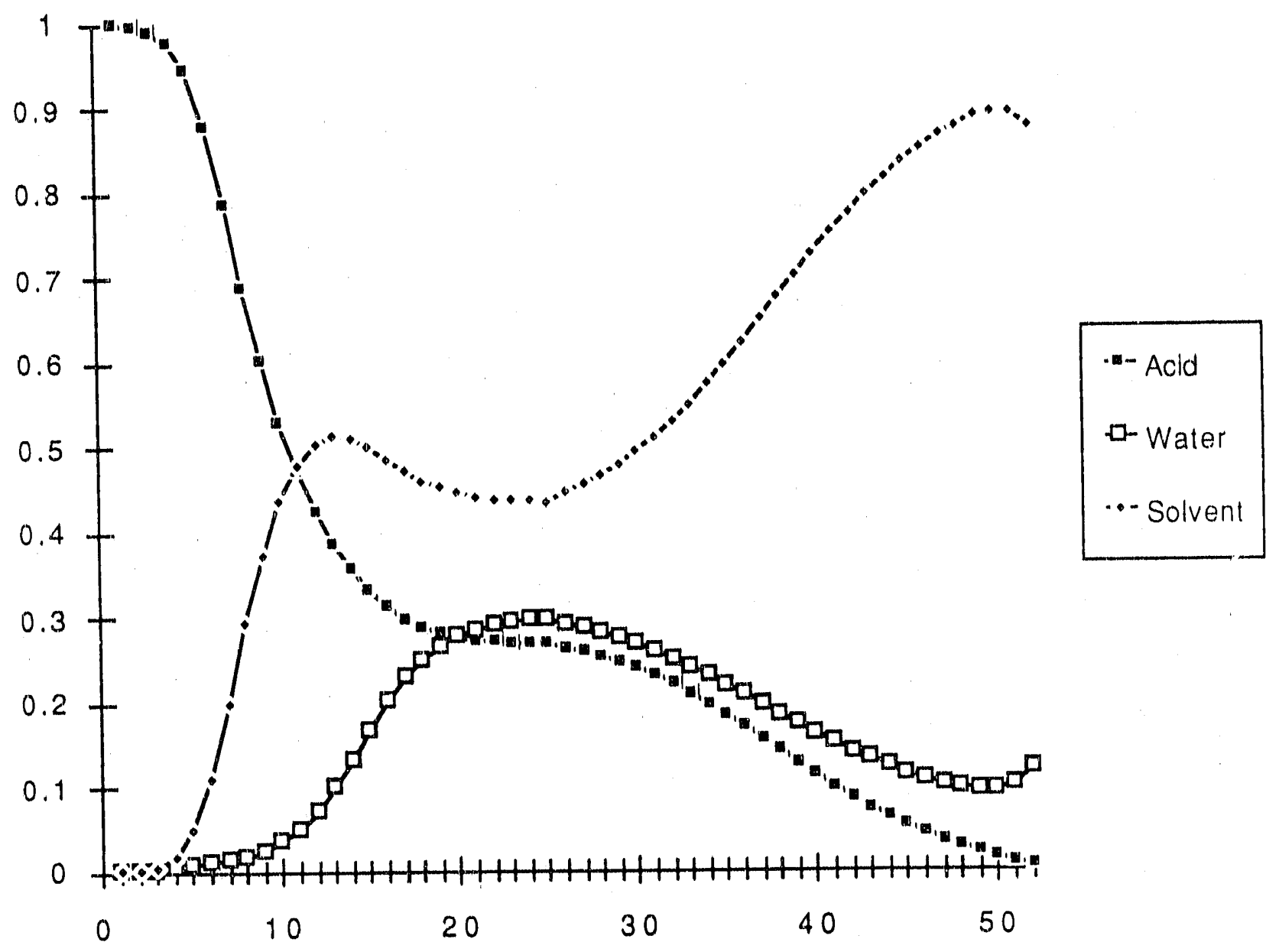

Figure 8

Composition Profiles in the TEC Azeo Column 
Product purity The relationship between product purty and energy is a consideration in understanding energy efficlency and utllization in distillation processes. A gerieral relationship between product purity and energy costs is shown in Figure 9. Note that the amount of energy required increases exponentlally as the destred product purity increases. In general, high purity separations require large amounts of energy, whereas low purity separations are less energy intensive.

Variation in the operating environment for a column operating in a typical industrial environment, the relationship between product purity and energy (as shown in Figure 9) orily tells part of the story. Typically most distillation columns suffer disturbances in the energy and materlal balances that cause changes in the operation of the column. These changes can propagate to the product as variations in the composition and purity. Figure 10 shows the effect of that variation on energy utilization. If the variation in product purity is high, the column must be adjusted to a higher energy level to insure that the minimum purity specification (set by the customer) is always met.

In addition to increasing the energy requirements, variation can also reduce substantially the production capactty of the column. Figure 11 lllustrates the magnitude of lost production as a function of variation. For production constrained plants, this can be a greater practical concern than the extra cost of energy. If the variation in the product purity is smaller, the column can be operated closer to the minimum energy requirement without Hisking production of off-spec products.

\section{Energy Curve for TEC Azeo Column}

As part of the economic analysis of the TEC azeo column, an energy vs purity curve was determined using a column simulation. The clirve is shown in Figure 12. The simulation program used was developed both at the Tennessee Eastman Company and the University of Tennessee. This program represents the state-of-the-art in distillation simulation. It is a detalled, dyna:?ic tray-to-tray simulation that includes propretary Tennessee Eastman Company data. 


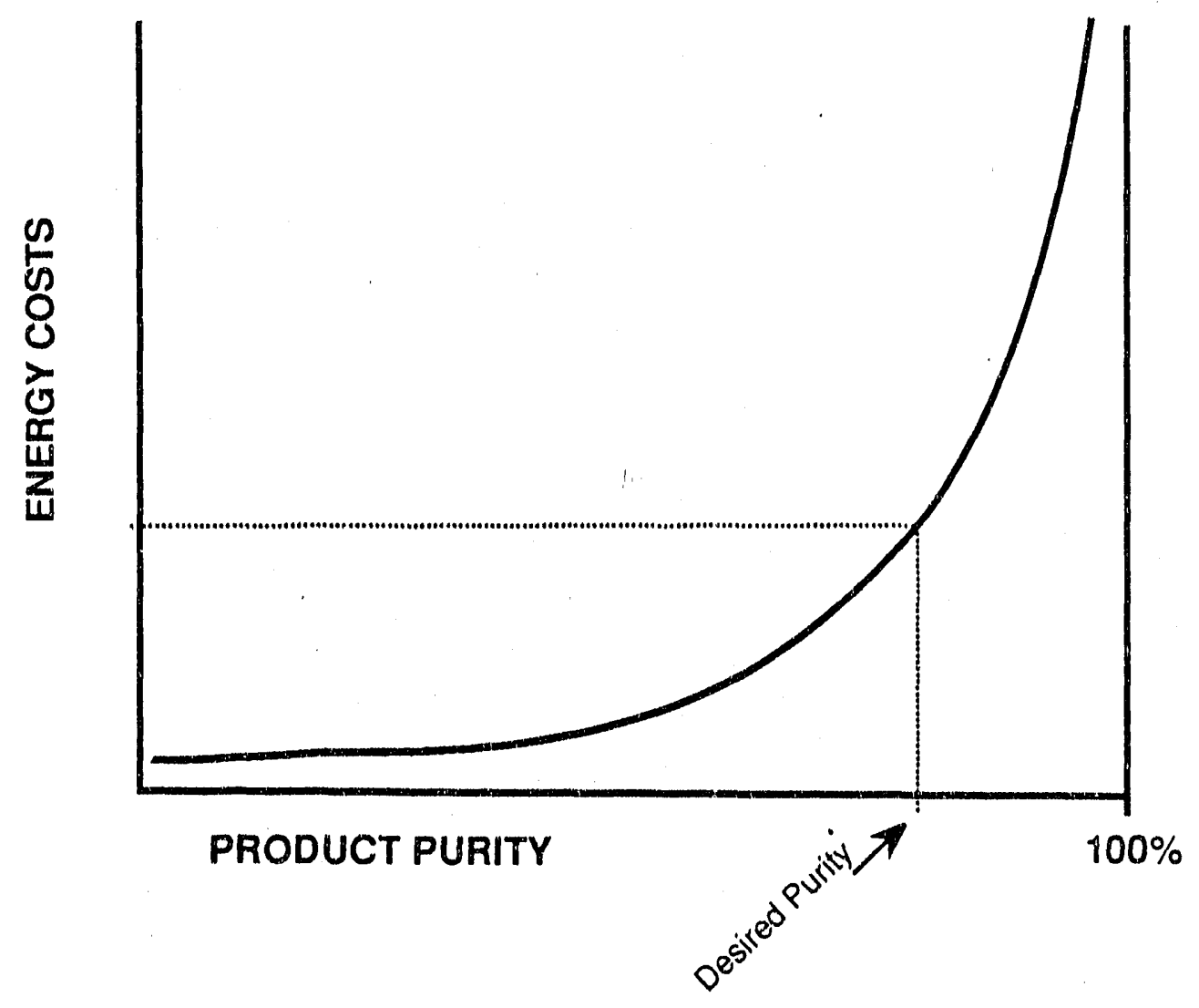

Figure 9

Energy Costs of Distillation 


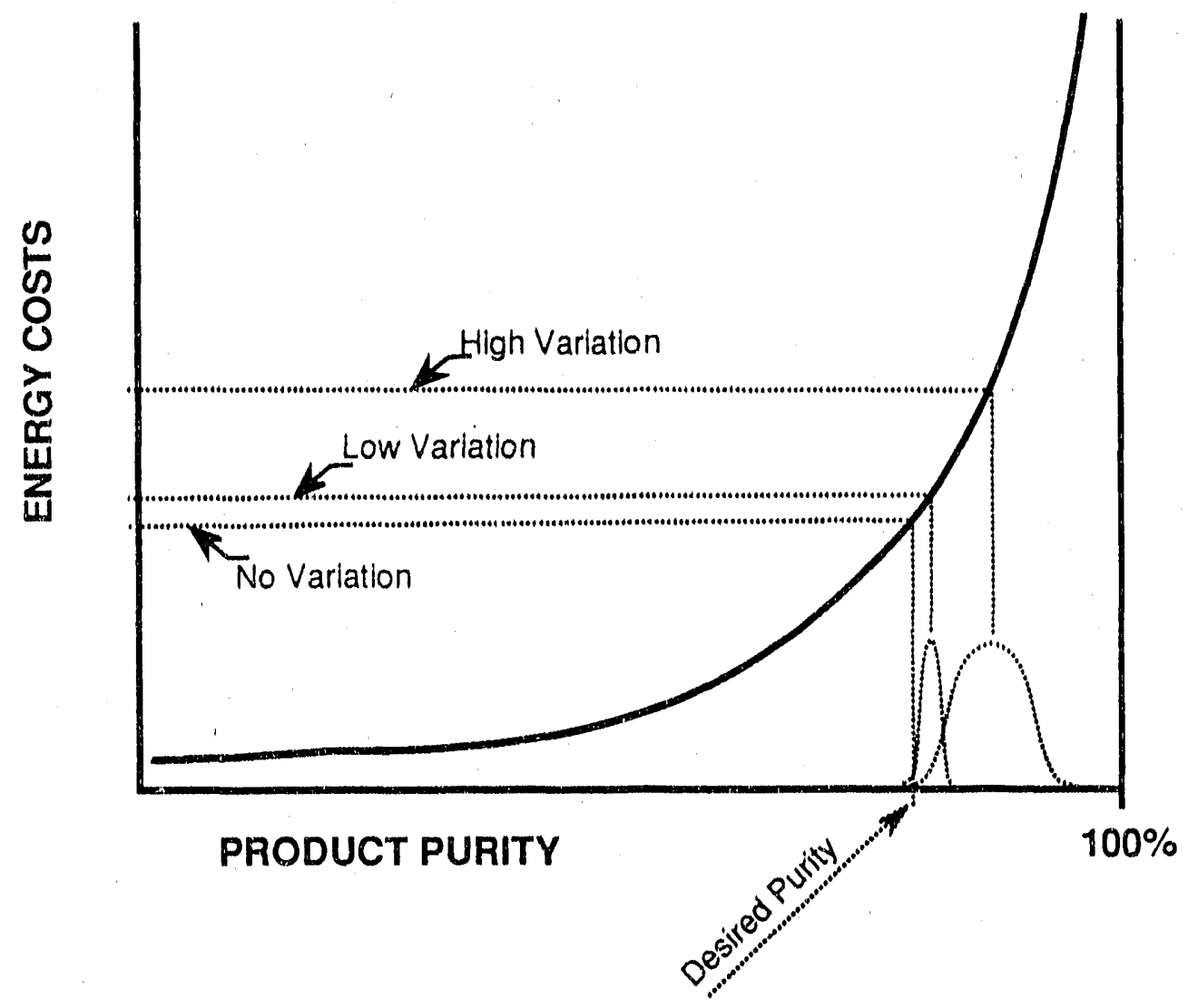

Figure 10

Cost of Variation in Product Purity 


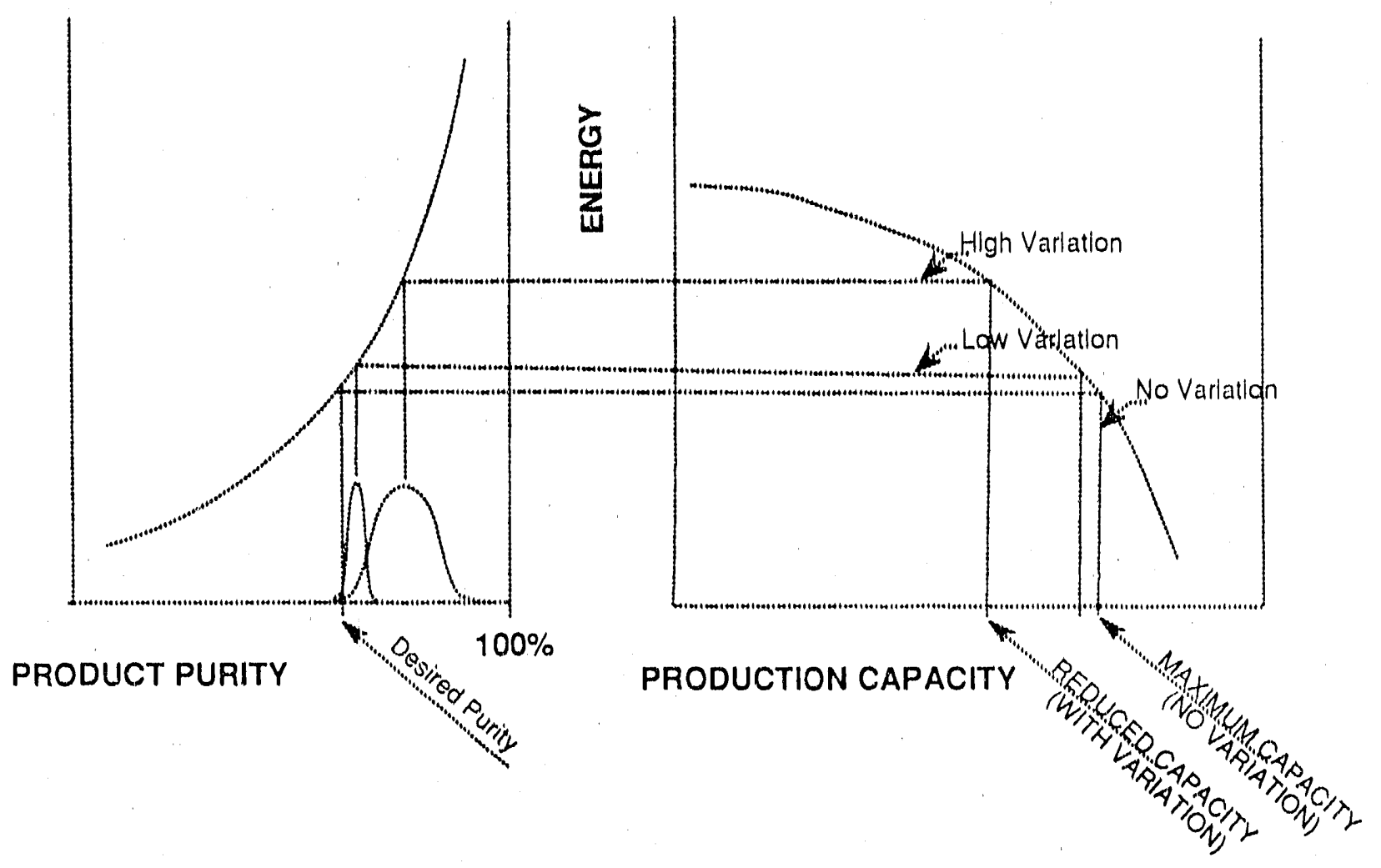

Figure 11

Production Loss Due to Variation 


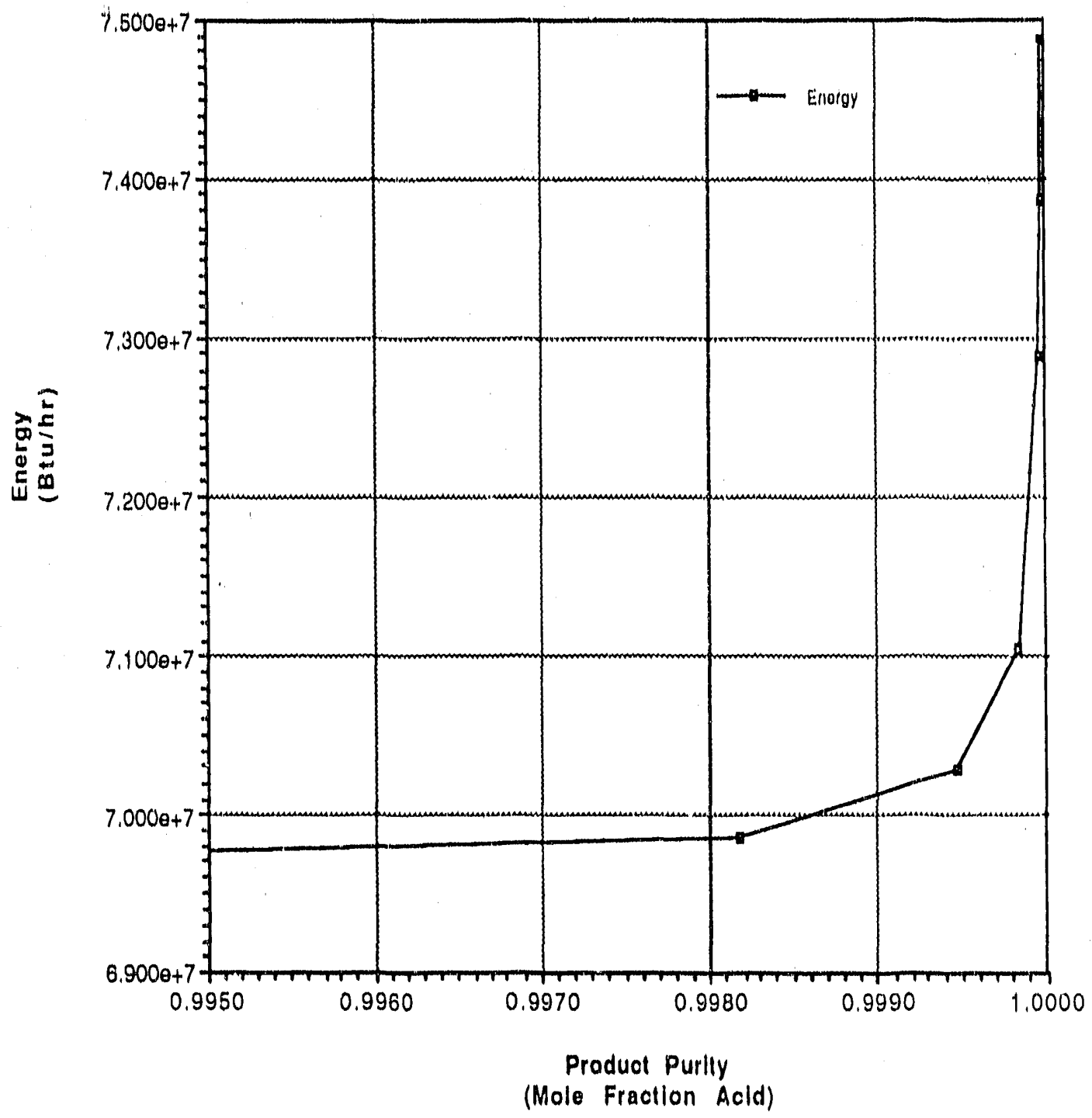

Figure 12

Energy Requirements vs Product Purity for the Phase III Azeo Column 


\section{Role of Process Control in Reducing Energy}

A distillation control system reduces energy consumption by mindmizing the effect of varlation on the product purtty. As can be seen in Figures $9 \& 10$, if the varlation in the product purity can be reduced substantlally, Improvements In both energy consumption and production capacity can be realked. A column control system attempts to reduce the vartation by changing the matertal and energy balances of the column based on process measurements.

Figure 13 ulustrates the control system currently used on the Phase III azeo column, It consists of two ternperature measurements and two controllers. One controller adjusts the reflux to malntaln the temperature on tray 42 ; the other adjusts the steam flow to malntaln the temperature on tray 12.

Figures 14 illustrates a proposed control system that uses compostlon measurement Instead of temperature. Both control schemes manlpulate the rellux and the steam rates. The difference between the schemes is the sensor type and location. The current system. (Figure 13) uses temperatures to indirectly measure composition. These temperature sensors were most probably located by simple rules-of-thumb. In the proposed system (14), the sensors will be replaced by the Raman based composition analyzer and have been carefully located to minlmize Interaction and maxdmlze sensitlvity.

For the TEC azeo column, the primary disturbances are: (1) changes in the feed rate, (2) changes in the feed composition, and (3) changes in the column pressure. When one or more of these events occur, the control systems react by changing both the reflux and the steam. In lerms of energy efficlency, the basic concern is how each control system performs with respect to the vartation in product purity. Again, low varlation in product purity allows the column to be operated much closer to the minimum energy without the risk of making product at a lower purity than the customer specifles.

\section{Comparison of Control Strategies}

For this preliminary energy analysis, four control systems and one source of column disturbance were considered. The four control systems considered were the two dual ended 


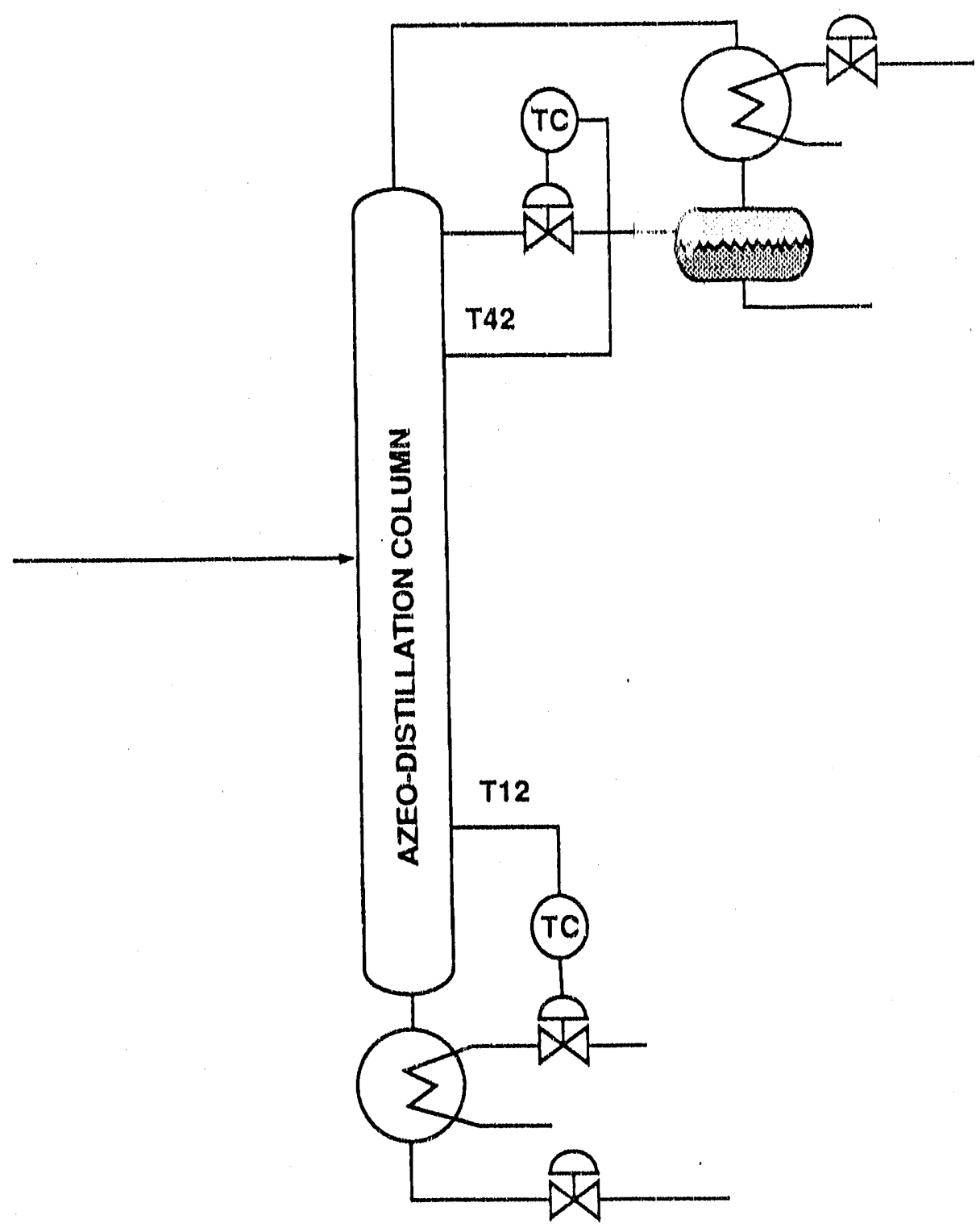

Figure 13

Preseni Control System-

Dual-Ended Temperature Control 


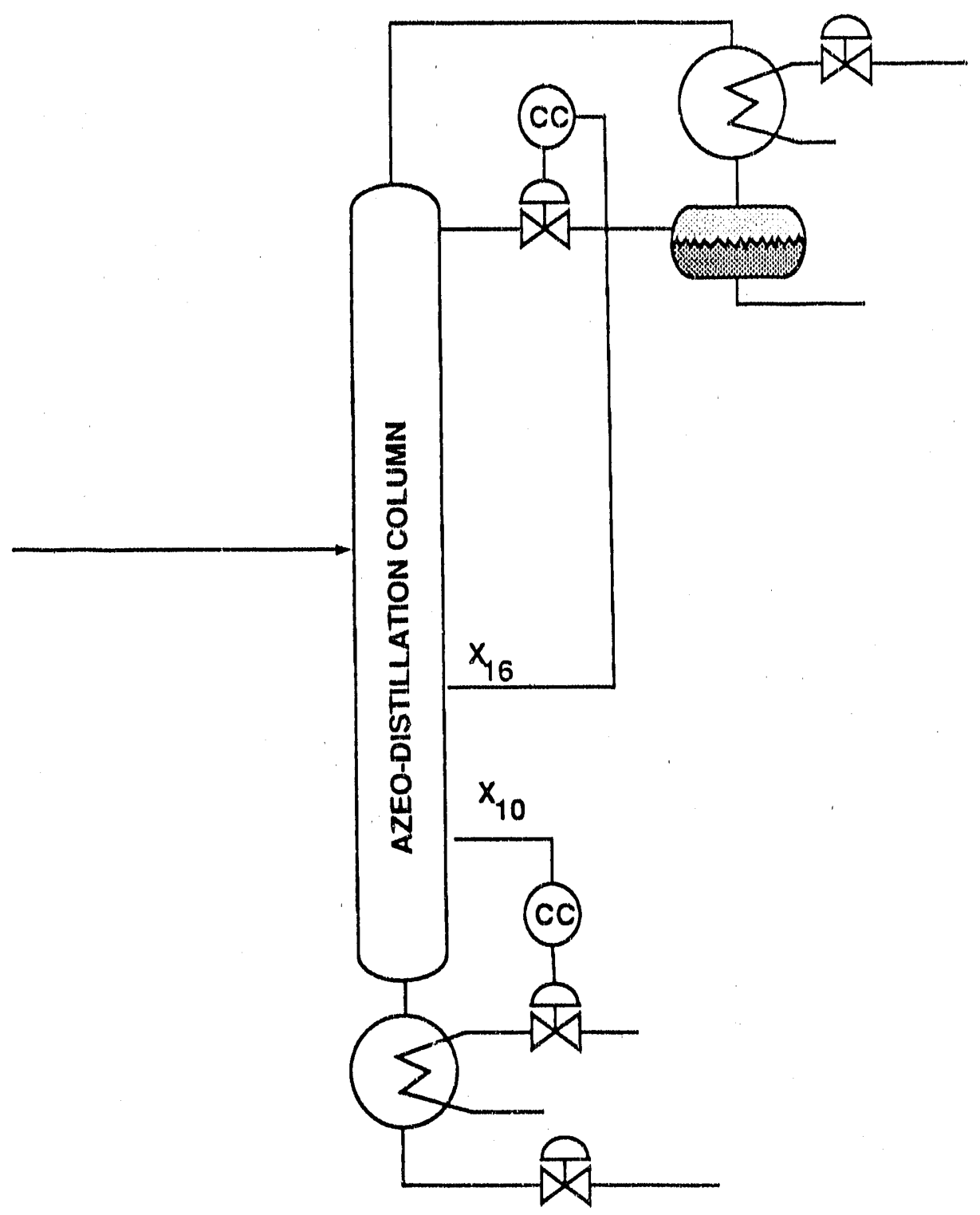

Figure 14

A Proposed Composition Based Control 
control systems shown in Figures $13 \& 14$, as well as a single ended variation of these two in which the top controller was turned off. Because it was identifled by the engineers at TEC as the disturbance with the most serfous effect on the control system only the feed composition disturbance was considered.

The results of this study are presented in terms of variation in product purity, Figures $15 \mathrm{a} \& \mathrm{~b}$, and in terms of energy reduction. Figure 16. The results indicate that variation in feed composition will propagate to the product purity for all control systems. However, the propagation is considerably less for the two composition based control systems. For the two temperature based control systems, it is interesting to note that the simpler single ended control system actually performs better than the dual ended scheme. There is very little difference between the two proposed composition control systems. Both perform much better than the current temperature based systems.

Figure 16 shows the result of the study in terms of the anticipated energy savings relative to both the dual and the single ended temperature control schemes. Note that the leverage offered by composition control depends on the magnitude of the vartation in the feed composition. Relative to current operation and practice, the potential energy savings that could be realized by a composition based control could well be an improvement of $5 \%$ or greater for large feed composition disturbances.

It is important to note that this preliminary study did not consider the increase in productivity which would be possible with tighter control over the product purity. Hydraulic data on the actual column will have to be obtained before such estimates can be made.

\section{Lacation and Resolution of Composition Measurement}

One important aspect of composition based control systems is the relationship between the composition measurement location and the required measurement resolution. One feature of the Raman based composition analyzer is that it can be used to measure compositions in the tray section of the column. (Conventional process analyzers are typically applied to only product streams). This offers several advantages for addressing the control and 


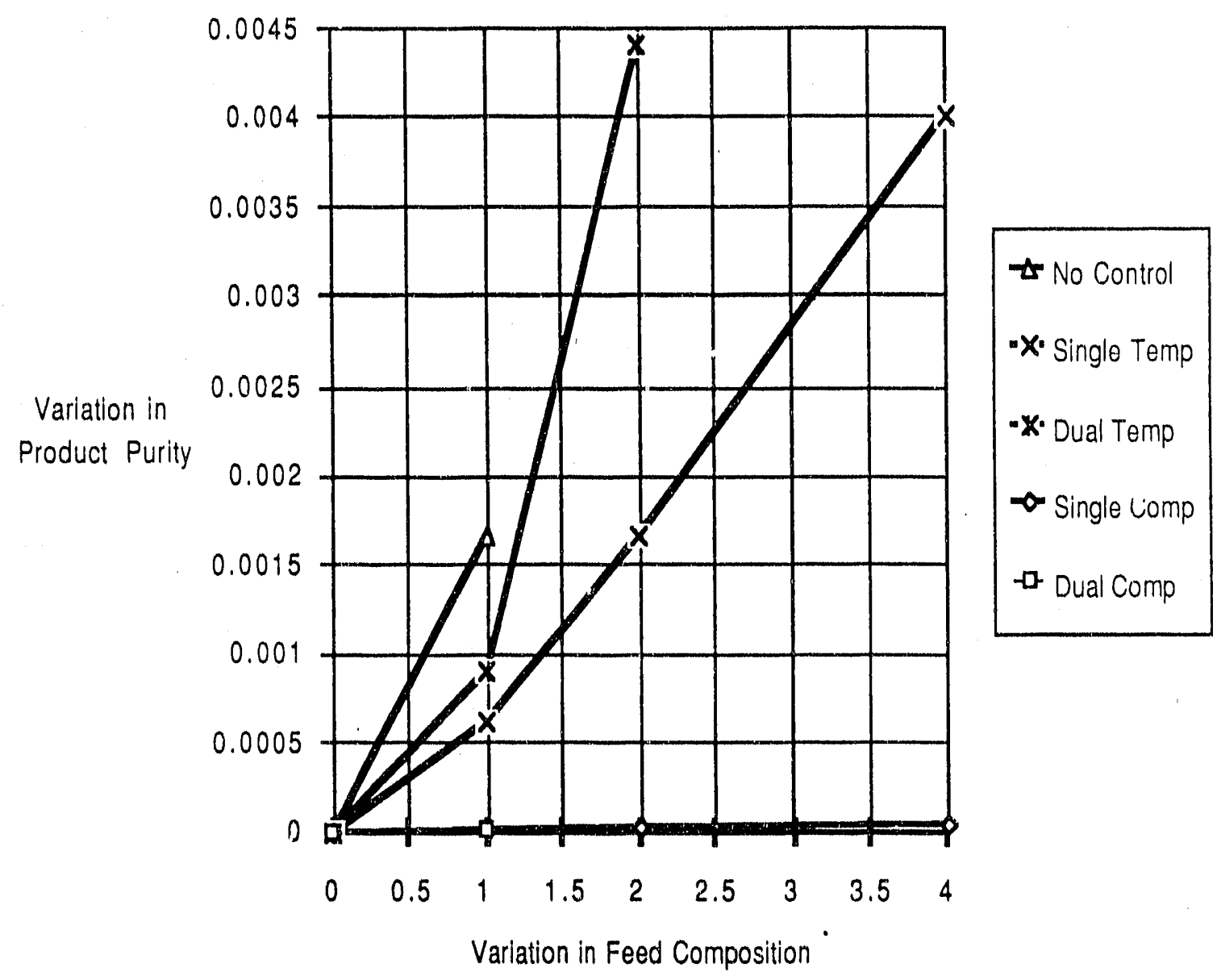

Figure 15 a

Variation in Product Purity vs Feed Composition. 


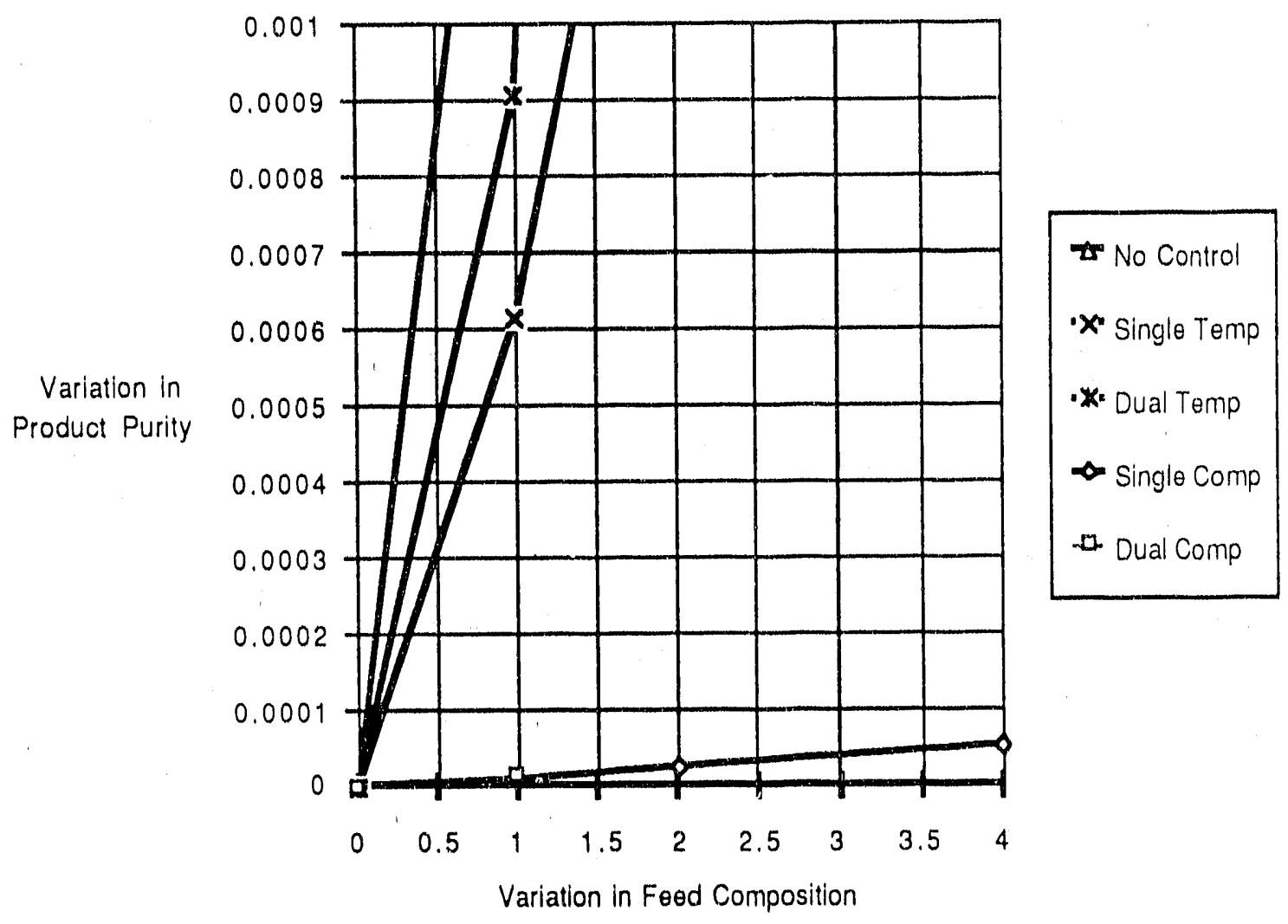

Figure $15 \mathrm{~b}$

Variation in Product Purity vs Feed Composition.

(magnified) 


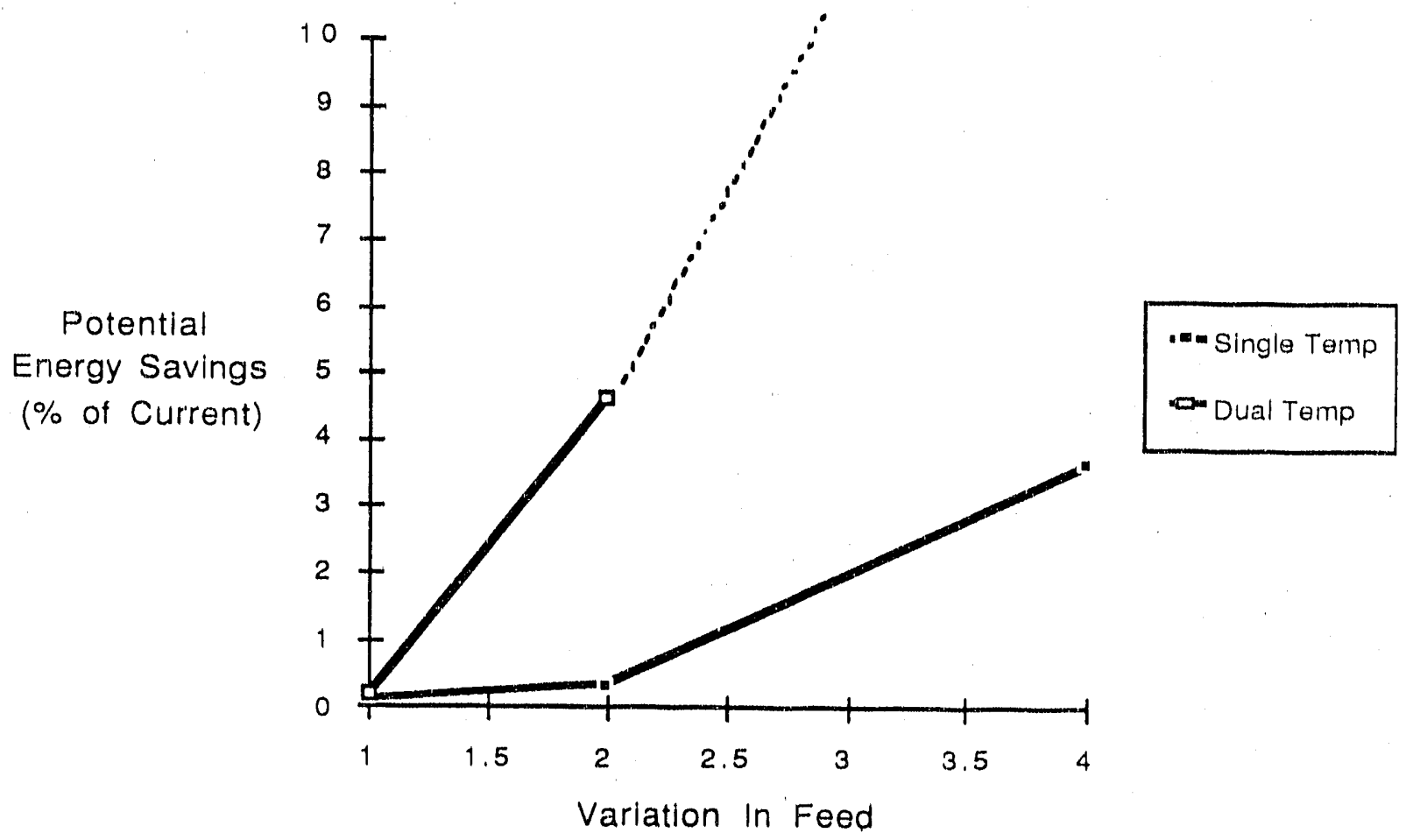

Figure 16

Potential Energy Savings Using

Composition Control 
energy reduction problems. The first advantage is demonstrated in Figures $17 \mathrm{a}, \mathrm{b}$, and $\mathrm{c}$ where the sensitivity of the composition proflles to changes in the reflux and steam are plotted for each tray location. Note that product ends (where conventional analyzers are applied, if applied at all) have very little sensitivity. The leverage in controlling composition is orders of magnitude greater if the measurement is made inside the column. This is a characteristic of the TEC azeo column, but it is also a general characteristic of most distulation processes. If composition information is to be used in controlling a column, it needs to be well selected internal composition and not product compositions.

Locating the composition sensors inside the column has another advantage that can be seen In Figure 18. Measuring and controlling composition at a sensitive tray in the column requires much less resolution of the composition analyzer. Figure 18 shows how vartation in composition of acetic acld at the control tray propagates to the production composition. Nole that a $4.5 \%$ variation in the composition at the control tray results in a variation in the product of $0.04 \%$. In terms of process control, this means that if the composition on tray 9 is maintained between .575 and .62 (6 standard deviations of 0.045$)$ this translates to a variation in the product between .9982 and .9986 (6 standard deviations of 0.0004$)$. The less stringent need for resolution implies that the analyzer can be made to respond faster and much less expensively.

\section{Summary of Economic Analusis}

The Phase II econornic analysis quantified the improvements in the TEC azeo column control that would be possible if the control system were based on composition measurements instead of temperature as at present. This preliminary study was conducted on a simulation of the proposed Phase III field test column and included two relatively simple composition control strategles (others will be considered in Phase III). The results of the study indicate that there is a clear advantage to composition based control. Both composition control schemes significantly reduced the variation in the product composition. Reducing variation saves 


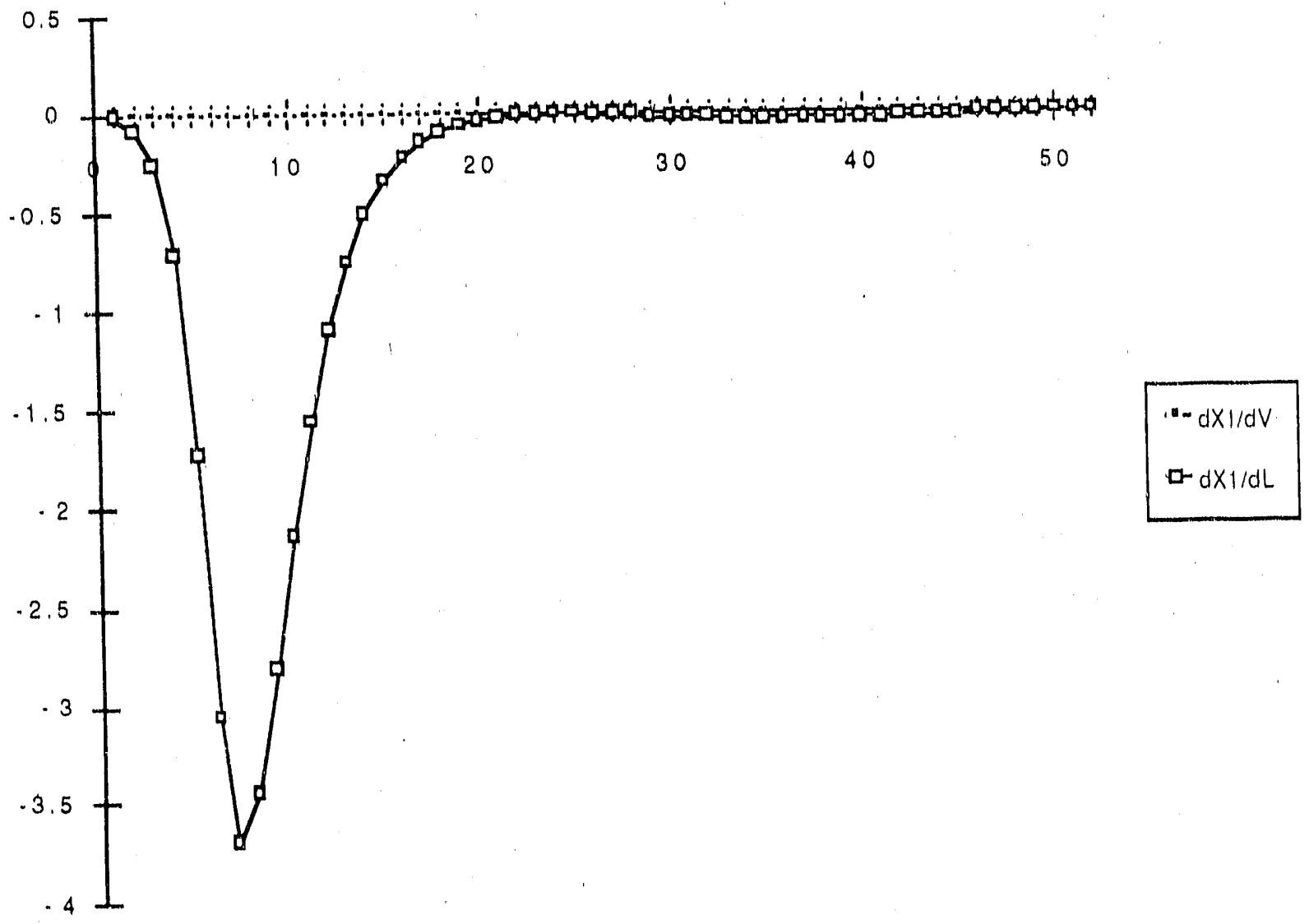

$\mathrm{dX} 1 / \mathrm{dV}=$ the change in acid composition with respect to the change in the vapor rate

$\mathrm{dX} 1 / \mathrm{dL}=$ the change in acid composition with respect to the change in the liquid rate

Figure 17 a

Acetic Acid Composition Sensitivity vs. Tray Location 


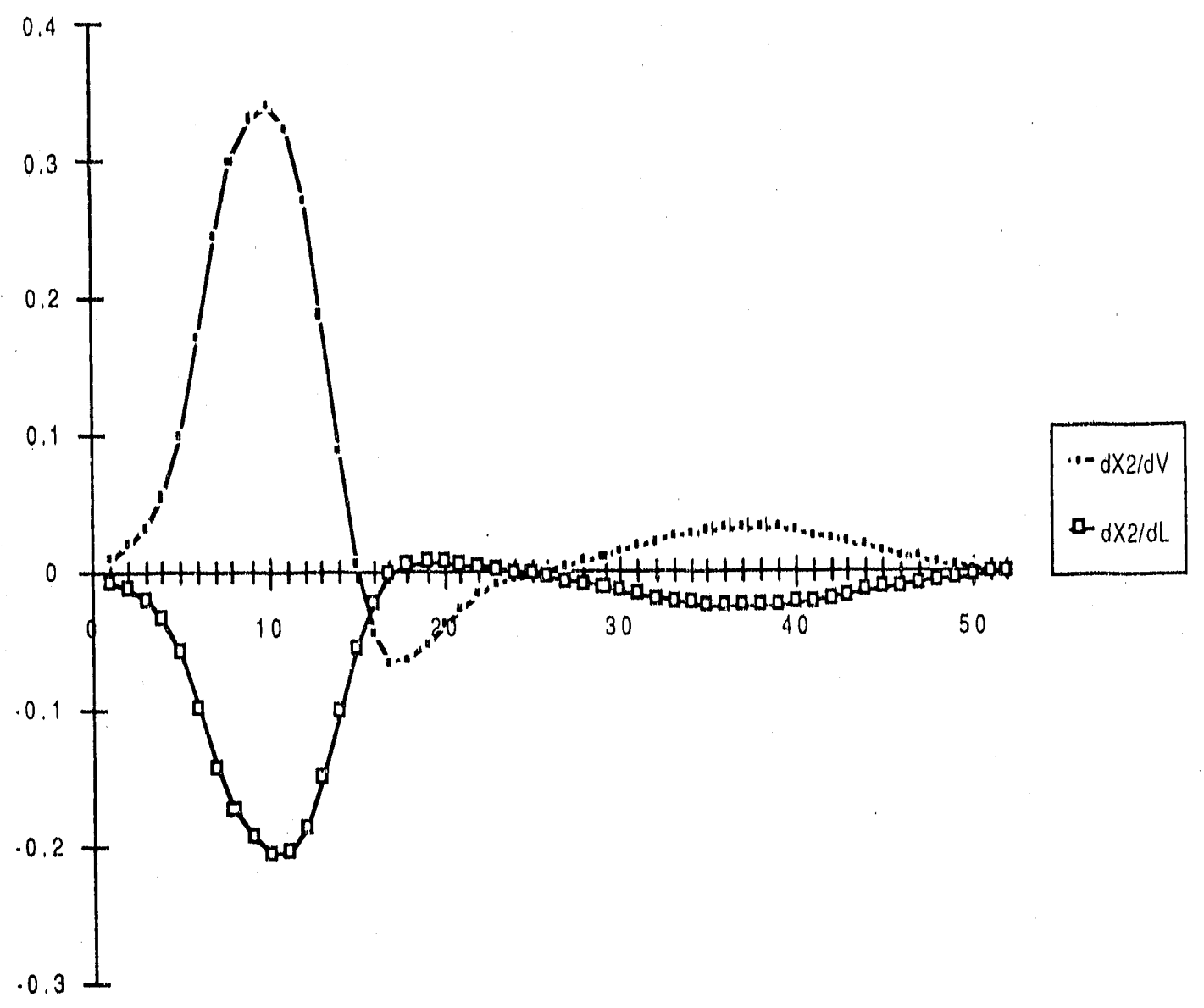

$\mathrm{dX} 2 / \mathrm{dV}=$ the change in water composition with respect to the change in the vapor rate

$\mathrm{dX} 2 / \mathrm{dL}=$ the change in water composition. with respect to the change in the liquid rate

Figure $17 b$

Water Con!position Sensitivity vs. Tray Location 


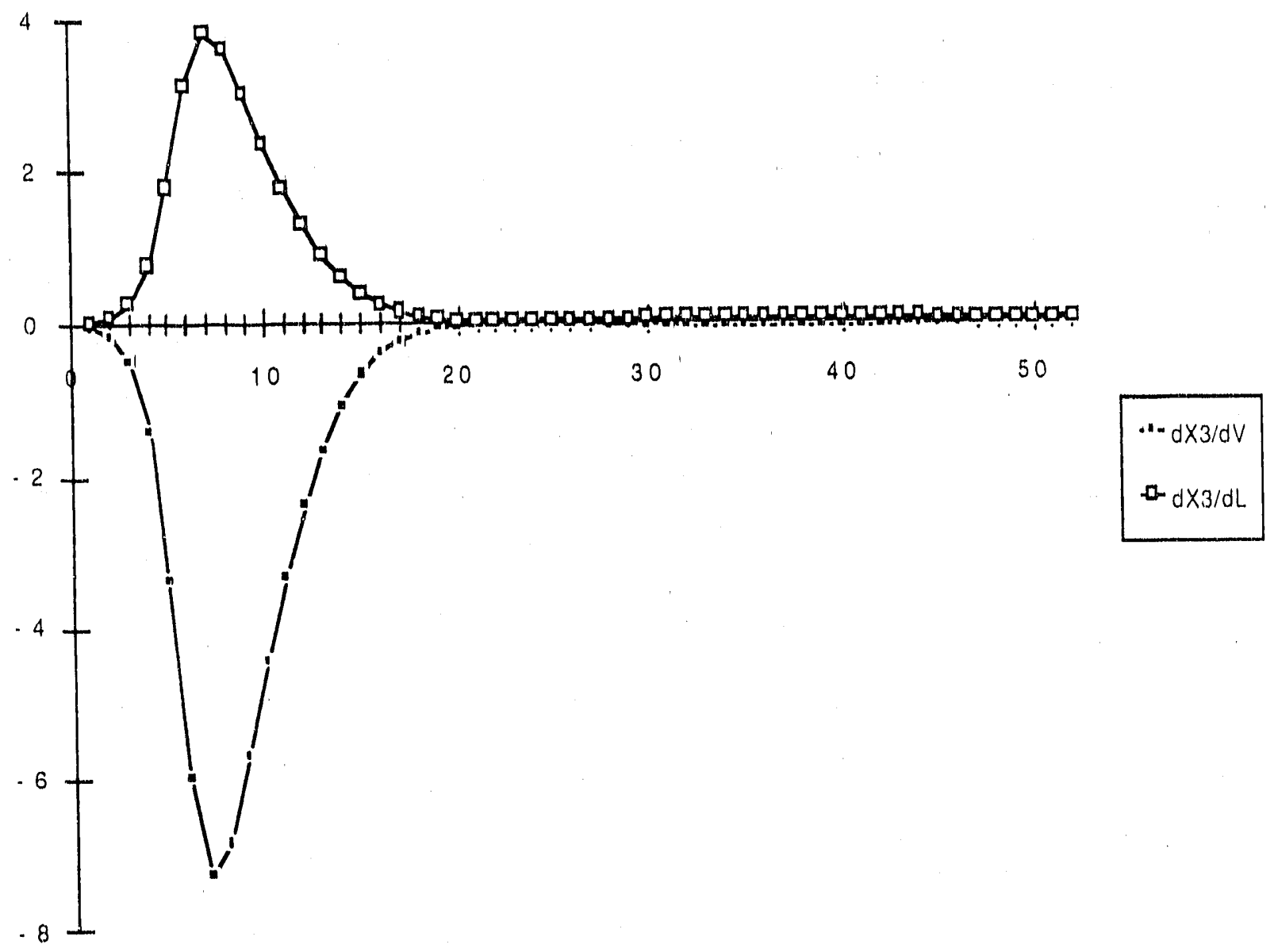

$\mathrm{dX} 3 / \mathrm{dV}=$ the change in solvent composition with respect to the change in the vapor rate $\mathrm{dX} 3 / \mathrm{dL}=$ the change in solvent composition with respect to the change in the liquid rate

Figure $17 \mathrm{c}$

Solvent Composition Sensitivity vs. Tray Location 


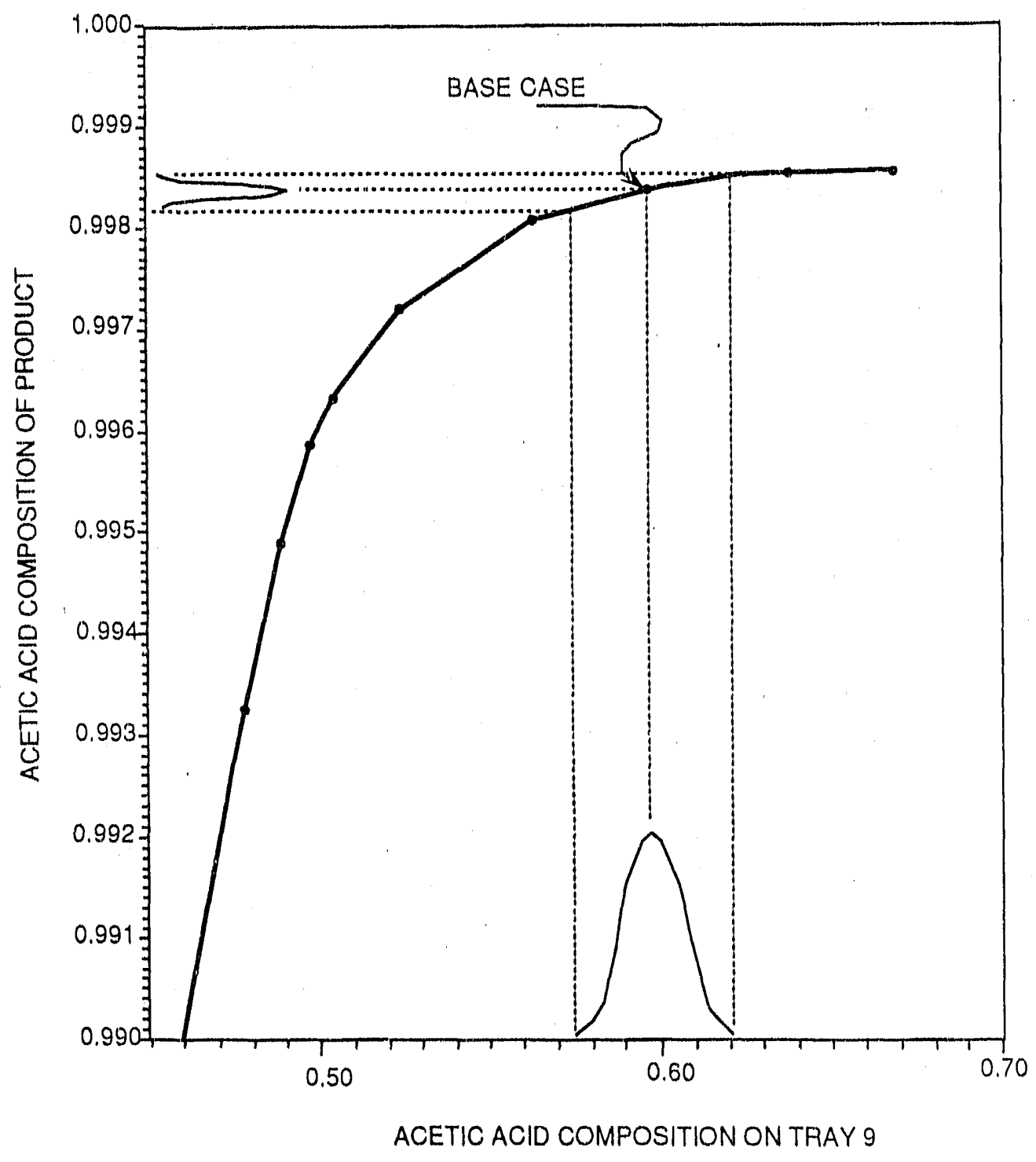

Figure 18

Transformation of Variation in Composition at Tray 9 to Variation in the Product 
energy by allowing operation of the column much closer to the minlmum energy, requlrentul wlthout Jeopardizing the product speciflcation.

Not specifically addressed in this economic analysis is the cost of the analyzer vs. the anticlpated energy savings. The general feeling is that the cost of the components ln the Phase II prototype system does not accurately reflect the price tag which would be on an Industralized, commerclal unit, However, this study demonstrates that the high resolution and mechanical sampling requirements placed on present Industrial analyzers are not necessary. High resolution and sampling both contribute to the capttal as well as the malntenance costs of current process analyzers. A commerclal Raman based analyzer should compete quite favorably with these existing technologies in both price and malntenance. Also, It should yteld much higher control performance. The control performance advantage ollered by the Raman based analyzer is that it can be applied with relatively little dlliticully to determine the internal composition of the column.

\section{CONTINUED APPLICATIONS DEVELOPMENT}

The FT-Raman composition sensor appears to have significant utility beyond the distllation application studled extensively in Phase I. During Thase II we have Investigated a number of samples obtained from industry and/or laboratary simulations of industrial mixtures. Some of this work has been with representatives of companies who are members or potential nembers of the center. Much of the work has direct signiflcance to the reduction of energy use in manufacturing processes.

Animal feeds are often analyzed for proteln content by KJeldahl analyses, a wet chemlcal method involving mixing of the feed with chemicals and a lengthy high-temperature cookdrig procedure. A modern optical analysis method for protein content would be attractive to feed manufacturers because of the time and cost reduction, and energy saving would be signilicant. The analyses were performed in conjunction with the Department of Agriculture of the State of Georgla. At this time, it appears that normal Raman is not sufficlently sensllive for this analysis. 
Analysls of ferllizer for varlous Inorgande components was also of linlerest to lle Georgla Department of Agriculture. The same Inorgande components are also of Interest to environmental analyses, such as munltoring wells. These analyses had some analydeal utllty in the range of Interest, and we plan further Investigation.

A number of products from 3-M were investigated for chemical compostlon. These Included sol-gel, packing tape, coated paper, transfer adhestves and epoxy resin. 'The curtug of' the epoxy was observed spectroscoplcally, but we will reculre a shorter analysls time to observe the curing process kinetics. These studles all relate to monitoring manulacturing processes for waste reduction. The company is studying the data produced.

A great deal of emphasis has been placed on analyses relaled to petroleum products. Consumer products such as lighter fluld, Coleman fuel, kerosene, gasoline, Lifiuld Wrench, brake cleaner, and WD40 have been analyzed. These all ylelded dissimilar spectra, showhy possibilities for analyses of these type products. A set of samples containing aromatle and allphatic hydrocarbons related to fuel octane measurements was obtained from a petroleum company. We have studied these samples extenslvely, including chemometric analysis to determine predlctive abllity. The results of the study were not quite as good as results oblanned at the petroleum company using near infrared spectroscopy, but showed great promlse for eventual applicablity of the Raman technque to petroleum process control.

We are working with another faculty member at the Unlversity to apply advanced mathematical techniques to the data analysis. A report on the current status of the data analysis program is included in Appendix A. This report concerns an allemalleve analysis of the data generalea with the Raman system using neural networks. This study is funded by the National Sclence Foundation as a Jolnt project between the Measurement and Control Englneering Center and the Center for Process Analytical Chemistry. The goal of this project is to determine the most suitable mathematical method to obtain the maximum infomatlon from spectral data. Selection of approprlate chemometrles can lead to a wider applicabllity of on-line spectroscople methods. 
Based on high enengy usage In the paper Industry, we have been Invest lgating a number of paper related mixtures for three compandes: Westvaco, Bowater and Champlon, Raman spectra al black llquor, pulp samples and brown stock have been obtalned, but slgnilleant lluorescence Interterenco was noted. We also attempted excltatlon at other wavelongths, but have not been successful in the application of Raman to these mlxtures.

Lactic acld is of Interest to Nablsco and other food manufacturers. The specllite need is for a sonsor In dough to monltor fermentatlon. The Inltal experiment in the Raman laboralory was to detomine the minlmum detectable concentration of lactle acd. Water solutlons wore cmployed as a sample matrix. The spectrum of high concentratlon lactlo acld, $85 \%$, is shown I1. ligure 19. As the concentratlon was reduced to levels such as those found in doughs, the Intensity of the spectral features was too low to be useful. This type of sample is clearly Inapproprlate to our current liber Raman spectrometer. This sample may be re-Investigated Using SERS later this year.

Many industrial manufacturing processes involve a change in the degree of saluratlon of a lat or resin. Currently, many of these processes are not well controlled due to the utilizallon of off line analysis methods. Samples of resins with varlous degrees of saturation were provlded by Hercules for this study. Degree of saturation is also of interest in the study of fats and other food products. Figure 20 shows the spectra of a serles of resins with differing extent of hydrogenation. The samples extend from highly unsaturated to fully hydrogerated. There are substantal spectral differences which should lead to a highly sensitive analytloal method.

A potentlally signlficant application of Raman spectroscopy is in the analysis of petroleum products during plpeline transport, Refined fuels are transported In large plpellnes following distillation. Different grades, such as regular and premlum, as well as different brands travel the same plpellnes. Measurement methods currently employed to determine the polnt where the stream changes from one materlal to the next are inaccurate, resulting in some mixing at the storage tanks. Products can become so contamlnated that they must be sold as a lower grade or reprocessed. We recelved samples of gasollnes from Laser Allanla, in 


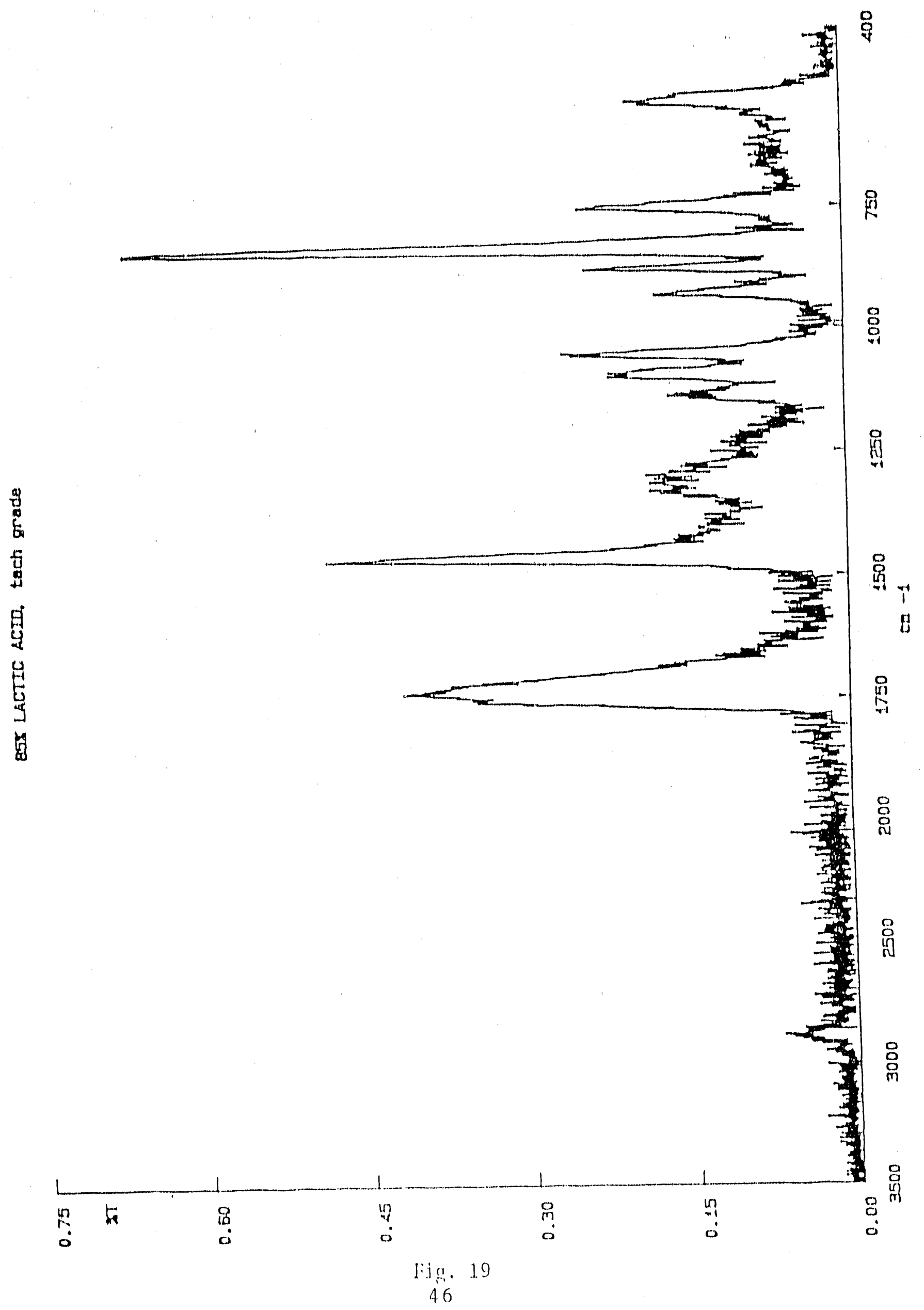




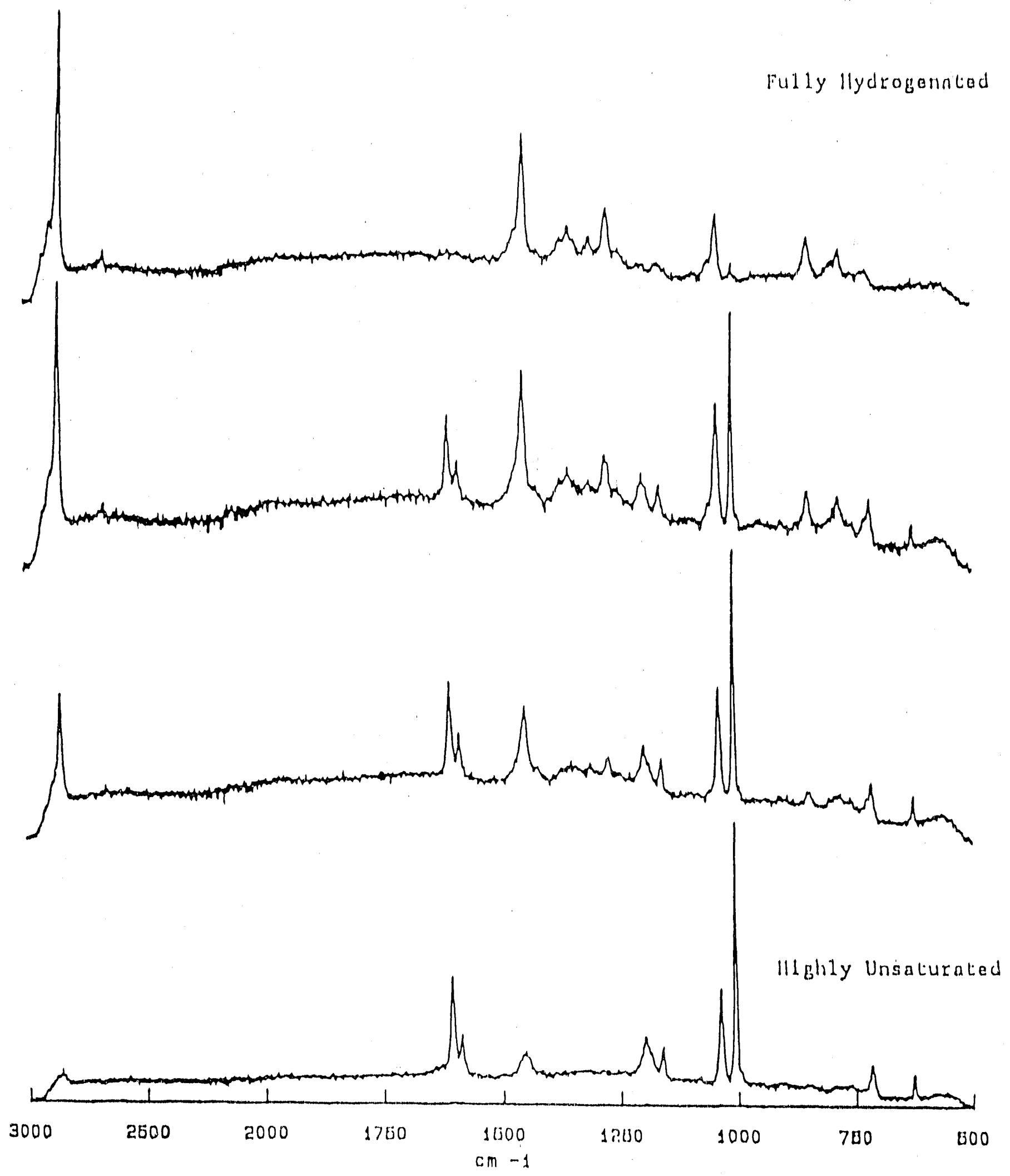

Figure 20. Spectra of a series of Resins with Differing Extent of Hydrogenation 
instrument manufacturer based in Atlanta, Georgla. Spectra of two gasolines are shown in Figures 21 and 22. These were acquired in thirty seconds and show clear differences between the materials. Based on our preliminary work with Laser Atlanta, Colonial Pipeline has expressed interest in a the development of a Raman instrument for determination of refined petroleum products in pipelines. We are continuing discussions with both companies.

\section{SURFACE-ENHANCED RAMAN SPECTROSCOPY}

\section{Project Objectives}

Surface-enhanced Raman spectroscopy (SERS) was considered during the DOE project Phase II as a technique for the detection and characterization of industrially important solutions. This project was concurrent with the on-line Raman analyzer project. A graduate student, David Bailey, was chosen to perform this work. David had SERS experience from Master's degree studies in Physics. The initial task was to perform a literature search of SERS techniques that employ FT-Raman instrumentation. It has been completed and is included in Appendlx B.

\section{Experimental Format}

The primary equipment used for this project consisted of the Perkun-Elmer FT-Raman interferometer, a CVI flashlamp pumped Nd:YAG laser, an IBM-compatible personal computer, and an electrochemical plating apparatus. Laser excitation at $1.064 \mu \mathrm{m}$ was used to minimize fluorescence. With one exception, measurements were made with the enhancing surfaces in-situ. All SERS substrates consisted of metallic gold with surface roughness featuri on the submicron scale. A vartety of surface-roughening methods were investigated.

\section{Initial SEFS Measurements}

The literature review indicated that a good first surface to test was electrochemically roughened, pure gold metal. It works well in the near IR and is resistant to chemical attack. Gold and platinum wires ( $1 \mathrm{~mm}$ diameter) were purchased to use as electrochemical cell electrodes. A BAS CV-27 cyclic voltameter was employed in initial experiments. 


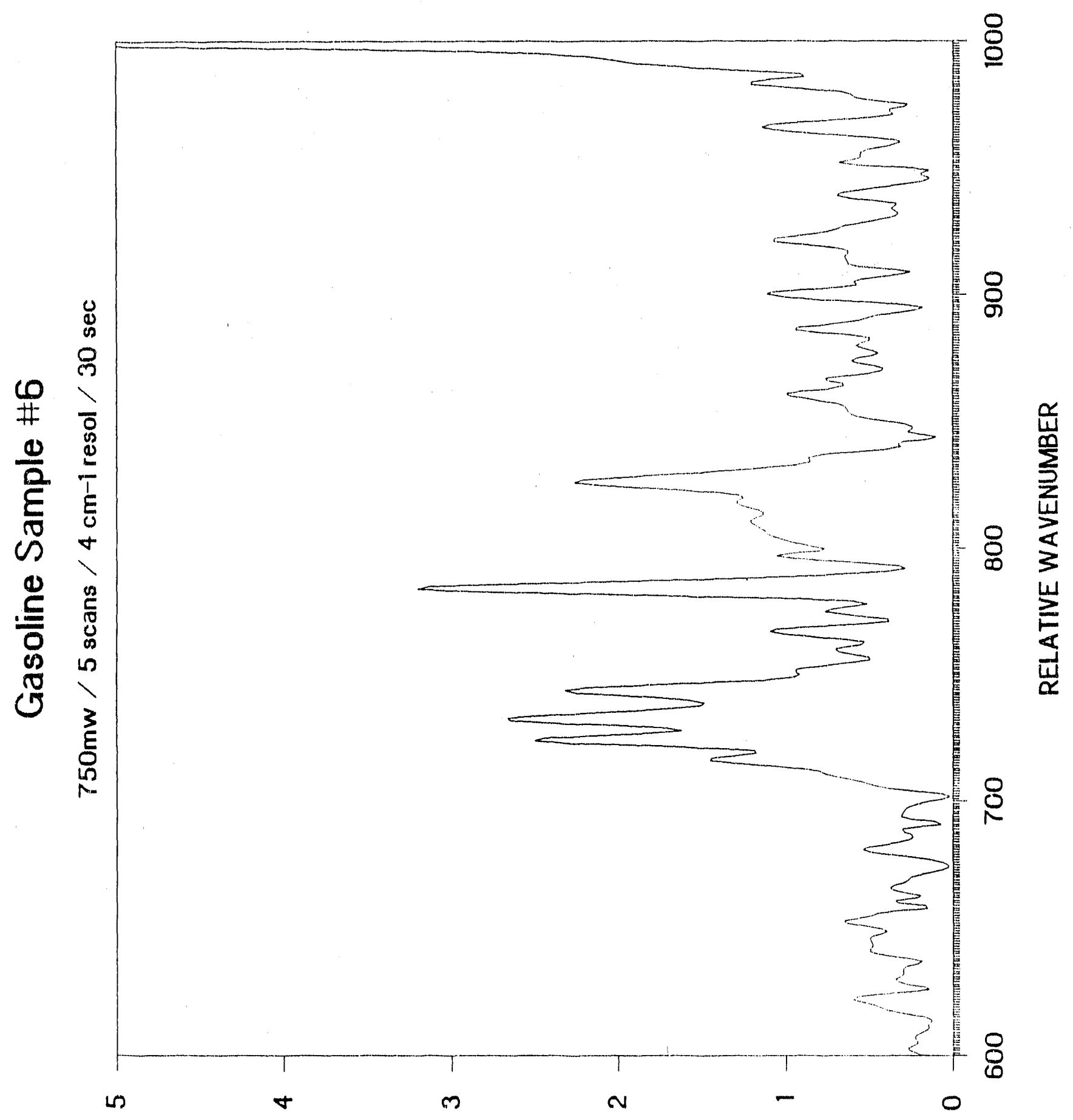

Fig. 21 - Spectrum of Gasoline \#6 


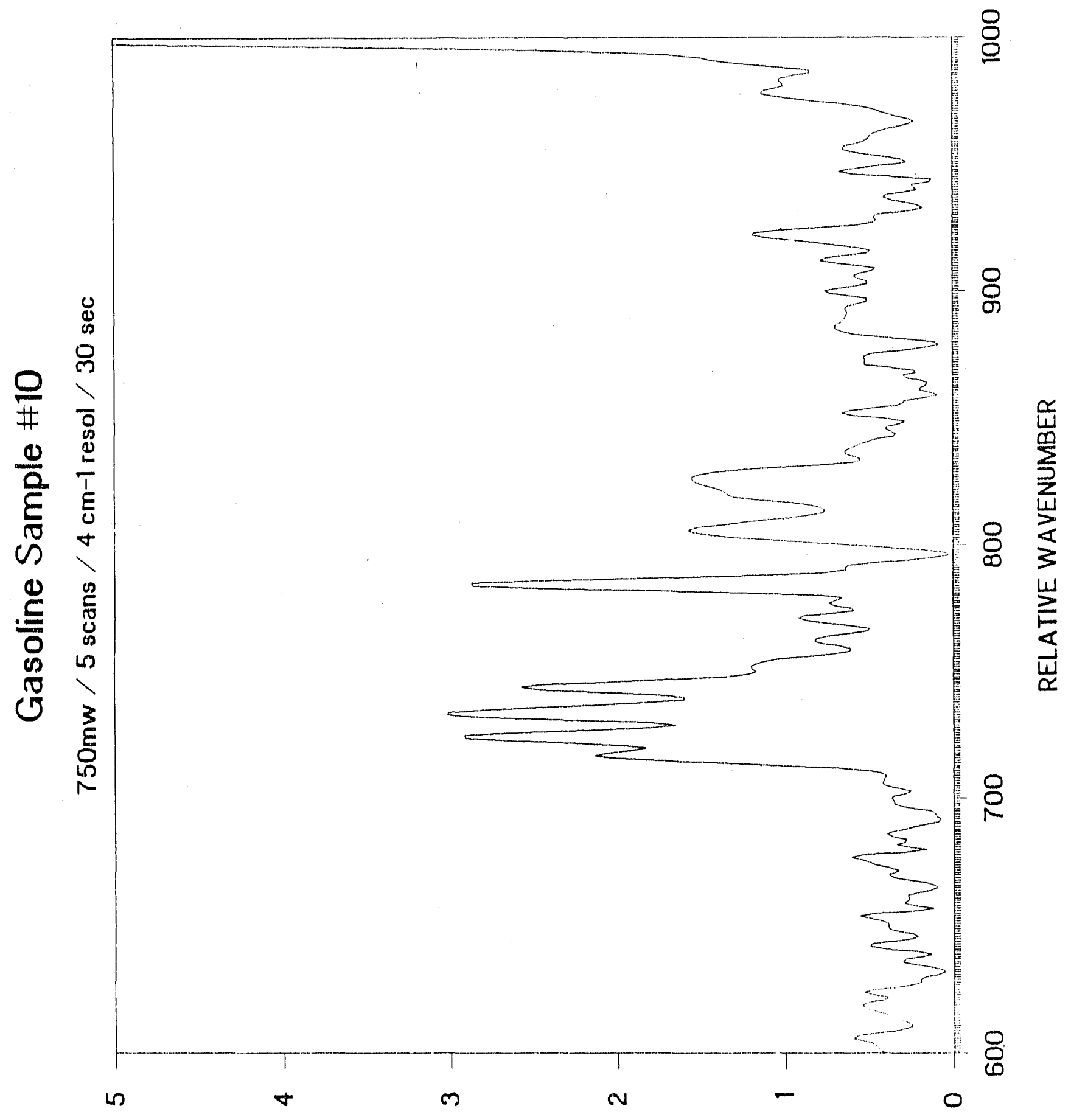

Fig. 22 - Spectrum of Gasoline \#10 
The surfaces were prepared according to a recipe published by Flelschmann et al. (5) A $1 \mathrm{~mm}$ diameter gold wire was pollshed with three successlvely smaller skes of alumina grit: $15 \mu \mathrm{m}, 1$ $\mu \mathrm{m}$, and $0.01 \mu \mathrm{m}$. The wire was then cleaned with distilled water. Successive oxidation and reduction cycles were performed in $200 \mathrm{ml}$ of 0.1 molar $\mathrm{KCl}$. The gold wire served as the working electrode and a platinum wire as the auxillary electrode, as llustrated in Figure 23. Potentials were referenced to a saturated calomel electrode. Fifty redox cycles were used to roughen the gold electrode. Each cycle began at $-0.3 \mathrm{v}$, scanned to $+1.2 \mathrm{v}$ at a rate $0.5 \mathrm{v} / \mathrm{s}$, paused for $4 \mathrm{~s}$, scanned to $-0.3 \mathrm{v}$ at a rate of $0.5 \mathrm{v} / \mathrm{s}$, and then paused for $20 \mathrm{~s}$ before repeating. The surface was then lightly rinsed in distllled water.

During the data acquisition process, a gold wire was positioned at the center of a $5 \mathrm{ml}$ testtube which contained the liquid sample. The test-tube was positioned inside the Interferometer sample chamber. Laser light was incident normal to the surface. A lens positioned before the prism mounted on the first interferometer collection lens was used to focus the light onto the sample. No potential was applied to the gold wire during data acquisition. The arrangement for data acquisition is illustrated in Figure 24.

Initially, spectra were taken with a variety of analytes. Encouraging results were obtained with 100 ppm pyridine and toluene. Refer to Flgure 25 for the Raman spectrum of neat pyridine and Figure 26 for the SERS spectrum of aqueous pyridine. A distinct pyridine Raman band at $1000 \mathrm{~cm}^{-1}$ can be seen. Other analytes such as benzene, acetic acid, and benzoylecgonine did not yield such impressive results. Benzoylecgonine was tested because of its significance as a blood metabolyte of cocalne hydrochloride. Later testing with other redox parameters allowed measurements of benzene to be made.

\section{Measurements with Vapor Deposited Gold Surfaces}

The SERS effectiveness of vapor deposited gold was also investigated. The surface roughening agents consisted of submicron-sized particles spin coated onto microscope slides. Vacuum vapor deposition of the gold over the particles was then performed to generate the rough surfaces. Three types of particles were tested: $0.01 \mu \mathrm{m}$ size alumina polishing grit, 0.261 


\section{Electrochemical Cell Plating Apparatus}

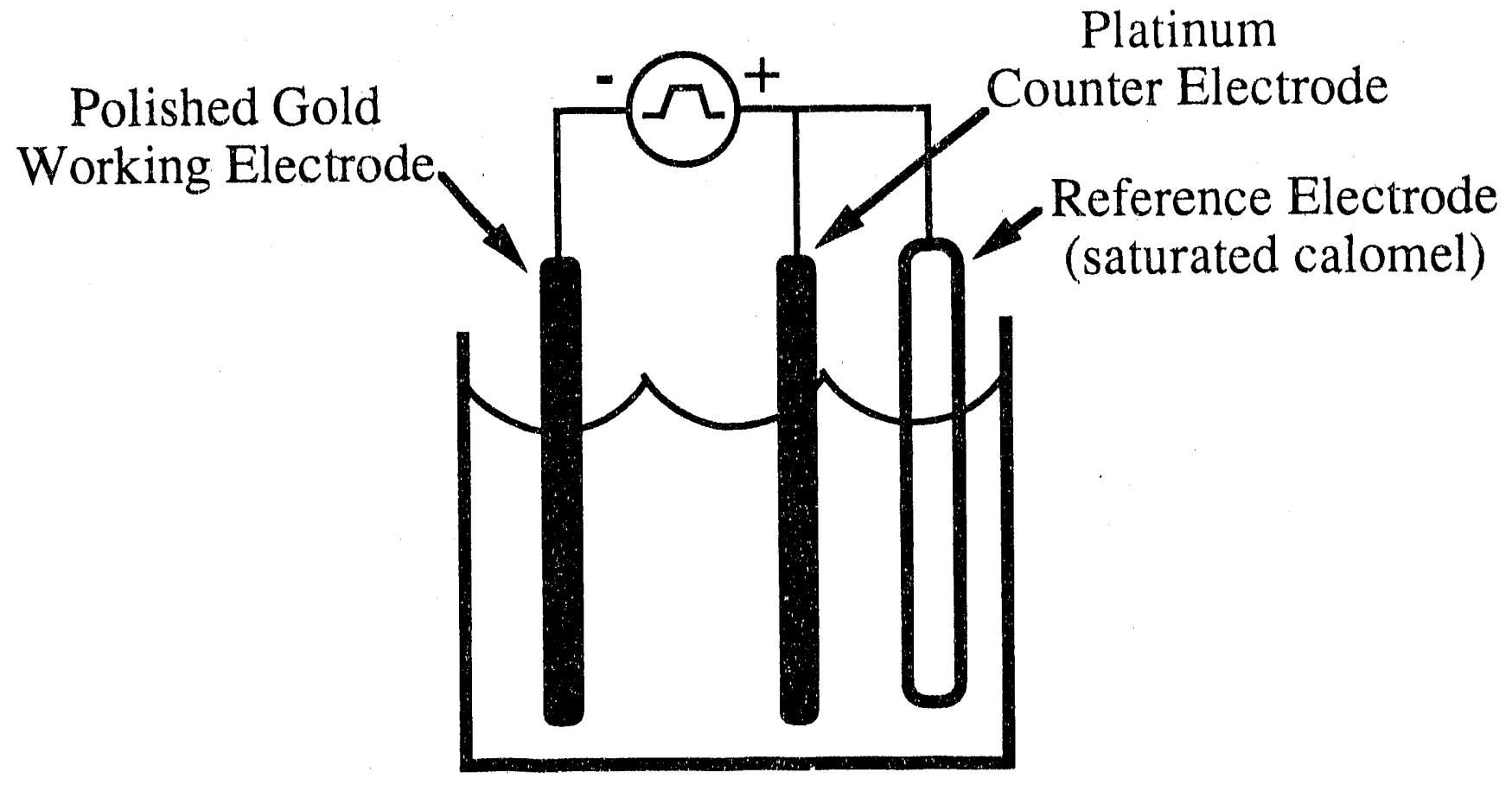

Electrolyte Solution

$(0.1 \mathrm{M} \mathrm{KCl})$

Figure 23 


\section{Near Infrared FT-SERS Experimental Apparatus}

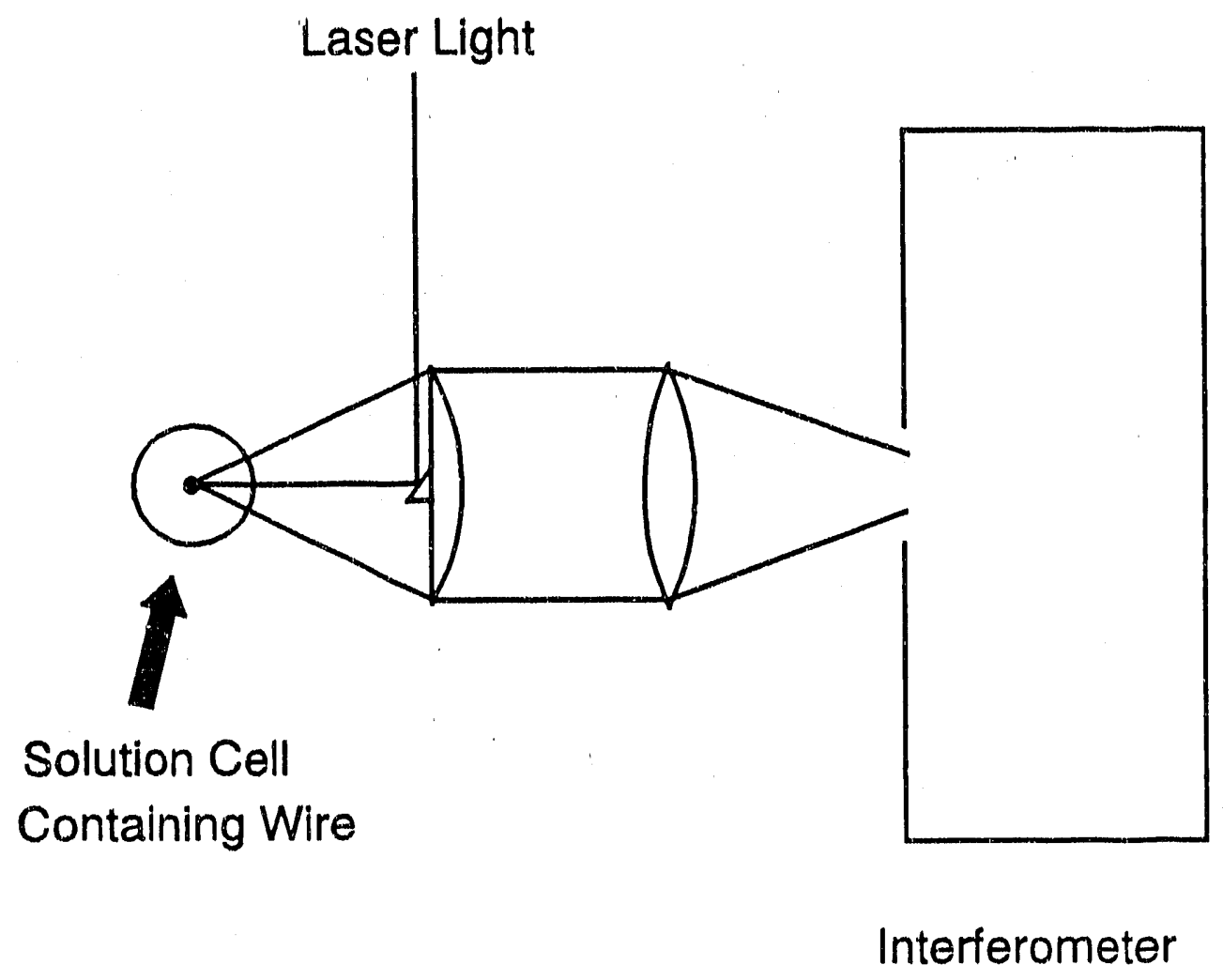

Figure 24 


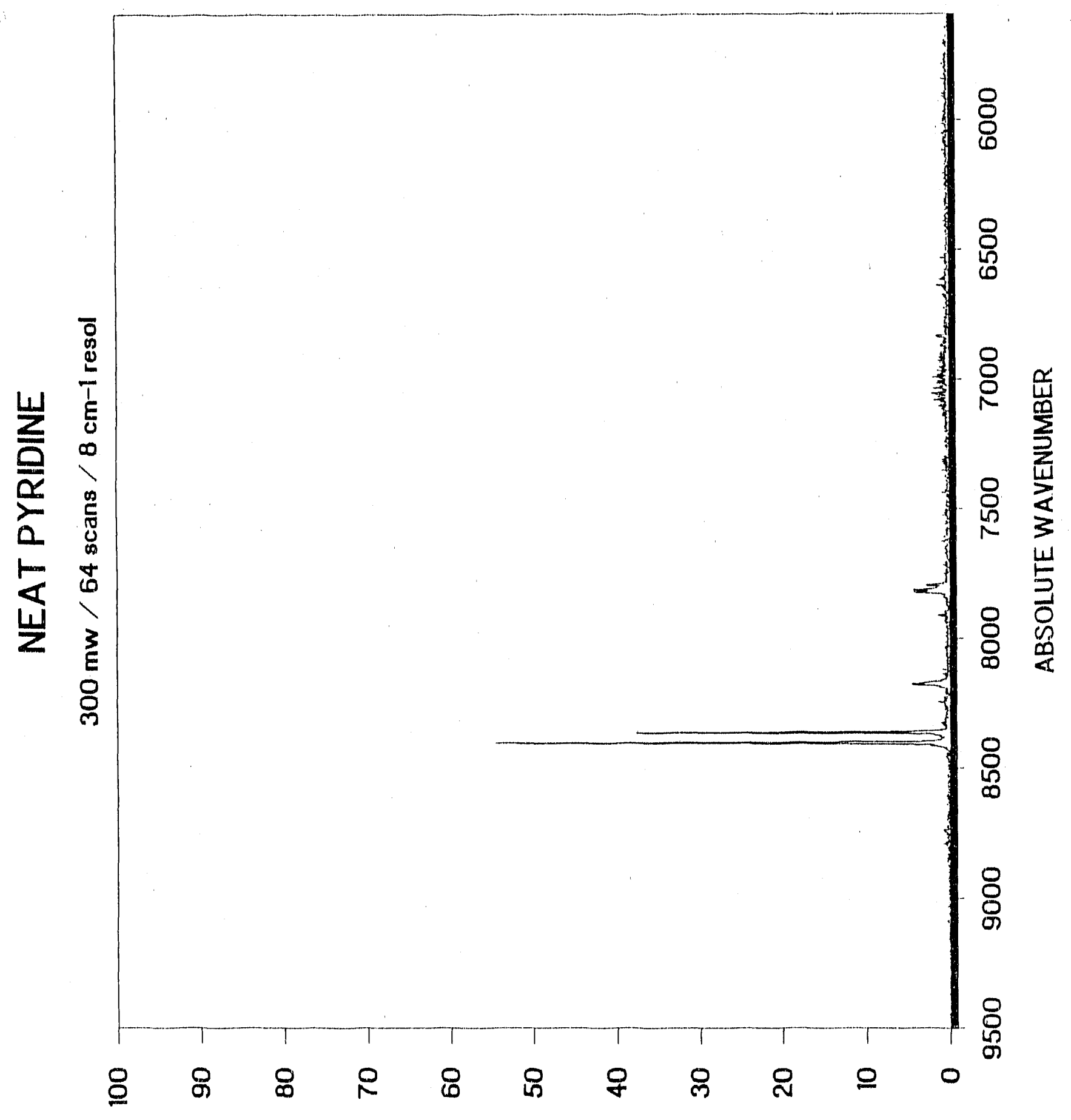

Figure 25 


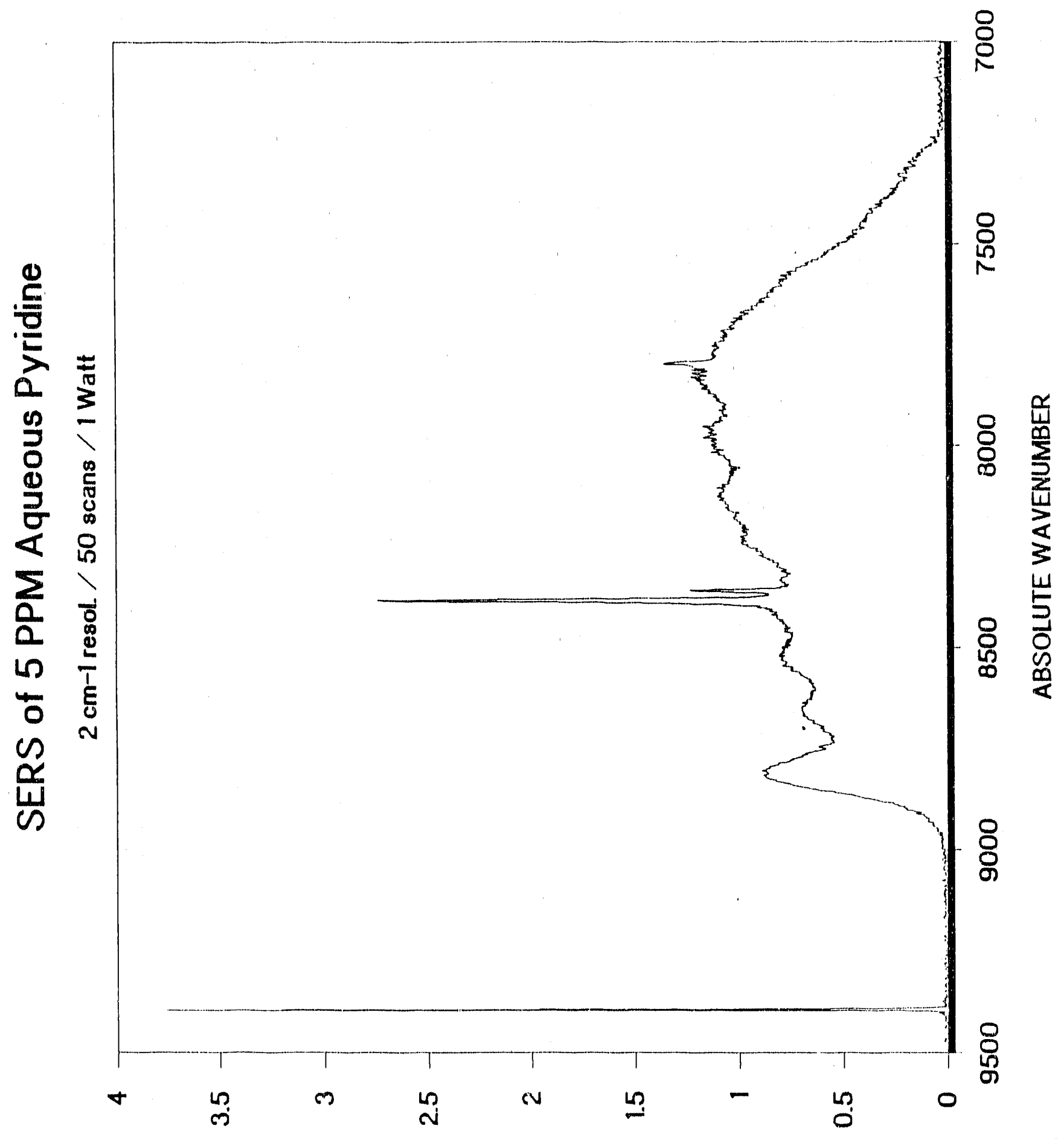

Figure 26 
$\mu \mathrm{m}$ diameter polystyrene spheres, and fumed sllica. The fumed sllica consisted of a distribution of submicron particle stzes.

Preparation of the three particle suspensions prior to their application to a glass surface was done by mechanical agitation. Each type of particle was mixed with distlled water and placed in an ultrasonic cleaner untll no particle clumps could be detected (approximately 1 min.). The concentration of each mixture was as follows: the polystyrene sphere-water mixture contalned $3 \%$ solids-by-welght; the fumed silica-water and alumina-water mixtures were at their respective points of saturation. Once a suspension was made, a few drops of the mixture were applied to a clean $25 \mathrm{~mm} \times 25 \mathrm{~mm} \times 1 \mathrm{~mm}$ microscope slide and spln-coated at $3400 \mathrm{rpm}$ for 20s. Thls was done for each of the mixtures, Vacuum vapor deposition of the gold metal took place in a diffusion-pumped vacuum evaporator equlpped with an electron bean source. The microscope slides were attached to a rotating platform directly above the e-beam source at a distance of $18 \mathrm{~cm}$. The platform was tilted so that the axis of rotation was at an angle of 20 degrees with respect to a vertical line passing through the e-beam source. The platform was rotated at $60 \mathrm{rpm}$ during the depositions. The baseline pressure was $3 \times 10^{-6}$ torr, and the evaporation pressure was $2 \times 10^{-5}$ torr. The evaporation rate was $0.5 \mathrm{~nm} / \mathrm{s}$. The evaporation thickness as measured next to the stage perpendicular to the direction of the metal vapor was $10 \mathrm{~nm}$. Refer to Figire 27 for a diagram of the apparatus.

After the deposition process, the samples were cut into rectangular pleces small enough to fit into the $10 \mathrm{~mm}$ opening of the solution cell test tubes. Attempts were made to collect SERS spectra from each surface. Spectra obtained with each surface immersed in a 100 ppm solution of aqueous pyridine were not encouraging. No pyridine Raman bands were detected for any of the three surfaces. Several factors could have caused the problems. (1) The surface roughness features were not of suitable size; (2) The gold layer was too thick or thin, or (3) contamination of the metal. Contamination by carbon from the electron beam crucible or chromium from prior evaporations were likely candidates. However, ESCA measurements of the surface of one 


\section{Vacuum Deposition Apparatus}

20 degree tilt

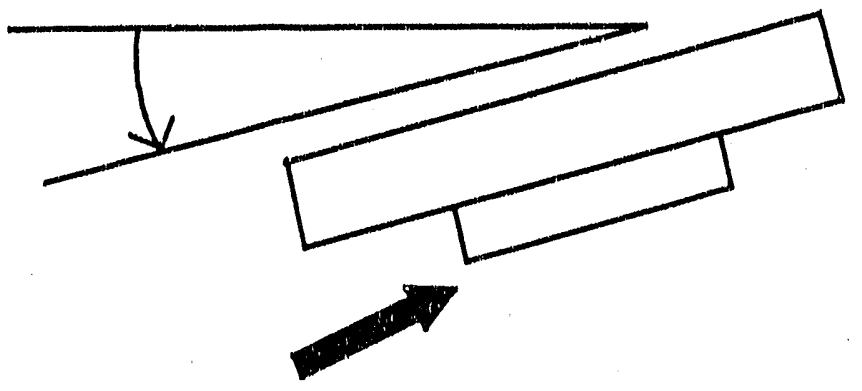

Sample

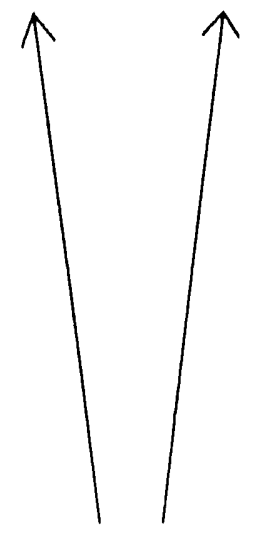

Rotating Sample Stage

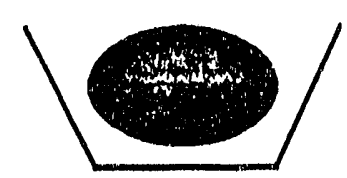

Crucible with molten gold

Figure 2? 
stmple ruled out those sources. Surfaces prepared in thas manner for liulute study should probably employ larger purticle slzes.

\section{Measurements with colloidal Gold Surfaces}

The SERS effectiveness of colloldal gold was also tested. The collolds were made according to the following reclpe, A 4\% by welght solution of acpucous AluCla was made, 'The solution, when the AuCla is fully dissolved, is a thlck llquid that resenibles reddish-brown

motor oll. Distlled water was used. A $1 \%$ by welght solullon of trlsodlun cltate In distllect water was also prepared. Twenty millllters of distllled water was brought to boll on a hot plate. A bolling chlp was not used. A E tal quantly of the trisodlum chtrate solutlon was added to the bolling water. A $1 / 2 \mathrm{ml}$ quantlty of the $\mathrm{AuCl} / 3$ was added to the bolling waler. 'The mixtire was allowed to boll for flve minutes. After the mixture had bolled for about 15 seconds, it turned black. The solution then tumed a raspberry red in about another 15 secondsi. It continually became more reddish as it bolled, but $t \mathrm{~d}$ did not change to another color. Alter. live minutes the beaker was removed from the hot plate and allowed to cool. The color remalned constant. Very pure millipore water was used lo make the solutions, A flrst atlempl with regular distlled water lalled, probably due to impurltes.

The gold collolds were extracted from the solution by flltering with a $0.02 \mu \mathrm{m}$ pore size filter pack. Approximately $1 / 2 \mathrm{ml}$ of the solution was drawn through the filter pack Into the syringe. The filter was removed and allowed to dry. This technlque produces callolds that range In stze from 50-150 nm. Three drops of $100 \mathrm{ppm}$ pyridine in 2-propanol were placed on the collotd-covered stde of the fllter and allowed to dry. The Raman spectrum of pyridne was; not evident In the flat background. Another sample was made and the experment was repeated. Again, no Raman bands were detected. In a last attempt, several drops of the liquid were placed on the filter and allowed to dry. The dull, reddish-brown color of thls filter was considerably darker than the prevlous filters. Three drops of the pyridine solution were placed on the collotd-coated side. The spectrum of this surface did reveal the characteriste broad 
background typleal of metalle gold. However, the low Intenslty Indlealed that there was probably not much gold present.

Several attempls were made wilh this type of surface but none was successful. The difliculty of the colloldal preparation rectpe also was a drawback.

\section{Concentration Dependence Measurements}

A study was performed In order to measure the SERS sIgnal Interislty as a function of analyte concentration. The surface used in this study was the electrochemleally roughened gold wire. Two analytes were used for this study: aqueous pyridine and benzene dissolved in 2 propanol. An Imiproved set of electroplating parameters allowed the detectlon of benzene during these tests. The electroplating parameters were: $-0.538 \mathrm{v}$ starting polnt, $0.5 \mathrm{v} / \mathrm{s}$ Increase to $0.86 \mathrm{v}, 4$ second pause, $0.5 \mathrm{v} / \mathrm{s}$ decrease back to $-0.538 \mathrm{v}$, and a 20 second pause before repeating. Fllty redox cycles were performed per sample. Potentlals were referenced to the platinum auxillary electrode. No calomel electrode was used. In addition, the gold whre was flattened to accommodate the slze of the laser beam during the spectra acquisitions, Analyte concentrations ranged from $0.001 \%$ to $50 \%$ by weight. The spectra were acquired in the sample compartment of the interferometer.

The Intensitles of the $1000 \mathrm{~cm}^{-1}$ pyridlne band above the background were analyzed as a lunction of concentration. The data show that a concentration cross-over polnt exlsts for the signal Intensity of the $1000 \mathrm{~cm}^{-1}$ band. For pyridine concentrations below $5 \%$ the Intensity of the $1000 \mathrm{~cm}^{-1}$ band was greater for the enhanced case than the same band in the unenhanced case. For concentrations above $5 \%$ the Intensity of the $1000 \mathrm{~cm}^{-1}$ band in the unenhanced case: was greater than that of the same band in the enhanced case. Refer to Figure 28. For benzene. the cross-over point for th. $1000 \mathrm{~cm}^{-1}$ band was between $1 \%$ and $5 \%$ concentration, Refer 10 Flgure 29. The SERS spectrum for benzene is noticeably weaker than that of pyridine for Identical test condilions. 


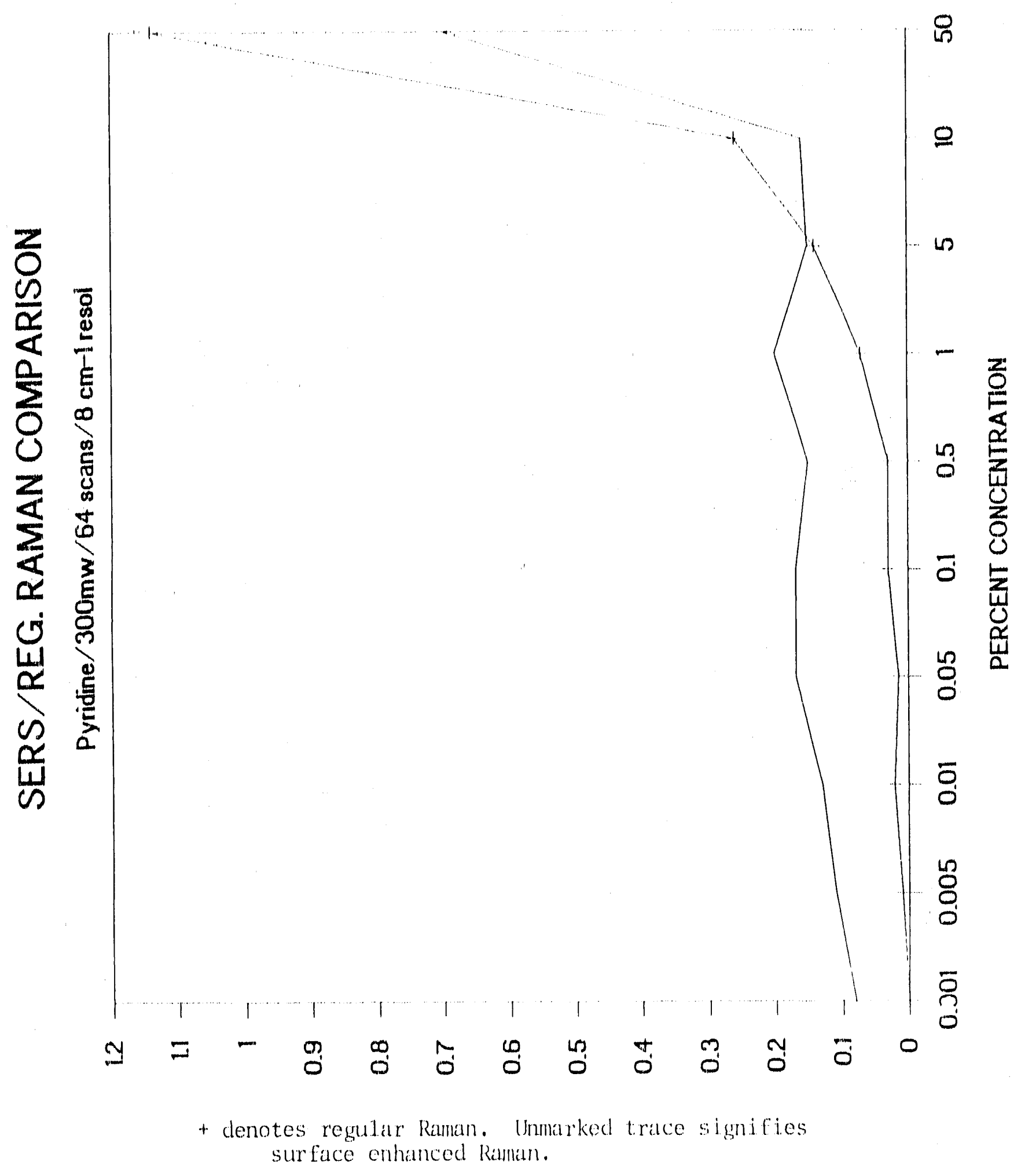

figure 28 


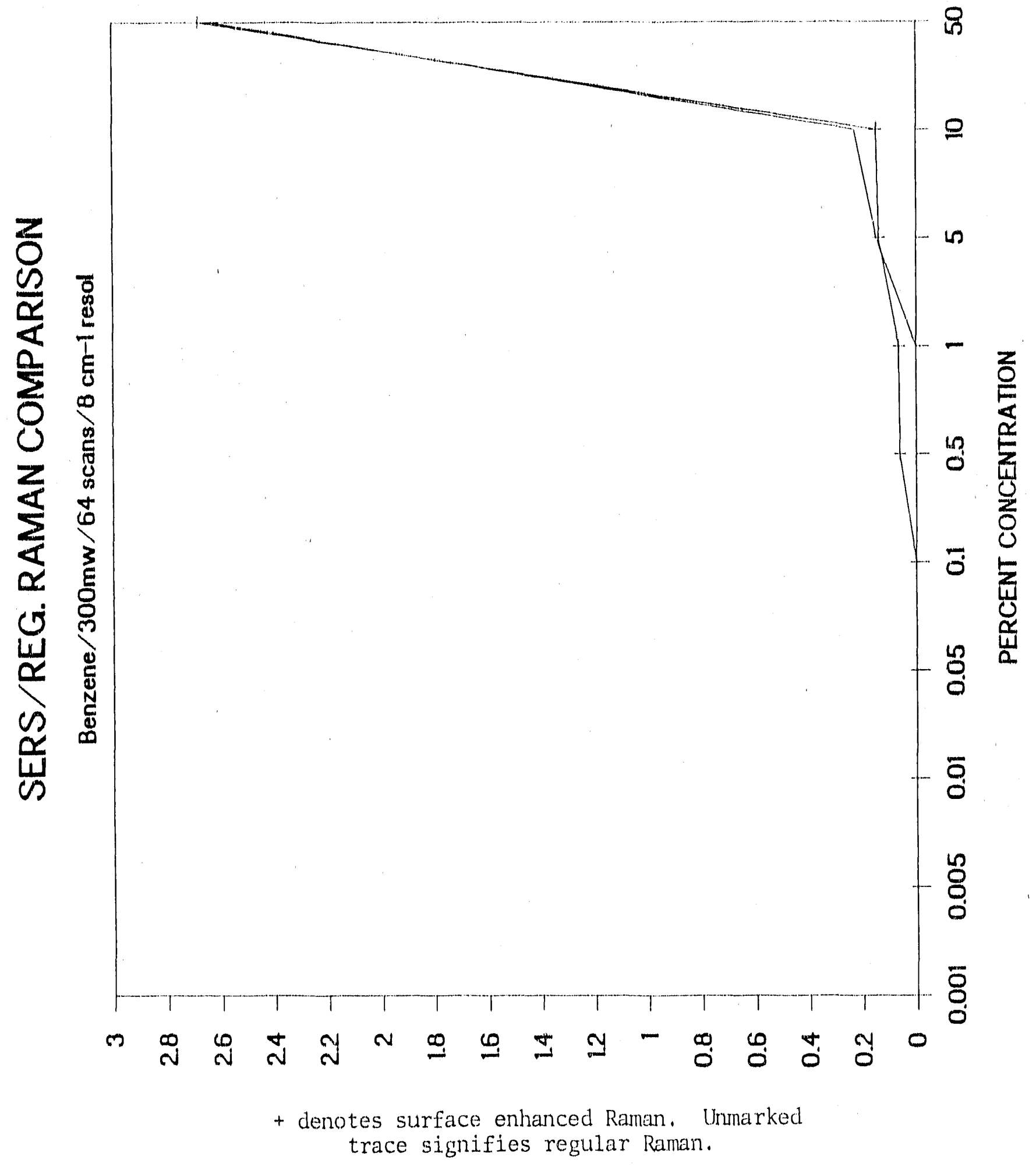

Figure 29 
Based on the hehavior of these chemicals, it is evident that any particular chemical of interest will most likely have a concentration cross-over point beyond which it is not practical to employ SERS. Analyte surface saturation is certainly a limiting factor when issues of signal linearity are addressed. Likewise, self-absorption in the liquid due to high analyte concentration and poor reflectivity from the roughened surface could be major contributions to losses of signal-strength.

\section{Development of a Low Cost Surface Fabrication System}

Equipment cost is a major concern when addressing instrumentation requirements for routine analytical testing of chemicals. The Blo Analytical Systems, Inc. model CV-27 cyclic voltameter used in our electroplating process, and other similar models, retall for thousands of dollars. We chose to address that issue by developing a low cost electroplating system for use with our measurements. The system consists of an American Reliance, Inc, model PPS-2322, dual channel, programmable power supply, an IBM-PC clone, and the usual electrochemical cell components. Refer to Figure 30 . The power supply is controlled by the IBM compatible computer via a National Instruments, Inc. General Purpose Interface Bus (GPIB). Custom control software was written in Microsoft Guick $\mathrm{C}$ version 2.2 in order to make the power supf 'y mimic some of the functions of a cyclic voltameter. Testing of the system has revealed that its operation sufficiently corresponds to that of a cyclic voltameter so that SERS surfaces can be made routinely. Also, due to the high current capacity of the power supply (2 amps max. per channel), large numbers of samples can be made simultaneously thereby reducing the cost per sample.

\section{Reproducibility Measurements}

Measurement reproducibility was also studied for the electrochemically prepared gold surface. The computer-controlled, electroplating system was used to generate surfaces for testing. Again, an electrochemically roughened gold wire served as the SERS surface and aqueous pyrddine as the analyte. The electroplating parameters were: starting point $-1.0 \mathrm{v}$ Increasing to $2.5 \mathrm{v}$ at a rate of $0.5 \mathrm{v} / \mathrm{s}$, pausing for 4 seconds, dropping back to $-1.0 \mathrm{v}$ at a rate ol 


\section{Electroplating Apparatus}

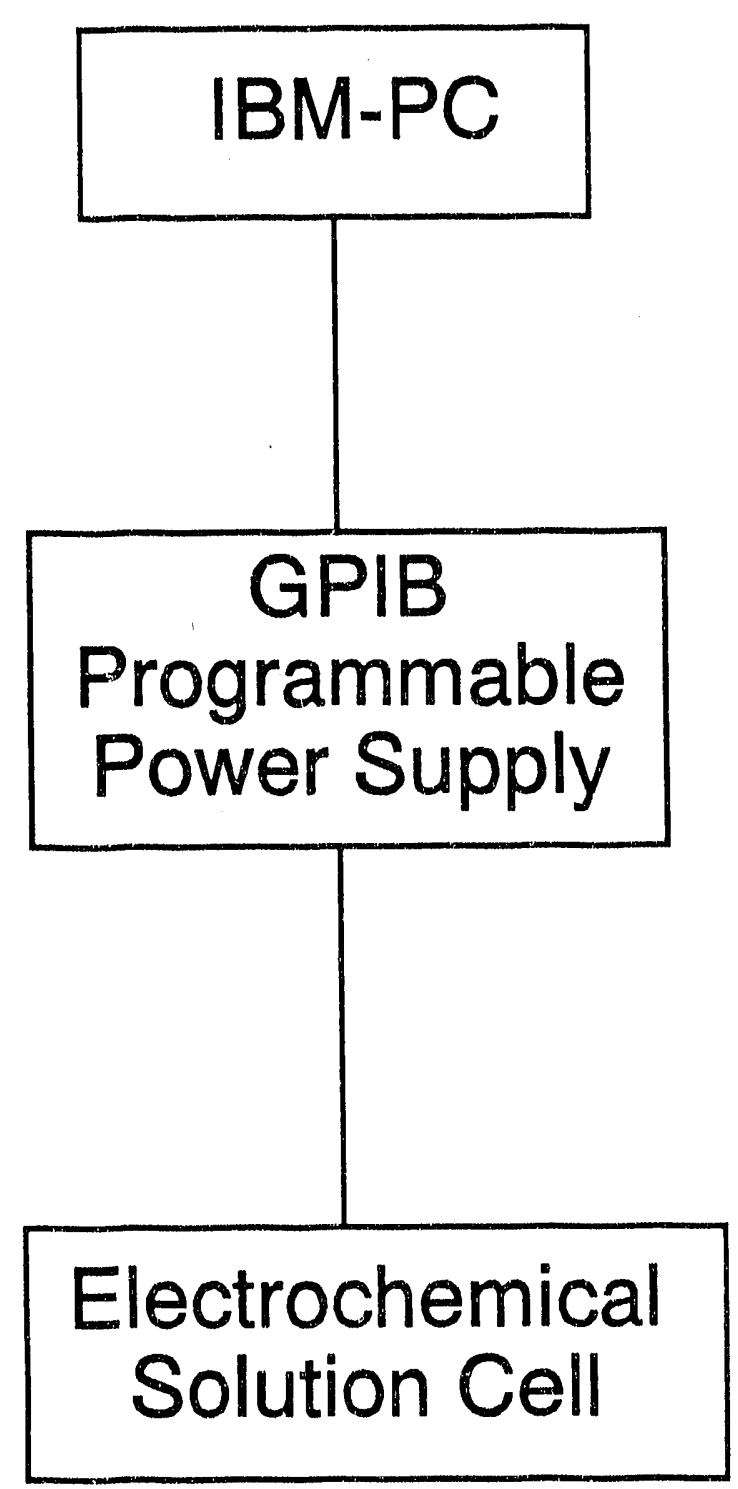

Figure 30 
$0.5 \mathrm{v} / \mathrm{s}$, pausing for 20 seconds, and then repeating. Ten redox cycles were used to fabricate each surface. The electrolyte solution consisted of 0.1 molar $\mathrm{KCl}$. Measurements of $5 \mathrm{ppm}$ aqueous pyridine on five separately prepared gold surfaces revealed qualitative reproducibility. Refer to Figure 31. All of the expertments were performed with the roughened wire in-situ. The average peak intensity above background of the $1000 \mathrm{~cm}-1$ band was 1.75 arbitrary units with a standard deviation of 0.53 . It is posstble to achieve greater reproducibility for higher analyte concentrations. However, this is due to an increase in the unenhanced Raman received from the liquid. Further work would be necessary in order to achieve a satisfactory level of reproducibility for on-line analytical applications.

\section{COMMERCIAL SYSTEM DESIGN}

The instrument that has been developed is based on excitation by a YA laser and spectrum measurement by an interferometer with a single detector. The YAG laser was chosen to avold problems with fluorescence and because relatively high power YAG lasers are avallable. An interferometer was chosen in order to simultaneously have the range and resolution required for a general range of analytes. The limiting system accuracy is determined by the signal-to-noise ratio of the optical detector. With YAG excitation the Raman spectrum is in the near infrared $(1.064$ to $1.5 \mu \mathrm{m})$ and in that region the best detector is an InGaAs photodiode. The signal-to-noise ratio of the diode in combination with the preamplifier determines the limiting system accuracy.

In the early stages of Phase II, basing the system on a shorter wavelength laser and a dispersive (grating-based) spectrometer with a charge-coupled device (CCD) array detector was considered. This combination was not chosen because rellable lasers with sufficient power at these wavelengths were not avallable and in a dispersive spectrometer there is an inherent trade-off between range and resolution. If range is increased, resolution is decreased, and vice versa.

Since that time big improvements have been made in both InGaAs photodiodes and array detectors which have reduced their noise significantly. The latest InGaAs detector is better by a 


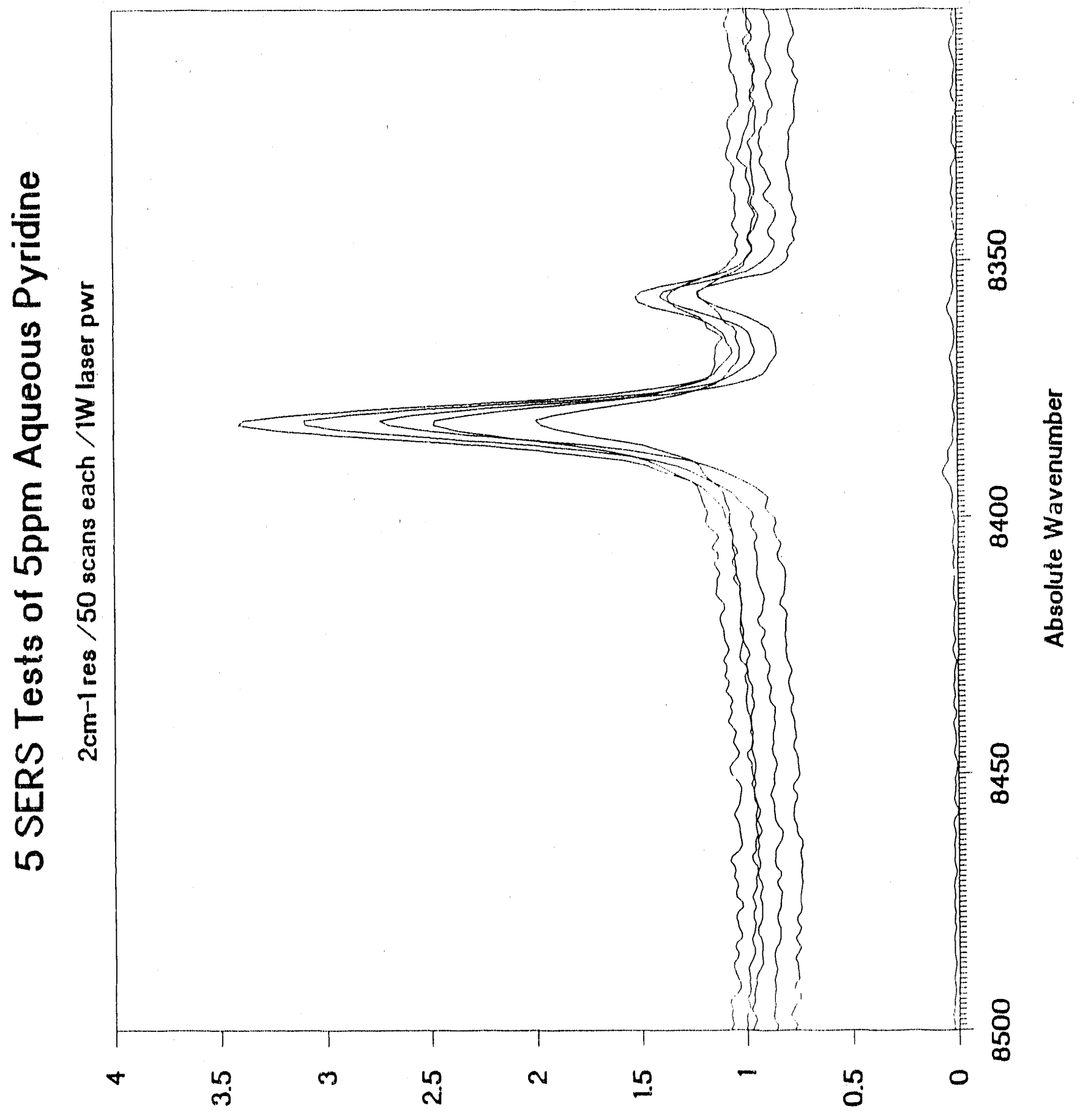

(sf!un que) Af!suaful

Figure 31 
factor of at least 5 than previous models. CCD array detectors have become so good that the systems are essentially noise limited by the inherent shot noise of the signal itself. Performance this good is said to be at the "quantum limit" and cannot be any better. In recent months a system with a Krypton laser, a dispersive spectrometer and a CCD array detector has been developed by a company which is a Center member. The system signal-to-noise ratio is extremely good, such that other problems (calbration inaccuracies, laser power fluctuation, thermal effects, etc.) will probably determine the ultimate accuracy of the instrument. Krypton lasers are not appropriate for long term operation in an industrial environment, but laser diodes at a wavelength appropriate for dispersive spectrometers have been improved. Dlode lasers are now avallable with $100 \mathrm{~mW}$ of power with a power spectrum narrow enough for spectroscopy. They are inherently much more rellable and rugged than Krypton lasers or even YAG lasers.

After three years of testing, the problems inherent in a system based on a YAG laser, Interferometer and InGaAs detector are obvious. It has been pushed to its maximum performance and been found adequate for process control in a distillation column but without a large margin for error. The system based on a diode laser, dispersive spectrometer and CCD array detector will surely have its own unique problems but has great promise because of its extremely good signal-to-noise ratio.

The estimated future costs of the two systems are comparable. The major components of each type of system are illustrated in Table 1 below:

\begin{tabular}{|c|c|}
\hline Interferometer-Based System & Dispersive System \\
\hline Diode-pumped YAG laser $\$ 15 \mathrm{k}$ & Diode laser $\$ 5 \mathrm{k}$ \\
\hline Interferometer with detector $>\$ 20 \mathrm{k}$ & Single-stage spectrograph $<\$ 10 \mathrm{k}$ \\
\hline & CCD array detector $\$ 25 \mathrm{k}$ \\
\hline
\end{tabular}

Table 1. Estimated cost of Interferometer and Dispersive Based Systems 
During Phases I and II there have been contacts with several companles having an Interest in process control with Raman spectroscopy. The most signilicant of these has been with Perkin-Elmer Corp, of Norwalk, Connecticut.

Perkdn-Elmer loaned us their model 1700 interferometric spectrometer for evaluation and we have used it extensively in our experimental development and will use it in the field trials. It was developed for laboratory measurements but has proven rellable and adaptable for Industrial use if it is kept in a benign environment as it will be in the field trials. PerkinElmer has explored the possibilities of developing an instrument for real-time process control measurements with various prospective users. To date there is no known commitment from Perkin-Elmer to develop such an instrument.

\section{DOCUMENTATION AND TECHNOLOGY TRANSFER PRESENTATIONS Documentation}

There are several elements to the documentation of the work in Phase II. The three main categories of documentation are 1) quarterly reports to DOE, 2) conference and journal articles and 3) Steve Kercel's Master's thesis.

The quarterly reports gave updates on the projects progress and have been received by DOE.

Conference and journal articles were published at several times during Phase II and a list follows. 


\section{CONFERENCE AND JOURNAL ARTICLES}

M. J. Roberts, A. A. Garrison, S. W. Kercel, D. S. Trimble, C. F. Moore and E. C. Muly, "Development and Applicallon of a Raman Spectroscopy Based Instrument for Mull-Polnt Composition Analysis and Control of a Distllation Column," ISA 90, New Orleans, LA, pp. 463-468, October 1990.

A. A. Garrison, E. C. Muly, M. J. Roberts, D. S. Trinible and C. F, Moore, "Raman Spectroscopy for On-Line Distillation Process Control," ISA 89, Phlladelphia, PA, pp. 357-363, October 1989.

A. A. Garrison, D. S. Trimble, E. C. Muly, M. J. Roberts and S. W. Kercel, "On-Line Chemical Analysis Applied to Distillation Control - A Status Report." American Laboratory, pp. 19-27. February 1990.

S. W. Kercel, M. J. Roberts, A. A. Garrison, and D. S. Trimble, "Development of a FiberOptic Based Instrument for On-Line Ramar, Analysis of Process Chemical Composllion," SENSORS EXPO WEST, March, 1990.

M. J. Roberts, S. W. Kercel and A. A. Garrison, "Recent Advances in the Development of a Fiber-Optic Based Instrument for On-Line Raman Analysis," SPIE, San Dlego, CA, July 1990.

S. W. Kercel, "A Sensor Using Raman Spectroscopy for On-Line Composition Monltoring of Distillation Mixtures in Real Time", Master's Thesis, August 1990. Universlly of Tennessee, Knoxvllle. Tennessee.

A.A. Garrlson, "Flber-Optlc based FT-Raman Spectroscopy for Process Control," FACSS, Anaheim, CA, October 1991.

A.A. Garrison, D.L. Balley, M.J. Roberts, C.F. Moore, "Vibrational Spectroscopy for OnLine ('hemical Composition Measurement", FACSS, Anaheim, CA, October 1991.

M.J. Roberts, A.A. Garrison, S.W. Kercel and E.C. Muly, "Raman Spectroscopy for OnLine, Real-Time, Multi-Point Industrial Chemical Analysis", Process Control and Quallty, accepted for publication.

Steve Kercel's thesis is a very good coordinated and detailed account of the progress of Phase II up untll August of 1990 Including hardware and software design, experimentalion and analysis. 


\section{Technologu Transfer Presentations}

During the course of the Phase II effort regular meetings were held with Measurement and Control Center members interested in the application of on-line chemical composition analysis to their processes and with other potential users of this technology. Table II is a listing of of those meetings. During each meeting company representatives were briefed on the results the developments to date and the future plans for this effort.

\begin{tabular}{|l|c|c|}
\hline \multicolumn{1}{|c|}{ Meeting } & \multicolumn{1}{|c|}{ Date } & \multicolumn{1}{c|}{ Participants } \\
\hline MCEC Information Meeting & August 14-16,1989 & $\begin{array}{l}\text { Non Member Industrial } \\
\text { Representatives }\end{array}$ \\
\hline $\begin{array}{l}\text { Fall Industrial Advisory Board } \\
\text { Meeting }\end{array}$ & Sept. 18-20,1989 & MCEC Industrial Representatives \\
\hline $\begin{array}{l}\text { Lignin Determination in Black } \\
\text { Llquor }\end{array}$ & Nov, 20-21,1989 & $\begin{array}{l}\text { Non Member Paper Company } \\
\text { Representatives }\end{array}$ \\
\hline $\begin{array}{l}\text { Spring Industrial Advisory Board } \\
\text { Meeting }\end{array}$ & April 9-11,1990 & MCEC Industral Representatives \\
\hline $\begin{array}{l}\text { Fall Industrial Advisory Board } \\
\text { Meeting }\end{array}$ & Sept, 10-12,1990 & MCEC Industral Representatives \\
\hline $\begin{array}{l}\text { MCEC Information Meeting } \\
\text { Npring Industrial Advisory Board } \\
\text { Meeting }\end{array}$ & April 8-10,1991 & MCEC Industrtal Representatives \\
\hline
\end{tabular}

Table 2. List of Technology Transfer Presentations

\section{PROJECT REVIEW MEETINGS}

Two project review meetings were held with DOE representatives during Phase II. The first meeting was held in Knoxville on October 9, 1989 to review the prellminary sensor system design. At this meeting the DOE representatives were joined by representatives from Perkin Elmer, MIDAC, Instruments SA, and Guided Wave. The second meeting was held at DOE headquarters in Washington, DC on March 1, 1991 to review the over all status of the project and discuss plans for the follow-on Phase III effort. 


\section{CONCLUSIONS AND FUTURE WORK}

A chemlcal analysis system based on Raman spectroscopy with a dlocle-puniped NoliYAC laser excltation source, optlcal libers to transmlt both excltalion and scallered light and all Interferometer-based spectrometer has been shown to be leaslble for on-line, real-llme process control measurements of chemical stream compasitlon with an mons uncertalnty of less thin $2 \%$ and a measurement system response time of 3 munutes.

During the course of Phases I and II other avenues of development were considered but nut pursued because of time and money restrictions. The more important ones were:

1. The use of a diode laser as an excitation source.

2. The use of a grating and a charge-coupled device (CCD) array for spectrum detection.

3. Alternate flber optlc probe designs.

4. A lower nolse preamplifter for the InGaAs photodiode deteclor.

Each of these areas could lead to an improvement in the signal-to-noise ratio of the measurement.

Dlode lasers have greatly improved during Phase II. It is now possible to get a dlode laser at $830 \mathrm{~nm}$ with a narrow-band output of $100 \mathrm{~mW}$. Even though this is a lower power than is avallable from a Nd:YAG laser at this shorter wavelength the Raman scattering efficlency is Improved by a factor of about 2.7 and most of the Raman scattering lies within the range of a sllicon detector. Sllicon detectors have Inherently lower dark current than InGaAs detectors and should be able to achleve lower system nolse and therefore better signal-to-nolse rallo lior the same optical power. The main advantage of a dlode laser is its ruggedness and long, lle: compared to any other laser including the dlode-pumped Nd:YAG.

CCD arrays have also greatly Improved during the course of Phase II and systems based on thern have been shown to have very high signal-to-nolse ratios. Since they spread the light spectrum with a grating there is a tradeoff between resolution and spectral range. If one is Increased the other must decrease. For many Industrial applicillons the capabillty of a grating-based instrument is entirely adequate. 
The present probe design is simple and relatlvely rugged but tt can be shown that other designs, at least in theory, have a greater light gathering capablity, These olher designs Involve the use of lenses or mirrors to collimate, filter and refocus the excltallon light and to gather and Image the scattered light onto a fiber. Every surlace causes a loss of light but wilh careful destgn and alignment these designs could probably gather more light overall than our present probe design. They also can gather the llght into a single small flber rather than into several large ones. This could greatly reduce the fiber costs which are a signlficant consideration in the overall system cost.

The signal-to-nolse ratio of the present system was greatly improved by the use of anew, lower noise InGaAs photodiode. Its noise is now low enough that other noise sources have become significant. The next most significant nolse source in an optimized preamplifter is presently the notse of its input devices, silicon Junction fleld-effect transistors (FET's). By the use of very low nolse FET"s the overall preamplifler nolse can be significantly reduced compared to present commercial designs. The Undversity of Tennessee's Measurement and Control Engineering Center is exploring this path under separate funding. 


\section{Appendix A}

Progress In Chemometric Data Analysis

Using Artificlal Neural Networks 


\title{
PROGRESS IN
}

\section{CHEMOMETRIC DATA ANALYSIS USING ARTIFICIAL NEURAL NETWORKS}

\author{
YING LIU
}

B.R. UPADHYAYA

\begin{abstract}
PROGRESS REPORT PREPARED FOR
THE MEASUREMENT AND CONTROL ENGINEERING CENTER THE UNIVERSITY OF TENNESSEE, KNOXVILLE
\end{abstract}

MARCH 1991 


\section{EXECUTIVT SUMMARY}

The results of performance analysis of neural networks with application to chemometrie data analysis are summarized In this report. Two important considerations for effective Implementation of neurat networks are the optimization of network architeoture and their robustness and sensitivity to signal-to-nolse ratio. For each study the results are averaged over one hunared test runs. Raman spectra of samples with five components are used in this study. The following are the results related to the performance of the network for estimating chemical composition using spectral signatures.

1. The number of processing elements (PEs) in the intermediate layer that provides minimum estimation error is found to be equal to the number of patterns used in network training.

2. The estlmation error can be reduced by using an ensemble of networks with same architecture.

3. The network with two hidden layers has a smaller prediction error compared to that with only one hidden layer.

4. The standard deviation of parameter estimation is less than 2 percent for spectral additive noise of up to about 3 i⿱ signal-to-noise ratio. 
5. Chemidal components can be assoclated with speciflc spectral regions. This is studied by (a) selectively adding nolse, (b) excluding all regions except the one of Interest, and (c) excluding only the reglon of interest from the spectrum. All these experiments provide consistent results in associating sensitivity of spectral changes to a given component.

6. The connection weights from intermediate layer to the output layer converge to constant values.

The analysis uses a chemical sample with flve components. Both single and multiple networks are used. Multiple networks (one for each component), in general, have higher fldelity compared to a single network used to estimate all components. Also combining two of the components with similar properties is found to be more effective than using a parameter vector of all components simultaneously. 


\section{INTRODUCTION}

A general architecture consisting of a first-stage Kohonen network and a second stage multi-layer perceptron is developed for application to large pattern sets. When the number of training sets is large, the network training time and accuracy will be affected to various degrees. Preprocessing of training patterns is one way to overcome this problem. The purpose of data processing is to reduce the size of training set. To accomplish this, a pattern classification is performed to organize the patterns into different classes. Probabilistic neural networks [1] or Kohonen networks [2] may be used for classification. Figure 1 shows a two-stage architecture using a Kohonen layer and a multi-layer perceptron (MLP).

The back propagation network (BPN) algorithm is currently the most widely used neural network paradigm and has been applied to many pattern-mapping problems. Typically, a multilayer perceptron has three or more layers. Since the number of hidden units play an important role in the network learning phase, one critical problem is the optimization of network architecture by selecting the number of hidden units. Another factor that may affect network learning is error in input patterns. Thus the study of the effect of noise on the 
network performance is an important issue in actual applications.

This report summarizes four sub-tasks that have been completed.

1. Selection of the number of hidden units and modification of the network architecture.

2. Network performance to changing signal-to-noise ratio.

3. Analysis of the sensitivity of the network output to input patterns.

4. Study of behavior of network connection weights. 


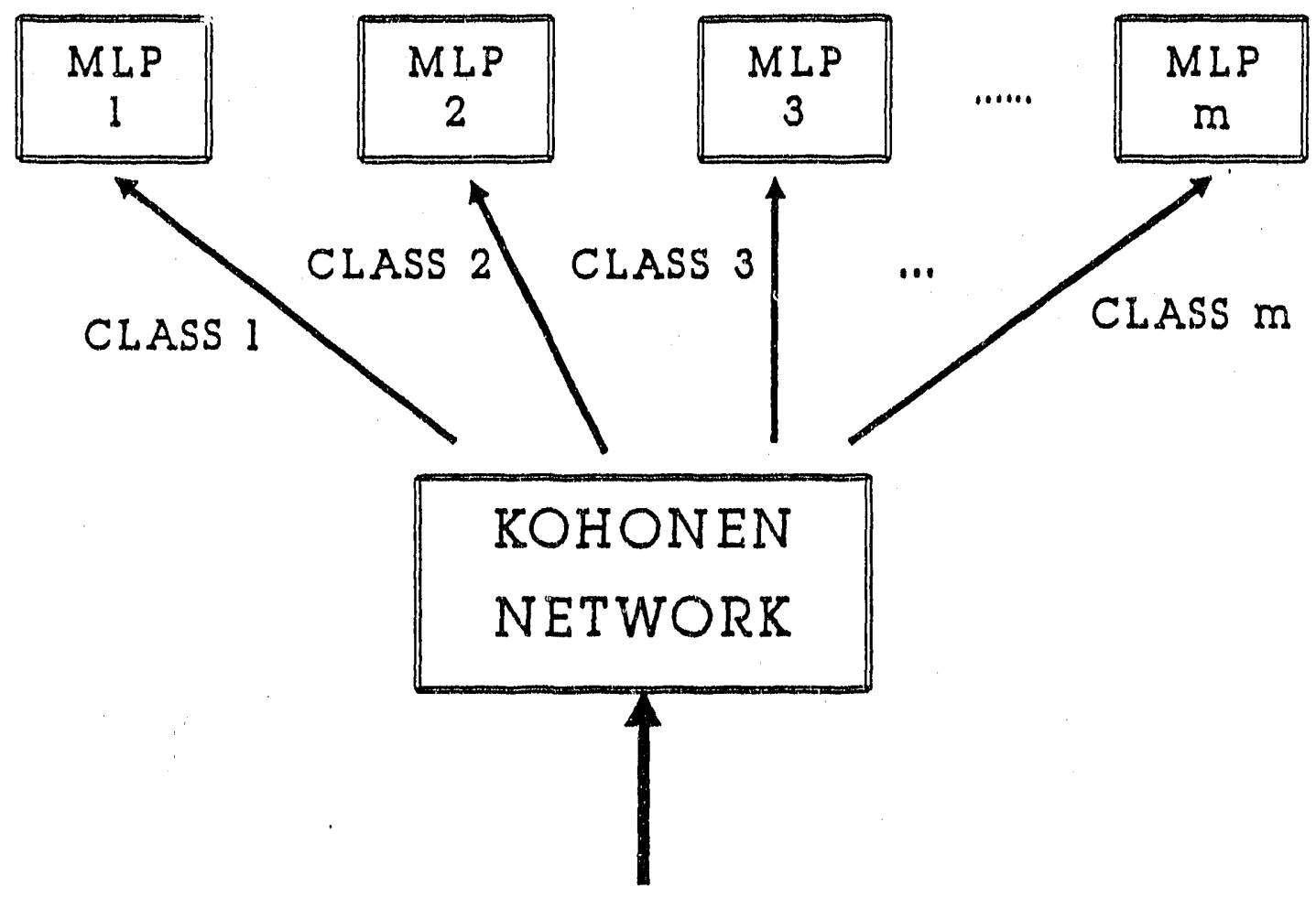

CHEMOMETRIC DATA

Figure 1. A combination of Kohonen layer and multi-layer perceptron (MLP) 


\section{METHODOLOGY}

2.1. Optimal structure of Neural Networks

In the back-propagation network learning phase, the computational complexity is significantly dependent on the number of hidden units. These "re-representation units" must be large enough to form a decision region that is as complex as is required by a given problem. However, training an excessively large number of synaptic weights may be computationally costly, and it becomes difficult to estimate the output feature reliably from the training data. Therefore, the choice of an optimal number of hidden units is highly desirable for effective learning. There is no established rule to make a prior estimation from irregular training patterns, but this number is closely related to the size of training sets [3]. In this study, the number of hidden units is determined from experimental results. The Raman spectroscopic data consists of 30 patterns, 22 of which are selected for network training, and the other serve as the test set. During the experiment, the number of hidden units is varied from 15 to 25 while the number of input and output units are fixed at 190 and 5, respectively. Each training case is repeated 10 times. The absolute error are obtained for each case and the minimum absolute error is then used to 
determine the optimal number of hidden units.

Secondly, three different configurations of the target outputs have been tested for training the network. One consists of five output components (n-hexane, iso-octane, toluene, p-xylene, and decane). Another has four output components (iso-octane, toluene, p-xylene, and the combination if $n$-hexane and decane). The third configuration models each component separately; thus five (or four) independent networks are required. As expected, the last configuration gives more reliable estimates of the composition for this problem. Figure 2 presents a typical three-layer feedforward network architecture for this application.

Finally, the performance of the network with different number of hidden layers is studied. Chester [4] has proved that the number of neurors in a network with one hidden layer might grow without bound to improve accuracy. This dramatic increase of hidden units will result in an extremely high computational cost. However, by using a network with two hidden layers, we can achieve a high degree of accuracy in network estimation. This may be because the neurons in the first layer partition the input space into small regions, thus the neurons in the second layer can compute the desired function within that region. 
In section 2.1 , we stated the importance of hidden units and hidden layers in network learning phase. We also notice that the residual error will persist even after optimizing aIl available network characteristics. In order to further reduce the estimation error, a method of "network ensembles" is invoked. Instead of a single network, we establish a set of networks which are trained using the same learning samples, but different initial conditions. During the recall phase, all the networks are used for estimation, and an average is obtained from the ensembles. From a statistical point of view, the average estimate is more reliable and accurate than the result from a single network. 


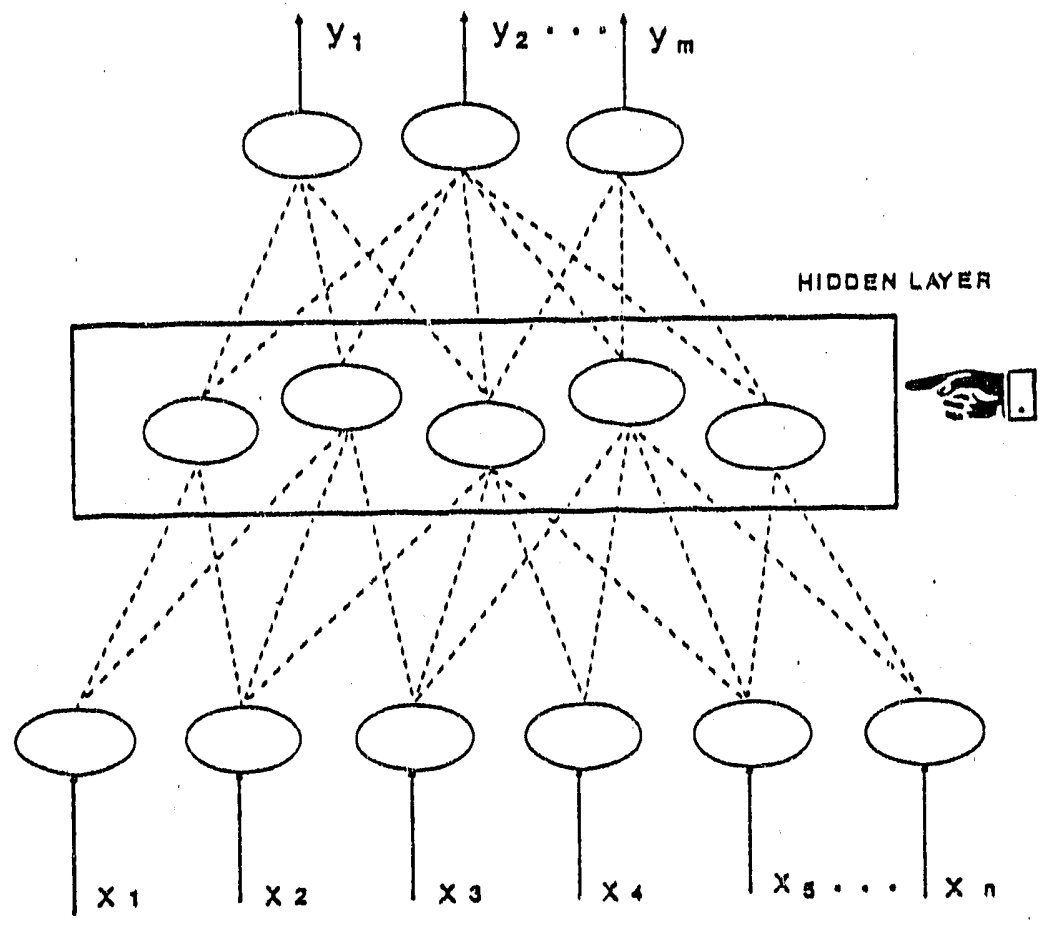

$(\mathrm{X} 1, \mathrm{x} 2, \ldots, \mathrm{X} n)$ : INPUT RAMAN SPECTRUM $(Y 1, Y 2, \ldots, Y m)$ : PERCENT COMPOSITION

Figure 2. Three-layer Network structure 9 A-11 
2.3. Effect of Measurement Nolse on Network Recall

To study the effect of network output to noise environment, two different types of tests have been performed. A FORTRAN program is used to generate 100 sets of random Gaussian noise patterns with standard deviations from 0.5 to 5\% of average amplitude of input spectral patterns. This noise is then added to the original signal and the resultant signal is used to test the network. The second test uses random noise with standard deviation 0.5 - 5\% of individual. spectral amplitudes. This noise is then added to the input spectrum to test the network performance in estimating composition values. The overalu. standard deviation of network prediction errors for 100 sets of data (statistical average) is calculated for each case. The performance of the network to recall parameters under noise corruption is compared with results for the noise-free case.

2.4. The Sensitivity Analysis

A detailed study has been made to determine the relationship between a given component(fraction) and spectral range(s). Three methods axe used for this study : (1) adding random noise to one of the peaks in the input spectrun; removing all but one peak from the input spectrum; 
(3) removing only one peak from the spectrum. The spectra that have been modifled in this manner are then used to test the network. The purpose of this study is to determine if one of the components in the sample is related to one (or more) of the peaks in the input spectrum. This can be used to verify that the network can learn the inherent relationships for the given data.

2.5. Effect of Phase Shifted Pattern

one other important study is to test the response of network output to phase shifted patterns which may be caused by instrumentation errors. To demonstrate the output behavior, we shifted the whole spectrum to the right and then predicted the output using the previously trained network for this new pattern. The results show that the network is sensitive to spectral position. Furthermore, the network is more sensitive to the shift than to the addition of random noise.

2.6. Performance of Network Connection Weights

The study of the behavior of connection weights is made for the weights between the hidden layer and the output layer in a three-layer network. The observation is made by plotting 
the magnitude of each connection welght for each iteration. 


\section{EXPURIMENTAL RESULTS}

3.1. Selection of Network structure for Th1s Application

Each network with a given number of hidden units was trained using the BPN algorithm. The overali performance for each network was taken over 10 trials (different starting values). The results of these experiments are plotted in Figure 3. The best average performance was achieved by the network with 22 units in the hidden layer. We also notice that this number is equal to the number of training patterns.

Figure 4 shows the network performance with different configurations. It clearly indicates that the network with single output unit provides the smallest estimation errors.

We also studied a network with two hidden layers ( 8 and 5 nodes espectively) and used this new network to perform training and prediction with the same chemometric data. The comparison of results indicated (in Flgure 5) that the average prediction error using two hidden layers is 0.0195 , while with one hidden layer the network error is 0.03017 .

our argument for using network ensembles is strongly supported by the experimental results. Figure 6 shows the 
concentration estimation using the average of 10 networks vs. the results with single network.

\subsection{Effect of Noise}

As described above, two types of random nolse were used for this study. Tables 1 and 2 summarize the experimental results. A bar plot is made in Figure 7 for the first type of nolse. The standard deviation for each network output reported In the table was obtained over 100 trials of the random noise testing. The network prediction error increases almost Iinearly as a function of percent input nolse. The prediction exror is approximately $2 \%$ for an input noise of $3 \%$. 


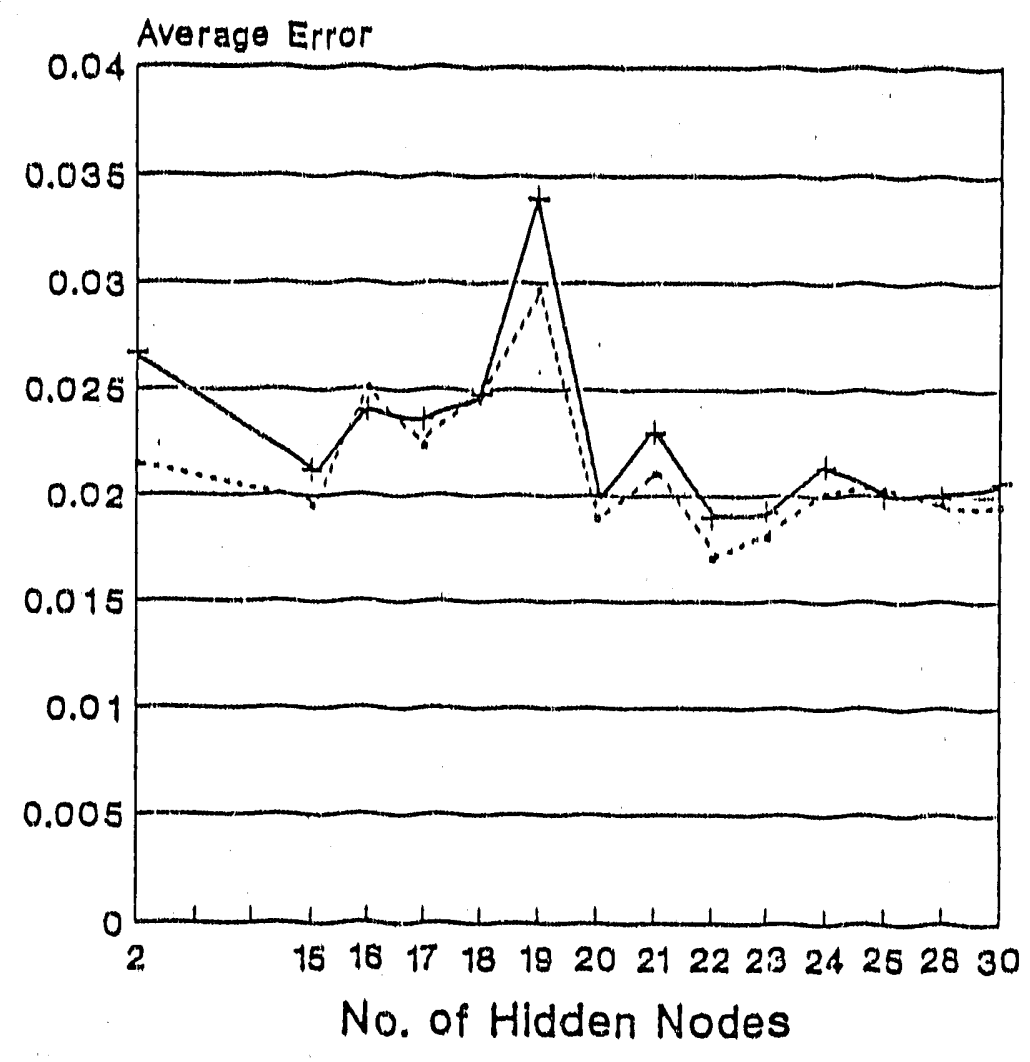

......... Training Pattern - Test Pattern

Figure 3. Network performance vs. hidden units

A-17 


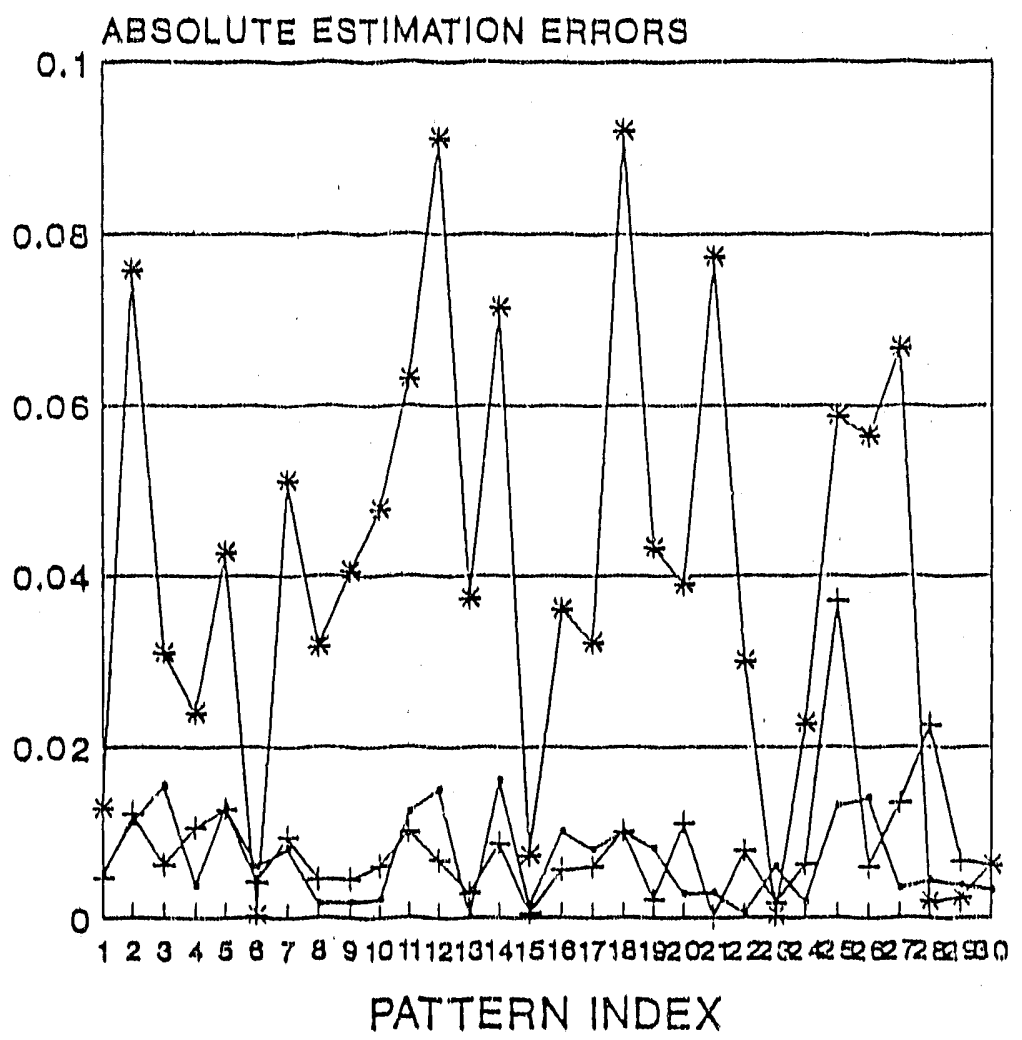

- Single output + Four output $\rightarrow$ Five output

Figure 4. Network performance with different configurations 
Table 1. Network performance for

signal noise

\begin{tabular}{ccccc}
\hline $\begin{array}{c}\text { Random noise } \\
(\%)\end{array}$ & \multicolumn{3}{c}{ Standard deviation of sample components $(\%)$} \\
\hline 0.5 & No.1 & No.2 & NO.3 & NO.4 \\
1 & 0.5 & 0.3 & 0.65 & 0.3 \\
2 & 1 & 0.5 & 1 & 0.67 \\
3 & 1.8 & 1 & 2.2 & 1.04 \\
4 & 2.7 & 1.6 & 3.2 & 1.5 \\
5 & 3.85 & 2.15 & 4.8 & 2.4 \\
\hline
\end{tabular}


Table 2. Network performance for signal dependent noise

\begin{tabular}{ccccc} 
Random noise & \multicolumn{4}{c}{ Standard deviation of sample components $(\%)$} \\
$(\%)$ & No.1 & No.2 & NO.3 & No.4 \\
\hline 0.5 & 0.6 & 0.2 & 0.48 & 0.417 \\
1 & 1.28 & 0.57 & 1.16 & 0.75 \\
2 & 2.38 & 1.03 & 1.9 & 1.47 \\
3 & 4.19 & 1.5 & 3.55 & 2.5 \\
4 & 5.3 & 1.78 & 3.89 & 3.16 \\
5 & 7.2 & 2.6 & 5.56 & 4.8
\end{tabular}




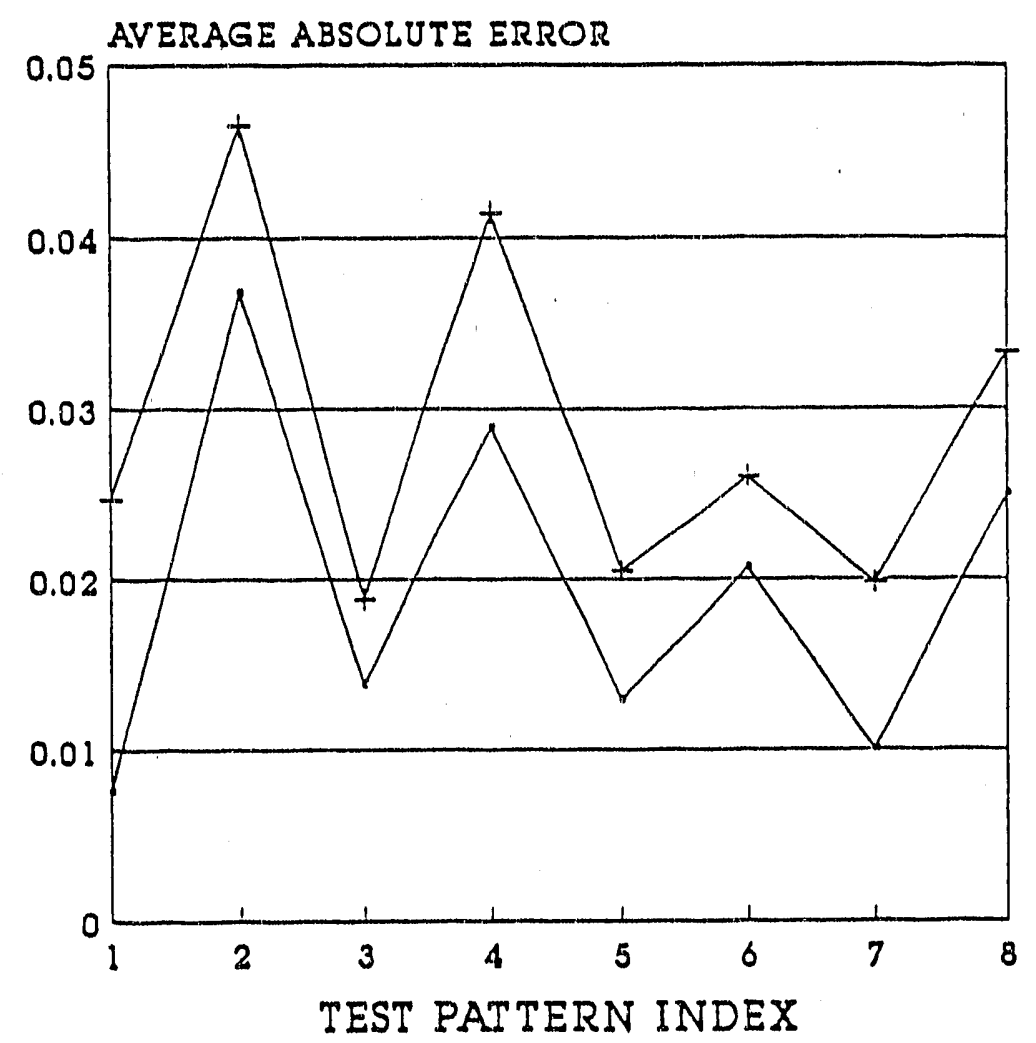

- TWO_HIDDEN LAYER T ONE_HIDDEN LAYER

Figure 5. Network performance with different number of hidden layers 


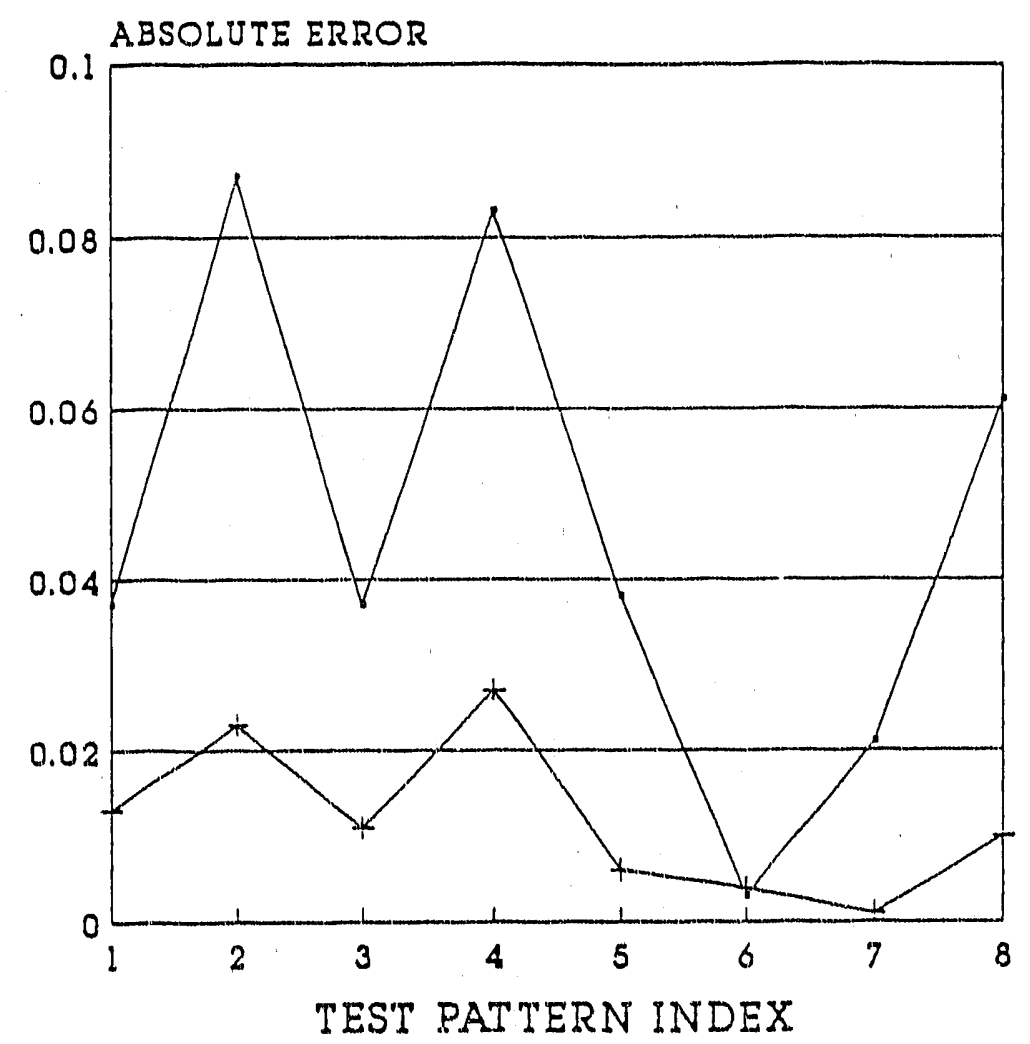

- SINGLE NETWORE - NETWORX ENSEMBLES

Figure 6. Comparison of ensembles and single network performance 


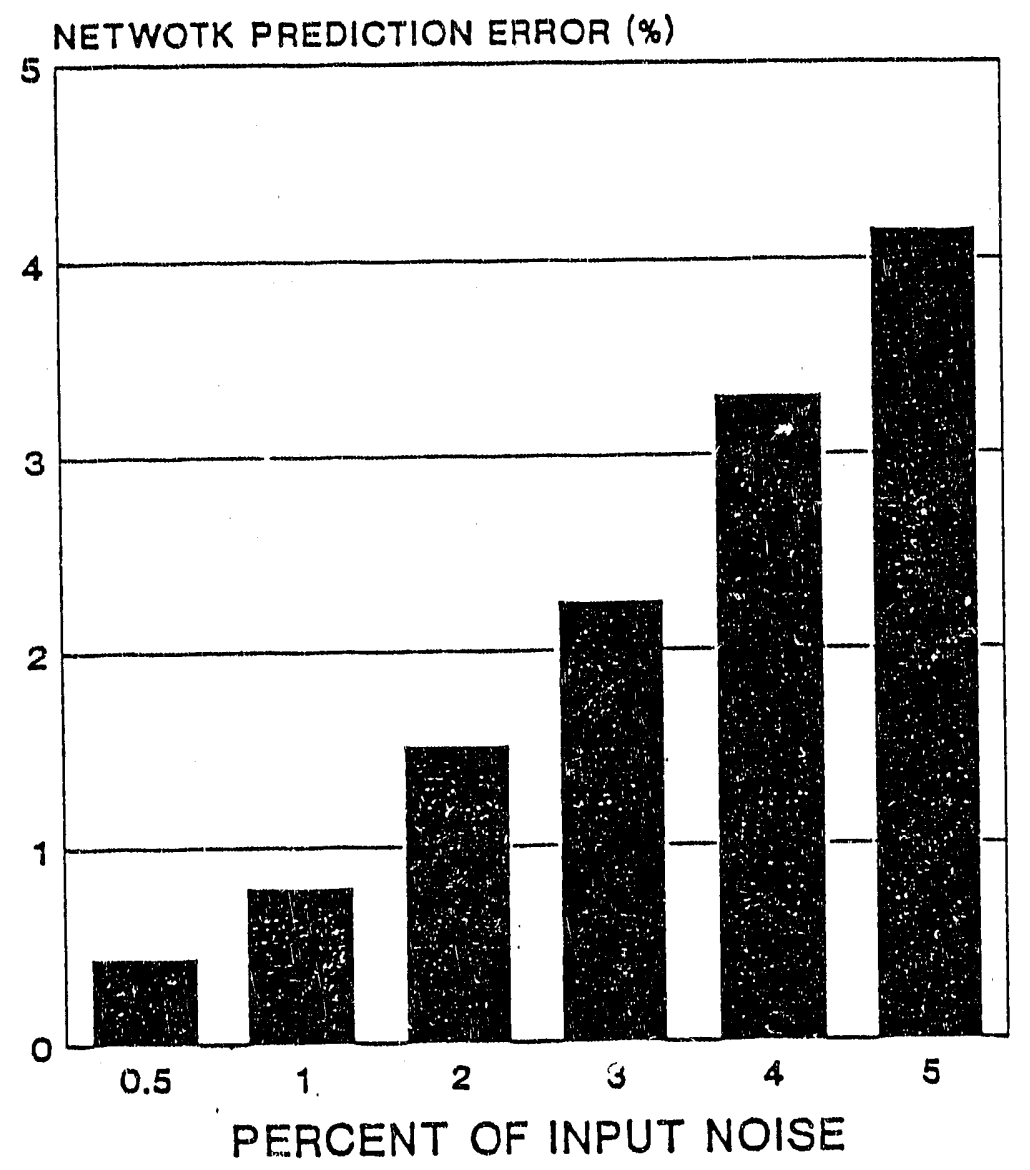

Figure 7. Effect of input noise to network estimation 


\subsection{The Sensitivity study}

Figure 8 shows the Raman spectral pattern used to relate a portion of the spectrum with one or more components in the sample. As an illustration of this study, approximately $5 \%$ bias error is added to the spectrum in the indicated portion in the figure. The resulting fractional components as estimated by the network and the error are shown in the Figure 9. This clearly indicates that the estimation of $n-$ hexanetdecane fraction is most sensitive to the bias error.

Further study of this sensitivity is made by selectively excluding the indicated region from the spectrum, and by excluding all the spectral features except the portion of interest. In both cases this perturbation has maximum effect on the prediction of $n$-hexanetdecane concentration. Thus, the current analysis has been able to associate Raman spe.tral region(s) with specific fractional component(s). 


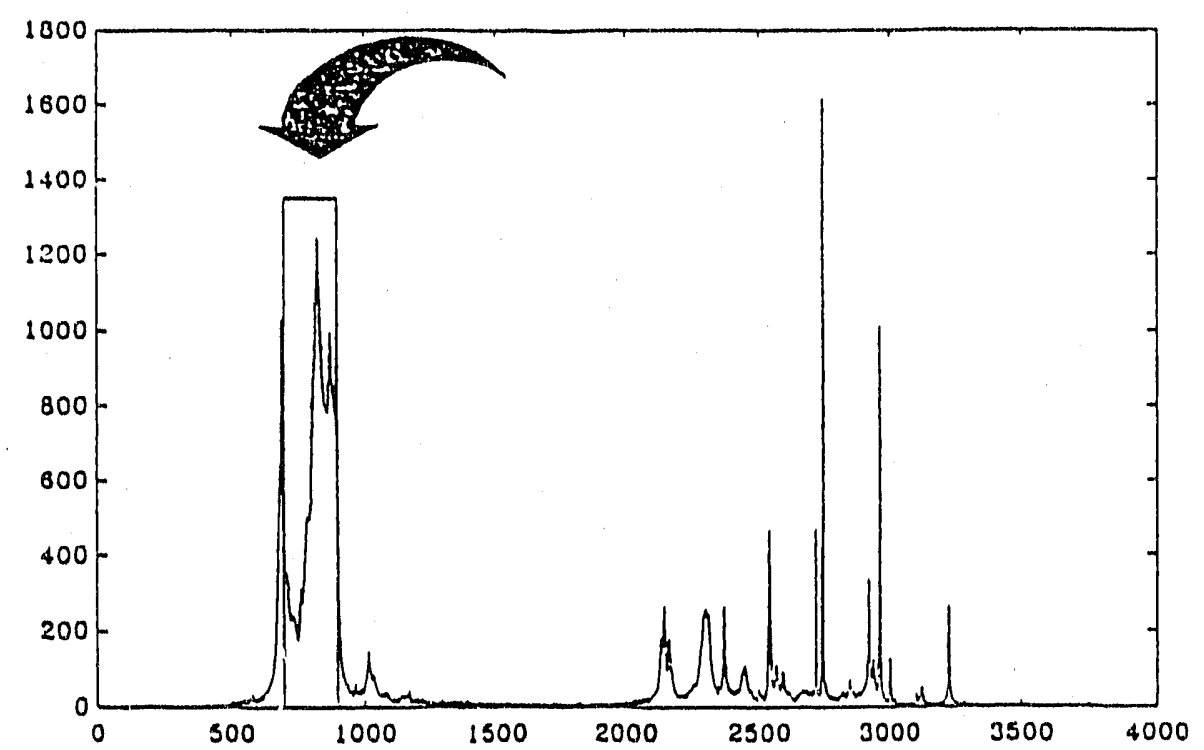

Figure 8. Regional perturbation in a Raman spectral pattern 


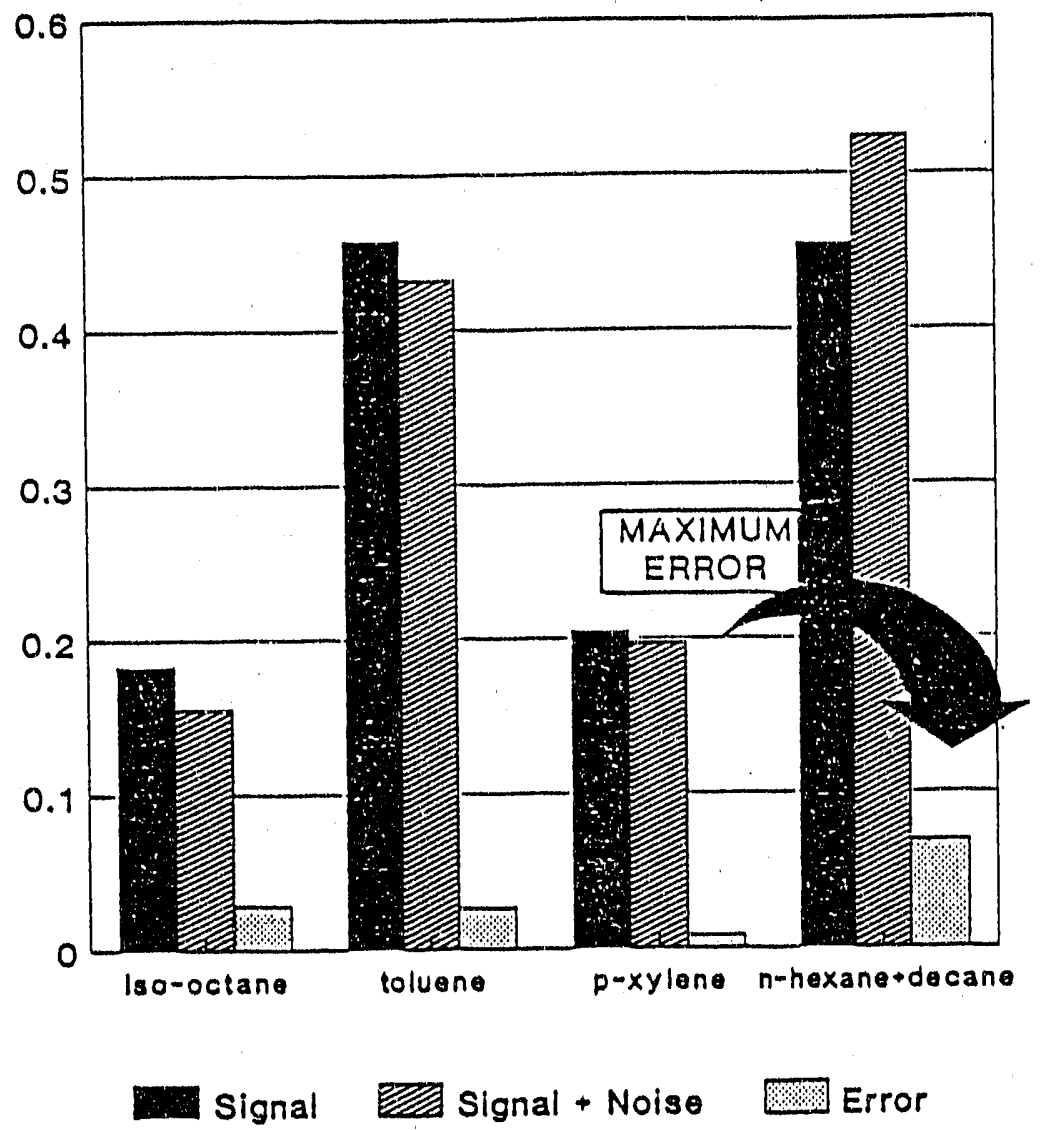

Figure 9. Sensitivity analysis with additive noise

$$
\begin{gathered}
24 \\
A-26
\end{gathered}
$$


3.4. Study of Phase Shifted Spectrum

Figure 10 shows the original and phase shifted (to the right) spectral patterns. We used both of these to test a trained network. Table 3 demonstrates the response of the network to these two patterns. The use of shifted spectrum produces large errors in concentration estimation.

3.5. Study of Network Connection Weights

Figure 11 shows the behavior of a typical connection weight as a function of iteration. The connection weight converges to a certain value with increasing iteration number. No fluctuations are noticed. 


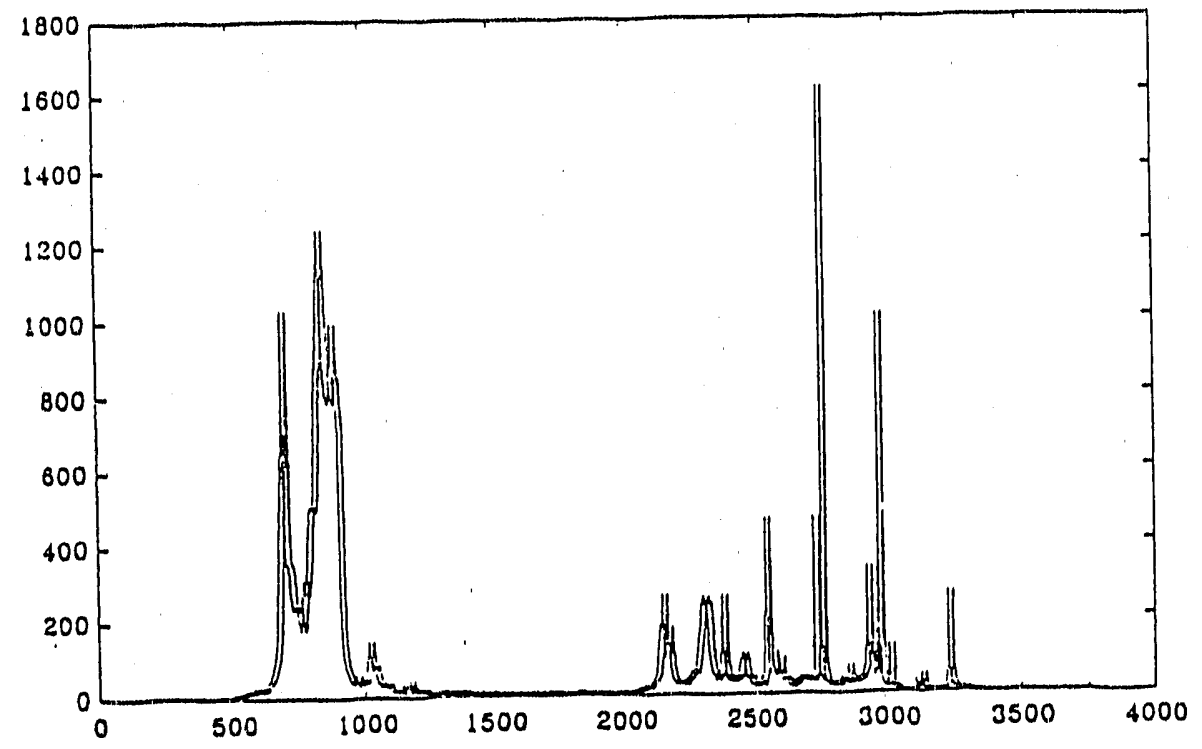

Figure 10. Phase shifted test pattern

26

A-28 
Table 3. Effect of phase shifted pattern

\begin{tabular}{lccc}
\hline $\begin{array}{c}\text { Network } \\
\text { output }\end{array}$ & $\begin{array}{c}\text { Target } \\
\text { output value }\end{array}$ & $\begin{array}{c}\text { Estimated value / abs. error } \\
\text { Before shift }\end{array}$ & After shift \\
\hline No.1 & 0.276 & $0.273 / 0.0027$ & $0.162 / 0.113$ \\
NO.2 & 0.340 & $0.323 / 0.0166$ & $0.375 / 0.036$ \\
NO.3 & 0.189 & $0.192 / 0.0034$ & $0.133 / 0.052$ \\
No.4 & 0.496 & $0.504 / 0.0078$ & $0.660 / 0.164$
\end{tabular}

The results indicate that spectral shifts can cause large errors in composition estimation. It is necessary to preprocess the data to ensure that proper spectral pattern matching is accomplished. 


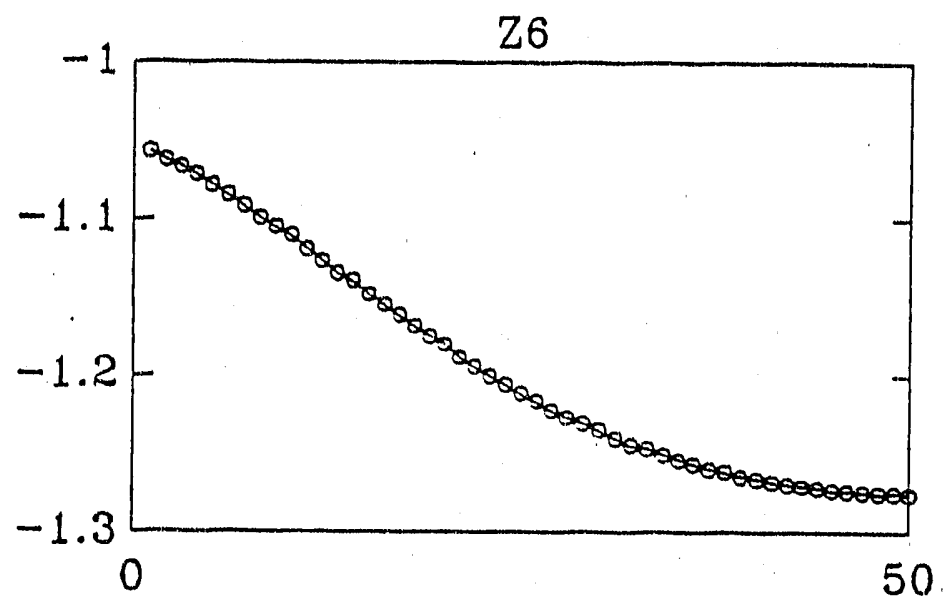

Figure 11. A typical connection weight behavior

28

A-30 


\section{CONCIUSIONS}

The number of hidden units necessary to obtain the best estimate for the network output has been determined for this composition identification problem. Multiple networks, each with single output unit, perform better than one network estimating all the parameters simultaneously.

The estimation errors can be reduced by using two hidden layers and an ensemble of networks.

The trained network using the Raman spectrum is robust to signal noise. This is illustrated by a small standard deviation of error in the estimated concentration, generally less than $2 \%$ when the standard deviation of noise is less than 3\%. The correspondences between spectral features and component fractions have been demonstrated using independent sensitivity analysis of the neural network. Shifts in the measured spectra cause large errors in estimating chemical composition. This problem may be avoided by spectral preprocessing and matching its features with significant features of known spectra. 


\section{REFERENCES}

[1] D. F. Specht, " Propabilistic Neural Networks and The Polynomial Adaline as Complementary Techniques for Classification," IEEE Transactions on Neural Networks, Vol. 1, No. 1, pp.111-121, March 1990.

[2] Judith Dayhoff, " Neural Network Architectures," Van Nostrand Reinhold, N. Y. 1990.

[3] S. Y. Kung and J. N. Hwang, "An Algebraic Projection Analysis for Optimal Hidden Units Size and Learning Rates in Back-Propagation Learning," IEEE Intl. Conf. on Neural Networks, pp. 363-370, July 1988.

[4] D. L. Chester, "Why Two Hidden Layers Are Better Than one," IJCNN-90, Wasinington, D. C., pp. I-265-268, January $15-19,1990$. 


\section{Appendix B}

A Literature Search of Near Infrared

Surface-Enhanced Raman Scattering Research

B-1 


\section{"A LITERATURE SEARCH OF NEAR INFRARED SURFACE-ENHANCED RAMAN SCATTERING RESEARCH"}

By: David Bailey 


\section{INTRODOCTION}

There are many techniques available to the scientist for identification of molecules. Since the advent of lasers in the 1960's and the development of sensitive, low noise, semiconductor-based light detectors, Raman scattering has emerged as one of those analytical techniques. For the purpose of molecular identification, the Raman spectrum of the molecule in question is essentially its fingerprint. clearly, such information can be quite valuable.

Unfortunately, there is a drawback to this technique. Raman scattering is a weak process. Only about one in a milition of the molecules excited by intense light will actually be induced to emit Raman light. This limitation usually necessitates that there be a large number of molecules present that exhibit a reasonable propensity for Raman scattering. If these conditions are not met, then a detectable spectrum may not be successfully obtained.

There is a technique that is useful in some cases for the detection of the Raman signal emitted from molecules present in low concentrations. This technique is called surfaceenhanced Raman scattering (SERS). The phenomenon was first reported by Milton Fleischmann et. al. in 1974. Since that discovery, much research has been performed which indicates that SERS may be useful as the foundation of a Raman scattering measurement process. In particular, we believe that our Raman-scattering-based process monitoring technique is a good candidate for implementation of SERS.

The basic instrumentation used for our SERS measurements is the same as that used for the conventional Raman measurements enhancing surface placed in the solution containing the analytes. our initial research goal was to draw upon the current literature of near infrared based, Fourier transform SERS to guide us in the choice of the test surface. Although the supply of literature was not replete with NIR FT-SERS experiment and theory, enough evidence was found to indicate that an electrochemically roughened gold surface is the best choice for our tests. The benefits attained with this surface are ease of preparation, the capacity for generating large enhancements of the Raman signal, and the inherent nonreactive nature of the metallic gold. These qualities also indicate that this surface may be ideal for other industrial applications in which we may become interested.

Contained in the following pages are the papers that constitute the literature search that is the first requirement of the Department of Energy grant that funds this research. The collection is preceded by a list of those papers that includes the authors names, the article titles, and the journals in which they were published. 
The Ube of Near Infrared Fourier Trangform Techniques in the study of Surface Enhanced Raman Spectra

AUTHOR(S): Fleischmann, M., Sockalingum, D., Musiani, M. M.

LOCATION: Chem. Dep., Univ. Southampton, Southampton, UK, SO9 $5 N H$

JOURNAL: Spectrochim. Acta, Part A DATE: 1990 VOLUME: 46A NUMBER: 2

PAGES: 285-94 CODEN: SAMCAS ISSN: 0584-8539 LANGUAGE: Engliah

Copyright 1990 by the Amertcan Chemical society

Near-Infrared Surface-Enhanced Ranan Spectra of 3-Picoline and 3-Chloropyridine on a Copper Electrode

AUTHOR(S): Angel, S. M.; Archibald, D. D

LOCATION: Environ. Sci, Div., Lawrence Livermore Natl, Lab., Livermore, CA, 94550, USA

JOURNAL: Appl. SpectroBC. DATE: 1989 VOLUME: 43 NUMBER: 6 PAGES: 1097-9 CODEN: APSPA4 ISSN: 0003-7028 LANGUAGE: Engliah

Copyright 1990 by the American Chemical society

Near-Infrared Surface-Enhanced Raman Spectroncopy Uaing a Diode Laser AUTHOR(S): Angel, Stanley M.; Myrick, Michael $L$.

LOCATION: Environ, Sci, Div., Lawrence Livermore Natl. Lab., Livermore, CA, 94550, USA

JOURNAL: Anal. Chem. DATE: 1989 VOLUME: 61 NUMBER: 15 PAGES: $1648-52$

CODEN: ANCHAM ISSN: 0003-2700 LANGUAGE: ENGLISH

Copyright 1990 by the American chemical society

Near-Infrared surface-Inhanced Raman spectroscopy. Part II: Copper and Gold Colloids

AUTHOR(S): Angel, S. M.; Katz, L. F.; Archibald, D. D.i Honigs, D. E. LOCATION: Environ, Sc1, Div., Lawrence Livermore Natl. Lab., Iivermore, CA 94550, USA

JOURNAI: APP:. SpectroBC. DATE: 1989 VOLUME: 43 NUMBER: 3 PAGES: 367-72 CODEN: APSPA4 ISSN: 0003-7028 ILANGUAGE: ENGLISH

Copyright 1990 by the American Chemical society

Near-Infrared Surface-Enhanced Raman Spectroscopy, Part I: Copper and Gold Electrode日

AUTHOR(S): Angel, S. M.; Katz, L. F.; Archibald, D. D; Lin, L. T.; Honiga, D. E.

LOCATION: Environ, Sci, Div., Lawrence Livermore Natl. Lab., Livermore, CA 94550, USA

JOURNAL: Appl. SpectrosC. DATE: 1988 VOLUME: 42 NUMBER: 8 PAGES: 1327-31 CODEN: APSPA4 ISSN: 0003-7028 LANGUAGE: ENGLISH

Copyright 1990 by the American Chemical society

Surface-Enhanced Raman Spectroscopy in the Near-Infrared AUTHOR(S): Chase, D. B.; Parkineon, B. A. USA

LOCAYION: Cent. Res. Dev. Dep., Du Pont Exp. stn., Wilmington, DE, 19898,

JOURNAL: Appl. SpectrogC. DATE: 1988 VOLUME: 42 NUMBER: 7 PAGES: 1.186-7 CODEN: APSPA4 ISSN: 0003-7028 LANGUAGE: ENGLISH

Copyright 1990 by the American Chemical society 
Surface-Enhanced Fourier Trangform Raman spectroscopy in the Near Infrared

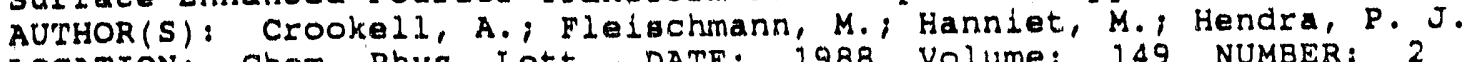
LOCATION: Chem. Phys. Lett. DATE: 1988 Volume: 149 NUMBER: 2 PAGES: 123-7 CODEN: CHPLBC ISSN: OOO9-2514 LANGUAGE: Engliah

Copyright 1990 by the American Chemical society

Near-Infrared Surface-Enhanced Raman spectra of 3-Picoline and

3-Chloropyidine on a Copper Electrode

Angel, S.M.; Archibald, D.D

Author Affil: Environ. Scl. Div., Lawrence Livermore Nat. Lab., CA, USA

Source: Appl. Spectrosc. (USA) vol.43, no.6, Pp.: 1097-9

Publication Year: Aug. 1989

CODEN: APSPA4 ISSN: 0003-7028

U. S. Copyright Clearance Center Code: 0003-7-28/89/4306-1097\$2.00/0

Surface- Mnhanced Fourier Transform Raman spectroscopy in the Near Infrared Crookell, A.; Fleischmann, M.; Hanniet, M.; Hendra, P.J.

Author Affil: Dept. of Chem., Southampton Univ., UK

Source: Chem. Phys. Lett, (Nétherlande) vol.149, no.2, pp.:123-7

CODEN: CHPLBC ISSN: 0009-2614

U. S. Copyright Clearance Center code: 0009-2614/88/\$03.50

Two-photon Regonant Four-Wave Mixing and Multiphoton Ionization of Ce日ium in a Hear Pipe Oven

Hamadant, S.M.; Stockdale, J.A.D.; Compton, R.N.

Author Affil: Div. of Health \& Safety Res. Div., Oak Ridge Nat. Lab.

TN, USA

Sponmor: SPIE

Publication Year: 1986

CODEN: PSISDG ISSN: 0277-786X

Two-Photion Resonant Four-Wave Mixing and Multiphoton Ionization of Cesium in a Heat-Pipe Oven

Hamadani, S.M.; Stockdale, J.A.D.; Compton, R.N.; Pindzola, M.S

Author Affil: Dept. of Phys. Astron., Western Kentucky Univ. Bowling

Grean, KY, USA

Source: Phys. Rev. A(USA) vol.34, no.3, pp.: 1938-43

Publication Year: Sept. 1986

CODEN: PLRAAN ISSN: 0556-2791 
Appendix C

Raman Spectroscopy For On-Line Real-Time Multi-Point Industrial Chemical Analysis

C- 1 


\title{
Raman Spectroscopy for On-Line, Real-Time, Multi-Point Industrial Chemical Analysis
}

\author{
M. J. Roberts, A. A. Garrison, S. W. Kercel and E. C. Muly \\ Measurement and Control Engineering Center, University of Tennessee, Knoxville, TN 37996-2000
}

\begin{abstract}
The applicability of Raman spectroscopy to real-time industrial chemical analysis is assessed. It is compared with absorption and fluorescence spectroscopy. Major factors in the assessment are the type, number and concentration of analytes, the number of measurement points, accuracy and time response. Also different instrurnent types are considered; principally the choice between a grating instrument and an intarferometric instrument and the excitation wavelength to be used. The use of fiber optics to multiplex the instrument capabiliiies to multiple measurement points is also explored. An instrumint design developed at the University of Tennessee is presented.
\end{abstract}

Keywords: Raman, spectroscopy, process, analysis, fiber optics, multiplexing, chemometrics, laser, grating, interferometer

\section{INTRODUCTION}

T) 2 solution to any measurement problem begins with a clear statement of the problem. The type of analytical method best suited to an on-line, multi-point chemical composition measurement in a process environment depends on several factors,

1. the chemicals to be analyzed (the composition of the analyte),

2. the number of components in the process stream,

3. the concentrations of the components,

4. the number of locations at which composition information is desired,

5. the accuracy required,

6. the time response required,

7. the environment in the local area of a measurement point; i.e., temperature, humidity, vibration, etc...,

8. the safety requirements in the local area of a measurement

and probably other factors in specific situations. All these factors interact with the economics of the system design.

Generally speaking, laboratory analytical instrumentation is very accurate and versatile but also expensive and delicate. Therefore if it is to be applied industrially the cost per measurement must be minimized and the instrument must be either ruggedized or otherwise protected from any harsh operating conditions $[1,2,3,4]$. One way to bring down the cost per measurement is to share the cost of the instrumentation among several measurements. Since the measurement points may be at some considerable distance from each other this means either bringing chemical sample streams to the instrument with the attendant installation costs, time delay and maintenance problems or somehow physically extending the instrument capabilities to the measurement locations. Optical analytical methods lend themselves to extension of the instrument to the measurement points because of the availability of low-loss optical fibers. Another advantage of this technique is that the expensive, delicate instrumentation can be located in a relatively benign environment (such as a control room) and only the optical fibers and some relatively simple sampling equipment need to be at the measurement point. There are installation costs for the fiber but they should be lower than costs for piping the process chemicals to the instrument and the maintenance cost should be 
significantly lower. Since light propagation through the fibers is practically instantaneous there is no transport lag to slow the system response, except in any local sampling system at the measurement point.

Once the decision is made to use an optical method the next question is which one to use. There are three common optical analytical methods in use today,

1. fluorescence spectroscopy,

2. absorption spectroscopy,

and 3. Raman spectroscopy.

Each of these methods requires a well-characterized excitation light source and an apparatus to analyze the spectrum of the light after its interaction with the analyte.

In fluorescence spectroscopy [5] the excitation light source is usually an intense lamp or laser of appropriate wavelength to cause fluorescence in the analyte. The shape of the spectrum of the fluorescence is characteristic of the chemical composition of the analyte and occurs in a range of wavelengths longer than that of the excitation light. In absorption spectroscopy the excitation light source is usually a broadband thermal source. It is passed through the sample and certain wavelengths are attenuated more than others forming the absorption spectrum. Since the measurement is usually change in strength of the transmitted excitation light with wavelength and not of scattered light, the signal is relatively powerful and the signal-to-noise ratio is therefore typically good although detecting small concentrations can be difficult since that involves detecting a small change in a strong signal. The range of wavelengths of the source can be from the ultraviolet to the infrared. In any absorption method control of the path length for the light is critical to the accuracy of the method since the amount of absorption is a direct function of path length and path length changes cannot be distinguished from changes in intrinsic absorption. In Raman spectroscopy $[6,7,8,9]$ the excitation light is almost always a laser. Its wavelength may be anywhere from the ultraviolet to the near infrared. The measurement is of the Raman-scattered light from the analyte. Raman scattering is the phenomenon of some very small percentage of the excitation light being slightly changed in wavelength through its interaction with the analyte. Rayleigh scattering also occurs and the power in the Rayleigh scattered light is much greater than that of the Raman scattered light (typically several orders of magnitude). The Raman spectrum of scattered light occurs on both sides of the excitation wavelength and at the same wavenumber (not wavelength) offset from the excitation light regardless of the excitation wavelength. The Ramanscattered light on the longer wavelength side of the excitation is called the Stokes spectrum and the Raman-scattered light on the shorter wavelength side is called the anti-Stokes spectrum. At all but extremely high temperatures the Stokes spectrum is much stronger than the anti-Stokes spectrum and is usually the one used for analysis. 
Below are summarized the major advantages and disadvantages of these three methods of spectroscopy.

Advantages Disadvantages

Fluorescence

Strong signal.

Compatible with silica fibers.
Broad, overlapping spectral features. Some analytes don't fluoresce.

Absorption:

Mid.Infrared $(5-10 \mu \mathrm{m})$

Near Infrared (0.8-2 $\mu \mathrm{m})$

Visible $(400-700 \mathrm{~nm})$

Raman
Features are fundamental and distinct.

Generally good signalto-noise ratio.

Compatible with silica fibers.

Generally good signalto-noise ratio.

Compatible with silica fibers.

Generally good signalto-noise ratio.

Sharp, distinct spectral features.

Any wavelength can be used for excitation (unless fluorescence is a problem). Presence of water poses no difficulty.
Incompatible with silica fibers.

Requires exotic optical elements.

Broad, overlapping spectral features.

A high water concentration can obscure other species in the spectrum.

Many analytes are clear colorless liquids and have no absorption spectrum. Broad, overlapping spectral features.

Signal-to-noise ratio can can be poor for low concentrations. Fluorescence can cover up features. made.

These factors should be seriously considered before the choice of an analytical method is

\section{SYSTEM DESIGN CONSIDERATIONS}

Once the decision is made to use Raman spectroscopy as an analysis technique some fundamental decisions must be made which control the system design. They are

1. excitation wavelength,

2. analytical instrument type,

3. optical multiplexing method,

and 4. optical coupling from laser to excitation fiber and from collection fiber(s) to spectrometer,

and of course these all interact. 
The choice of excitation wavelength depends mostly on three factors,

1. whether or not it causes significant fluorescence in the analyte,

2. the attenuation of the light in the optical fibers at the excitation wavelength and

3. the type of detector used to measure the spectrum.

Generally speaking the best excitation wavelength [10] is the shortest one that does not cause significant fluorescence. A shorter excitation wavelength is desirable because the Raman scattering efficiency is directly proportional to the fourth power of the excitation frequency and therefore inversely proportional to the fourth power of the wavelength.

The wavelength of minimum attenuation in silica fibers is typically in the range from 1.3 to $1.5 \mu \mathrm{m}$ (Fig. 1) [11]. Because of practical considerations associated with available laser wavelengths and sensitivities of detector systems, the excitation wrvelength must generally be less than $1.3 \mu \mathrm{m}$. Therefore there is a trade-off between the increased Kaman scattering efficiency and decreased Raman-scattered light power due to increased fiber ittenuation as the excitation wavelength is shortened. Since the total attenuation in the fiber depends on the wavelength and the fiber length, for short fibers the attenuation may not be a problem, whereas for longer fibers it could be.

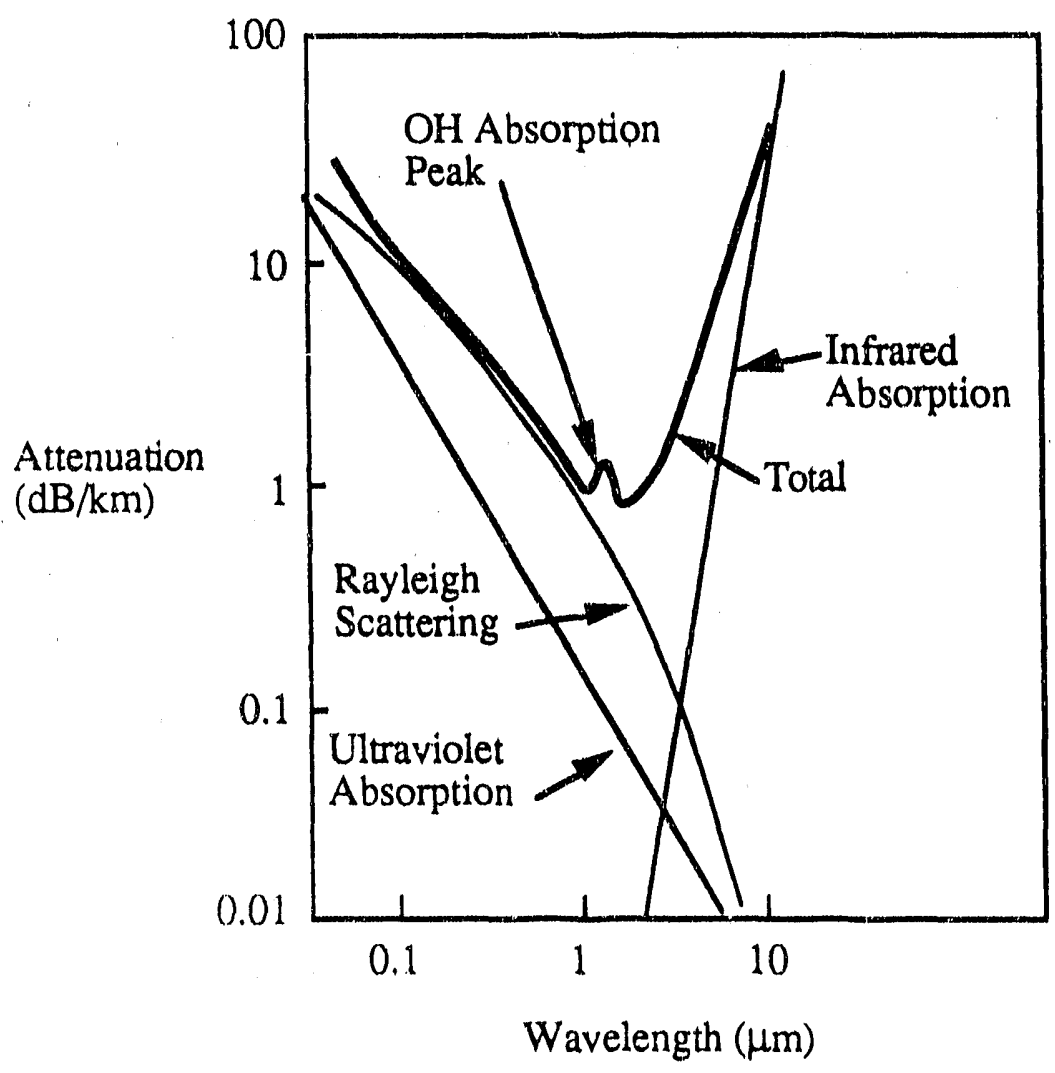

Fig. 1 Attenuation in silica fibers as a function of wavelength

Some commonly used excitation wavelengths are:

$514 \mathrm{~nm}$ Argon laser line:

High power available (several watts optical), good scattering efficiency, strong probability of fluorescence, expensive laser not reliable enough for most industrial applications, not best match with silica fibers but acceptable in some applications 
$632.8 \mathrm{~nm}$ Helium-Neon laser line:

Low power available (tens of $\mathrm{mW}$ ), low cost laser, moderate scattering efficiency, relatively reliable, some probability of fluorescence, fairly good match with silica fibers

$676 \mathrm{~nm}$ Krypton laser line:

Moderate power available, moderate scattering efficiency, some probability of fluorescence, laser not reliable enough for industrial applications, fairly good match with silica fibers

725-830 nm Diode laser lines: Low-to-maderate power in a single longitudinal mode (up to $100 \mathrm{~mW}$ ), moderate scattering efficiency, low probability of fluorescence, good match with silica fibers, very reliable compared to other lasers

$1.064 \mu \mathrm{m} \mathrm{Nd:YAG} \mathrm{laser} \mathrm{line:}$

High power available (several watts optical), low scattering efficiency, very low probability of fluorescence, laser fairly reliable, excellent match with silica fibers

There are three commonly-used types of detectors; photomultipliers, photodiodes and chargecoupled devices (CCD's) [12].

Photomultipliers convert light to electrical current through the photoelectric effect: They have been used extensively for laboratory spectroscopy because of their high sensitivity. They are vacuum tubes, therefore delicate and require high voltage power supplies. Their usable sensitivities generally extend to wavelengths no higher than $1.1 \mu \mathrm{m}$. For best signal-to-noise ratio they must be cooled to reduce their dark current. For all but a few special laboratory measurements photornultipliers are being supplanted by photodiodes and charge-coupled devices (CCD's).

Photodiodes are solid-state devices which convert photons to separated electrons and holes which are accelerated in opposite directions and contribute to current flow. They do not require high voltage bias (unless they are avalanche photodiodes and even then the voltage is not as high as that required for photomultipliers), and some have usable sensitivity beyond $1.1 \mu \mathrm{m}$. The most common types of photodiodes used in optical spectroscopy are silicon (Si), germanium $(\mathrm{Ge})$ and indium gallium arsenide ( $\mathrm{InGaAs}$ ). Silicon detectors are useful up to wavelengths of about 1.1 $\mu \mathrm{m}$, germanium and InGaAs up to about $4 \mu \mathrm{m}$. Photodiodes may be used as single detectors in interferometric systems and traditional monochromators with rotating gratings or as linear arrays in so-called "polychromators" with fixed gratings. For maximum system sensitivity the photodiode should be cooled to reduce its dark current. In many cases thermoelectric cooling may be adequate; in others where the signal is especially weak, liquid nitrogen cooling $(77 \mathrm{~K})$ may be necessary.

CCD's are also solid-state devices, usually silicon, and the basic mechanism of conversion from light to electrical charge is the same [13]. The electrons are collected for some finite time in in potential well under the gate electrode and then are swept out and measured later to determine the total light energy that illuminated on the CCD during that time. CCD's are usually made in arrays and must be cooled to minimize dark current. They are also available in two-dimensional array's so that multiple measurements of spectra can be made simultaneously, each spectrum being imaged onto one row of the array. Their wavelength range is essentially the same as for silicon photodiodes; that is, up to about $1.1 \mu \mathrm{m}$. 
The choice of analysis instrument type depends on several factors,

1. wavenumber range required,

2. wavenumber resolution required,

3. signal strength

4. instrument throughput

and 5. signal-to-noise ratio.

There are two basic types of spectral analysis instruments; dispersive and interferometric. Dispersive instruments form the spectrum of the light by using a grating (Fig. 2) $[14,15,16,17]$. The grating spreads the spectrum of the light in space and it can be detected by either a rotating grating and a single detector or a fixed giuting and an array of detectors. Interferometric instruments use a Michelson interferometer to form an interferogram by the movement of one mirror and the light intensity is detected by one detector as the mirror moves (Fig. 3). The power spectrum of the light is then found by taking the Fourier transform of the interferogram $[18,19,20,21,22,23,24,25,26,27]$.

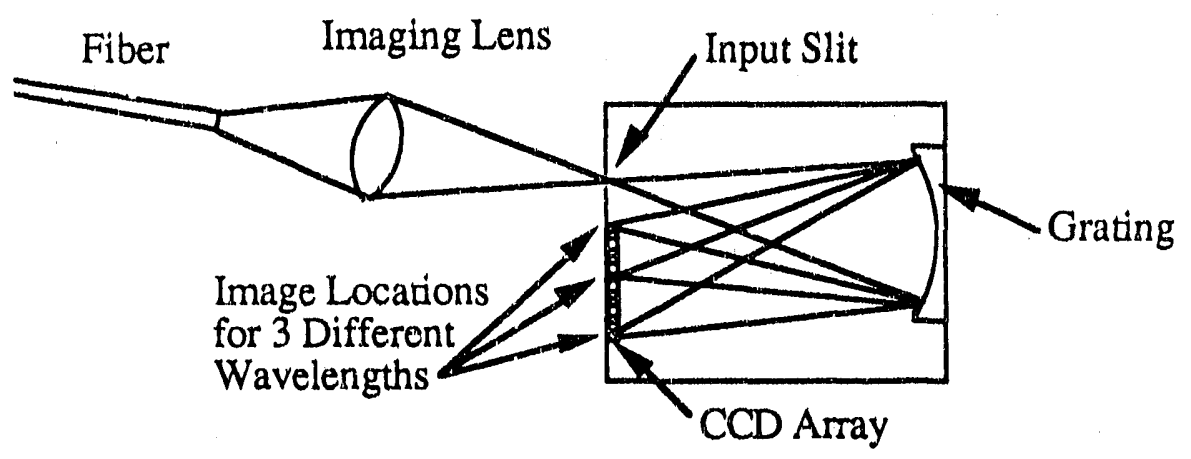

Fig. 2 Simplified diagram of a grating spectrometer

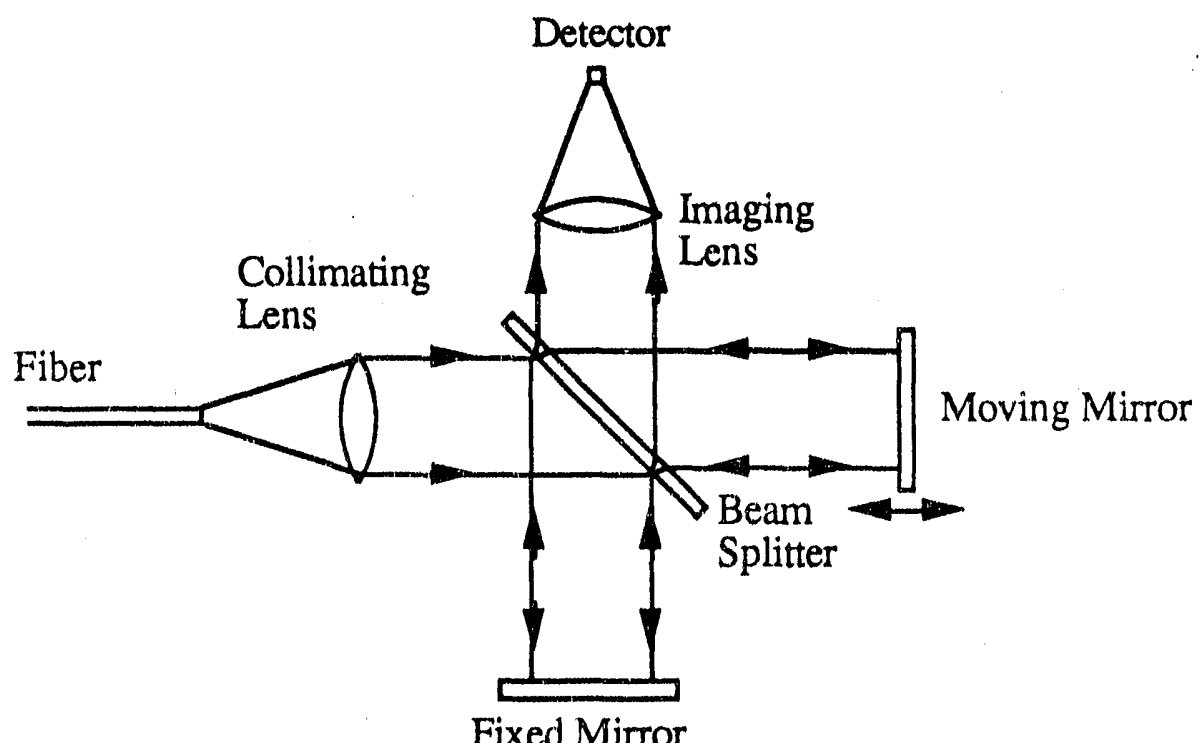

Fig. 3 Simplified diagram of an interferometric spectrometer

Each type of instrument has advantages and disadvantages as summarized in the following table: 
Mechanically simple and low-cost. High light throughput requires low resolution.

Wide spectral range requires low resolution.

Diode laser can be used for excitation
Mechanically complex and expensive. High light throughput and high resolution simultaneously.

Wide spectral range and high resolution simultaneously. YAG laser required for excitation (at the present time).

Either type of instrument has been shown to be usable in Raman spectroscopy and the best choice depends on the details of the application. If the range of wavenumbers required for analysis is small or the resolution required is low, a grating instrument is probably the better choice. If a wide range and high resolution are required simultaneously an interferometric instrument will be needed.

Optical multiplexing is needed to share the laser and the spectrometer among several analysis points. There are two basic approaches that can be taken (Fig. 4). The laser light can be simultaneously shared among several excitation fibers with each fiber carrying a fraction of the laser light all the time (space multiplexing). Or the laser light can be moved from one fiber to another in turn so the excitation fibers time-share the laser light (time multiplexing). In either case the average power transmitted by any single fiber to the analyte over a long period of time is the same (assuming no loss of the excitation light in either method). Space multiplexing lends itself naturally to the use of a grating spectrometer because the CCD array used as a detector can be twodimensional and the return fibers from the process carrying the Raman-scattered light can (at least in principle) be simultaneously imaged each onto a separate row of the CCD array. Time multiplexing is more appropriate for an interferometric spectrometer since a single detector is used. The advantage of space multiplexing is that there is no movement of the fibers once the system has been aligned. The disadvantage is that the initial alignment process is critical and must be maintained for a long period of time in industrial applications. The advantage of time multiplexing is that alignment is not so critical. The disadvantage is that some fiber movement is needed at least on the spectrometer end and probably on both ends to put the appropriate fiber in the position to be imaged onto the detector at the right time. 


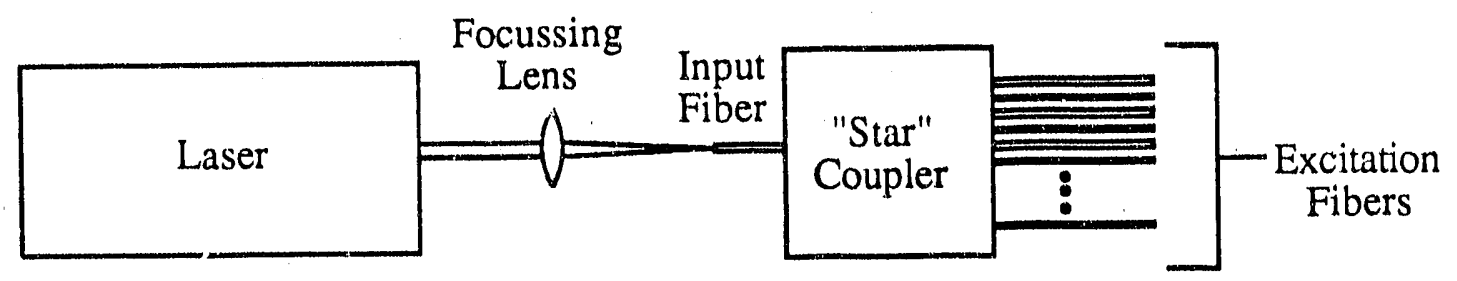

Space Multiplexing

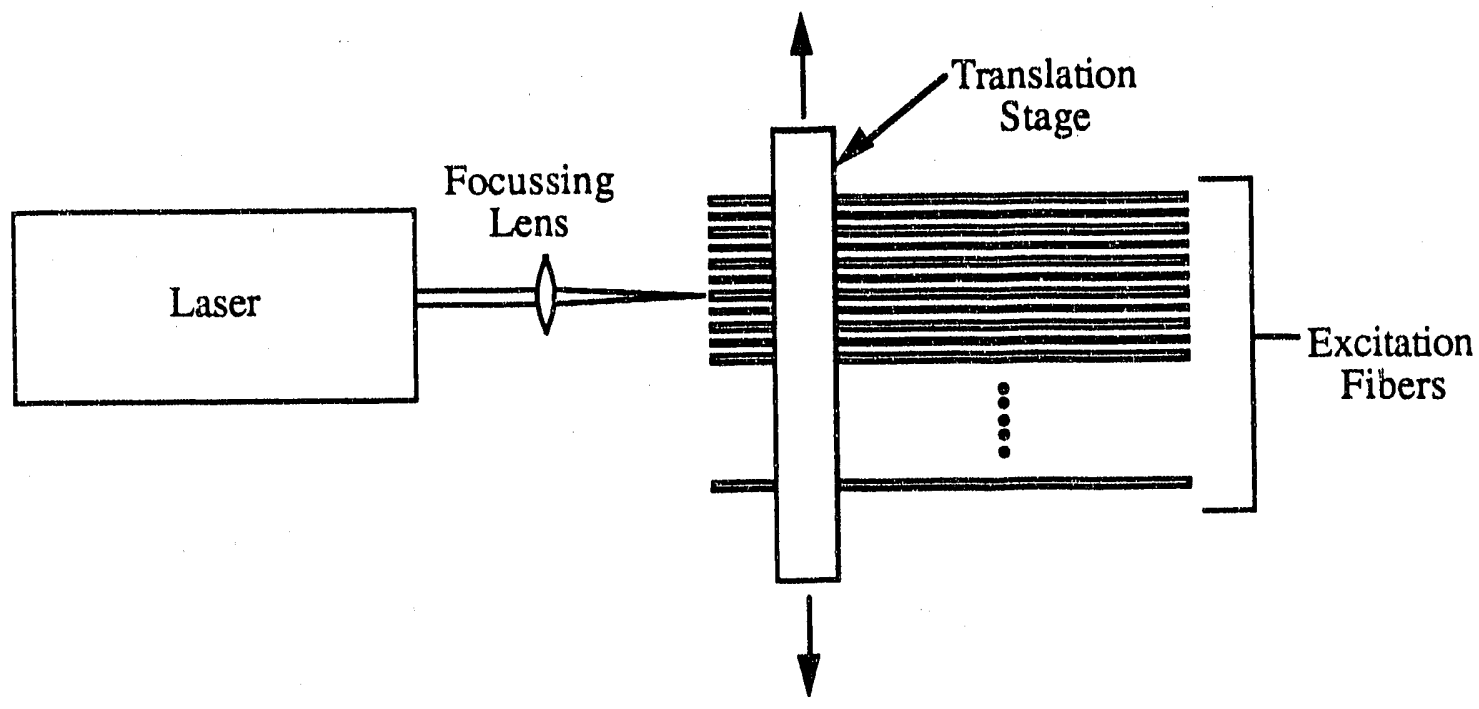

Time Multiplexing

Fig. 4 Space and time multiplexing at the excitation fiber end

Since Raman spectroscopy is an inefficient scattering phenomenon and light gathering efficiency is at a premium it is important to carefully consider the coupling of light from the laser into the excitation fibers and especially from the light-gathering fibers into the spectrometer $[28,29]$. In both cases an important optical principle must be observed; conservation of "etendue". Etendue is the product of area and solid angle of emission for a light source and is the product of area and solid angle of collection for a light detection system. If all the light from the excitation source is to be coupled into the excitation fibers or all the Raman-scattered light is to be coupled into the spectrometer the etendue of the excitation fibers must exceed that of the the excitation source and the etendue of the spectrometer must exceed that of the fiber or fibers which transmit the Raman-scattered light [30].

At the excitation end the coupling is relatively simple. The input light source is a laser. If it is any laser except a diode laser, its light output is almost perfectly collimated. Being collimated the solid angle of emission of light is essentially zero and therefore so is its etendue [31]. This guarantees that (at least in principle) all the laser light can be coupled into the excitation fiber. A microscope objective can be used to focus the light to a diffraction-limited spot and the excitation fiber core is centered on this spot. With a good quality translation stage the fiber positioning is relatively easy for large core fibers $(200 \mu \mathrm{m}$ and up). It becomes more tedious for smaller diameter fibers (below $200 \mu \mathrm{m}$ ) but is still feasible. The output beam from a diode laser has significant divergence and is generally astigmatic (elliptical cross section) but diode lasers can be purchased with correction optics to circularize the cross section and "collimate" the beam making the coupling considerations effectively the same as for any other laser. (The beam cannot be truly collimated since the laser diode is not a point source but since the diode laser output aperture is very small the divergence angle of the "collimated" beam is small.) A practical problem that has been observed 
with diode laser coupling to fibers is that the retro-reflection from the polished fiber end back to the laser tends to spoil the diode laser's cavity resonance and reduce its output power. 'This can be eliminated by interposing a directional coupler to stop the back reflection or, more simply, by tilting the incident angle so that the retro-reflection cannot re-enter the laser diode cavity. Because there are multiple glass-to-air interfaces in the coupling path, $100 \%$ efficiency cannot be achieved. But coupling efficiencies close to $90 \%$ have been achieved experimentally without taking any heroic measures. If the surfaces are all anti-reflection coated at the laser wavelength the efficiency can rise into the high 90 's.

At the spectrometer end, efficiently coupling the returned Raman light is a more complicated problem. The coupling method depends on several factors. First if the spectrometer is dispersive the light enters it through a slit. The return fiber or fibers must be imaged onto that slit by appropriate optics. If there are multiple return fibers they should be arranged in a straight line, side-by-side, to most closely match their shape to the slit. If the spectrometer is interferometric the fibers are generally arranged in a pattern which most closely approximates a circular disk (close packed) so as to optimally image onto the detector which is usually circular (Fig. 5) [32,33]. Both dispersive and interferometric systems have an effective etendue which is determined by the geometry of their internal optical components and the size of their detector. If the etendue of the fiber(s) is smaller than that of the spectrometer it only remains to find the best optical system to match them. If, for instance, the range of angles of the spectrometer exceeds that of the fiber(s) and the detector is smaller, the optical coupling system would demagnify the fiber(s) to image them onto the detector.

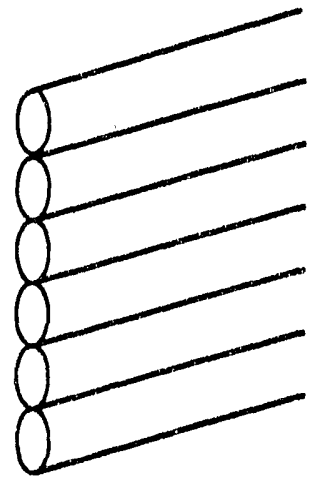

Linear Fiber Arrangement for Dispersive Instruments

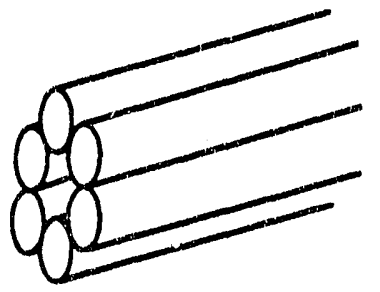

Circular or "Close-Packed" Arrangement of Fiber Ends for Interferometric Instruments

Fig. 5. Two fiber end arrangements for two types of spectrometers

Finally the software used to analyze the spectrum and determine the concentrations of the different components of the analyte must be considered [34,35,36,37,38,39,40]. There are at least three methods popular today; 1) multiple linear regression, 2) partial least squares and 3) neural networks. In each method a set of "training" or "calibration" data must be taken over a range of concentrations including the expected range to be measured in practice. The number of training sets must be more than the number of components to be analyzed; many more if there is significant noise in the data. Each of the methods uses the training data to create a model of the relation between spectral features and concentrations. The model is used to estimate concentrations of unknowns from new snectra. 


\section{THE UNIVERSITY OF TENNESSEE (UT) DESIGN}

The first decisions in the UT design were directed to determining which analytes would be targeted. In cooperation with the member companies of the University of Tennessee Measurement and Control Engineering Center (MCEC) three analytes were identified:

1. a mixture of acetic acid and a proprietary solvent with a small water content which is found in an acetic acid recovery column at Tennessee Eastman Corporation's plant in Kingsport, Tennessee,

2. a mixture of cumene and cumene hydroperoxide, with low concentrations of acetophenone and di-methyl benzyl alcohol, found in a process developed by Hercules

and 3. a mixture of isopropanol and water found in the student experimental distillation column in the chemical engineering department of the University of Tennessee.

The Raman spectra of these analytes are shown in Figures 6 through 8.

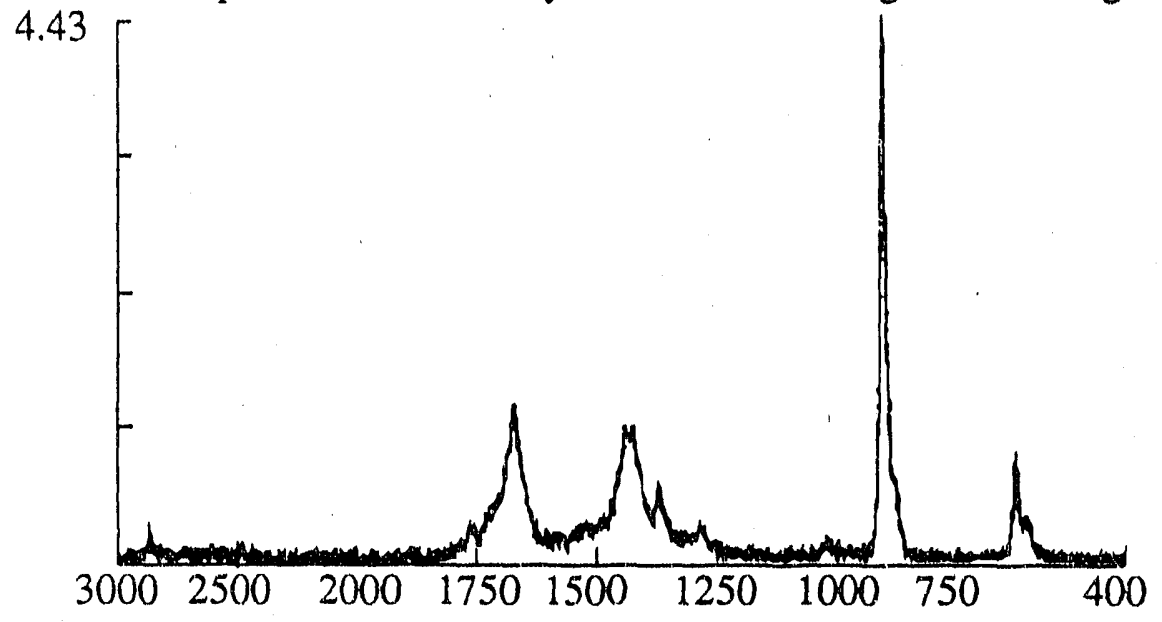

Fig. 6 Raman spectrum of acetic acid-solvent analyte

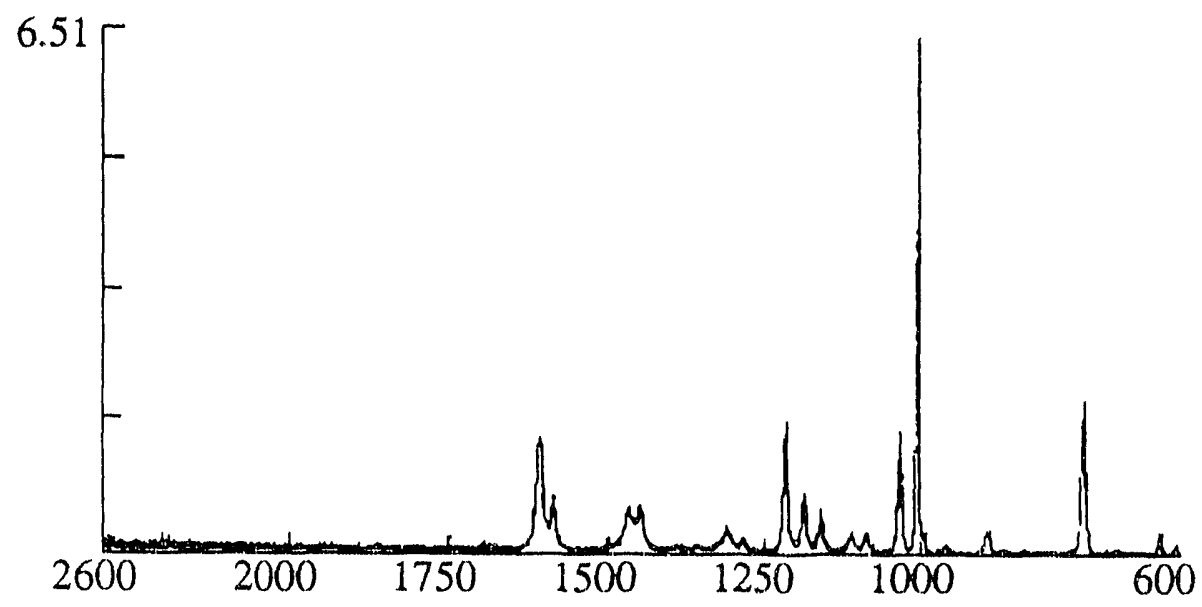

Fig. 7 Raman spectrum of cumene-cumene hydroperoxide analyte 


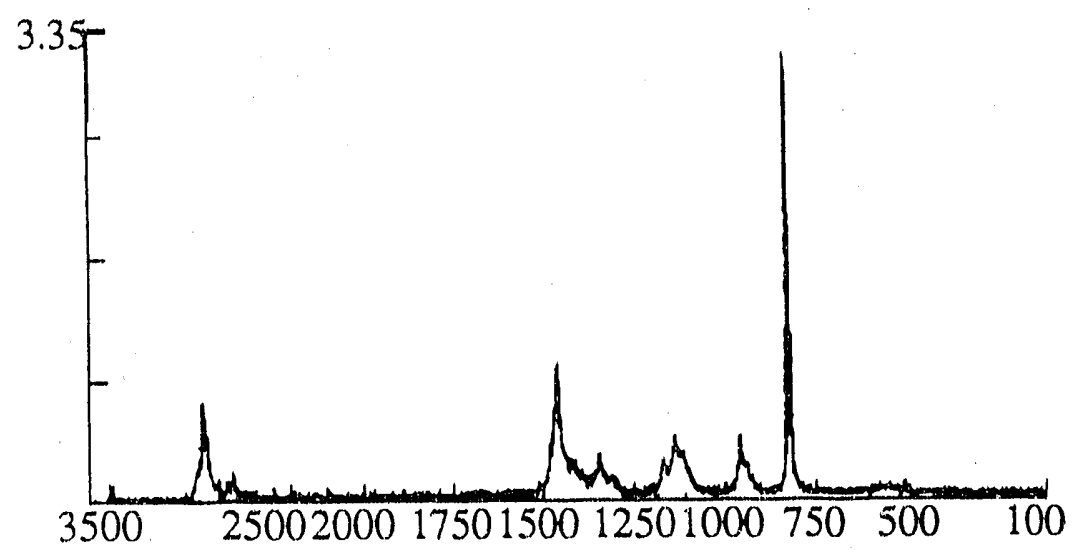

Fig. 8 Raman spectrum of isopropanol

The range of significant features is from about 500 to about 2700 wavenumbers relative to the exciting line. Also, in the cumene analyte the strongest cumene hydroperoxide and acetophenone features lie very close to each other and to distinguish between them requires resolution of two wavenumbers or less. Given this combination of wide range and high resolution requirements an interferometer was chosen as the analysis instrument.

Several tests were conducted to determine the shortest practical wavelength that could be used for excitation without causing fluorescence. These included an argon laser at $514 \mathrm{~nm}$, a krypton laser at $676 \mathrm{~nm}$, a diode laser at $725 \mathrm{~nm}$ and a YAG laser at $1024 \mathrm{~nm}$. At $514 \mathrm{~nm}$ the fluorescence in one analyte was very large, obscuring the Raman spectrum. At $676 \mathrm{~nm}$ there was a noticeable background but Raman features were visible. At 725 and $1024 \mathrm{~nm}$ there was no noticeable fluorescence at all in any of the analytes. The most powerful diode lasers available with a narrow line (single longitudinal mode) have a power of $100 \mathrm{~mW}$ at about $830 \mathrm{~nm}$. Our range of wavenumbers in the Stokes spectrum would push the Raman spectrum up to about $1000 \mathrm{~nm}$. Thus silicon detectors could be used. The maximum power available in CW Nd:YAG lasers in a single longitudinal mode is about $20 \mathrm{~W}$. The useful Raman spectrum extends to about $1.3 \mu \mathrm{m}$. This range is ideal for transmission through silica fibers. Even though a diode laser is preferable from the point of view of size, reliability and Raman-scattering efficiency we chose to use the $\mathrm{Nd}$ :YAG laser because the available power is much higher and we need the high power to make the signal-to-noise ratio of the measurement adequate for fast analysis. (When diode laser powers approach $500 \mathrm{~mW}$ in a single longitudinal mode they will probably be preferred.) With YAG excitation the detector cannot be silicon and an InGaAs photodiode was used. A germanium photodiode could also have been used. We chose a diode-pumped YAG with about $2 \mathrm{~W}$ of power.

The probes we chose are made according to a DOW Chemical Co. patent [41]. They consist of a single $400 \mu \mathrm{m}$ core, low-water, silica excitation fiber and 6 identical fibers arrayed around the excitation fiber to collect the Raman-scattered light (Fig. 10). The collection fibers are arrayed at a small angle to the excitation fiber in order to increase collection efficiency. The optimal angle depends on the optical characteristics of the fiber (numerical aperture and core size) and the analyte (refractive inclex and attenuation). 


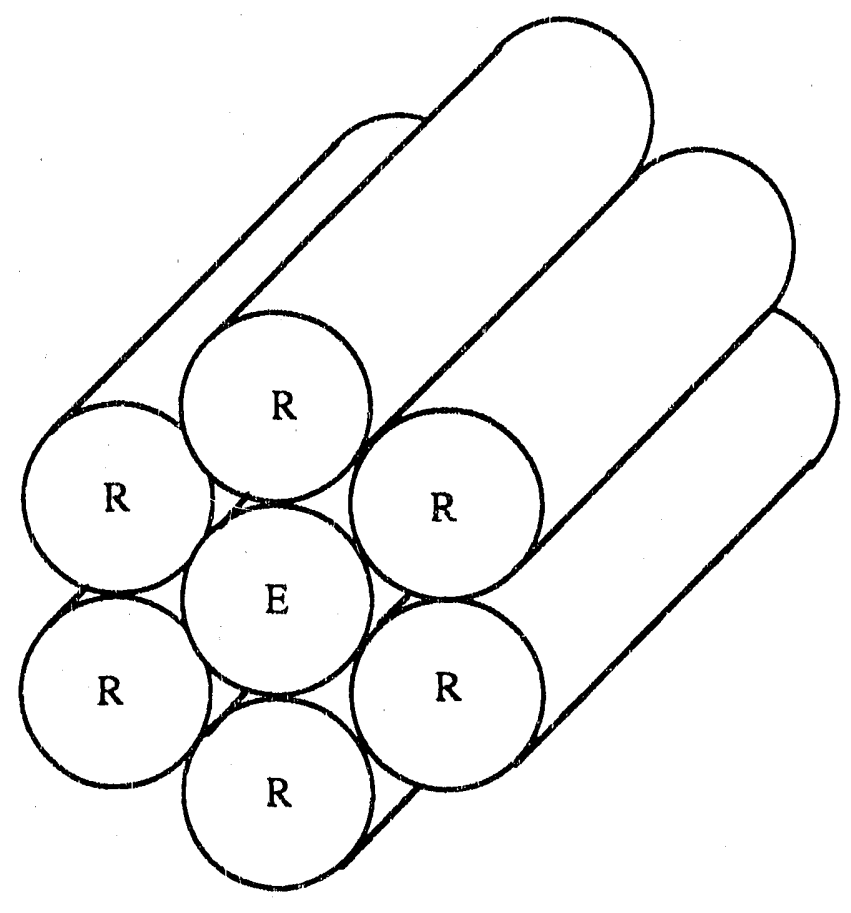

E - Exciting Fiber
R - Receiving Fiber

Fig. 9 DOW fiber probe design concept

There are no intervening optical elements at all. The amount of light collected depends simply on the overlap of the cone of light from the excitation fiber and the cones of acceptance of light of the collection fibers (Fig. 11). The analysis of collection efficiency involves a complicated 5dimensional integral which must, in general, be solved numerically. Numerical analysis has shown that for the fibers we used the optimal angle was near 10 degrees for our analytes which have refractive indices near 1.5 and very little attenuation at $1.064 \mu \mathrm{m}[42,43,44]$. 


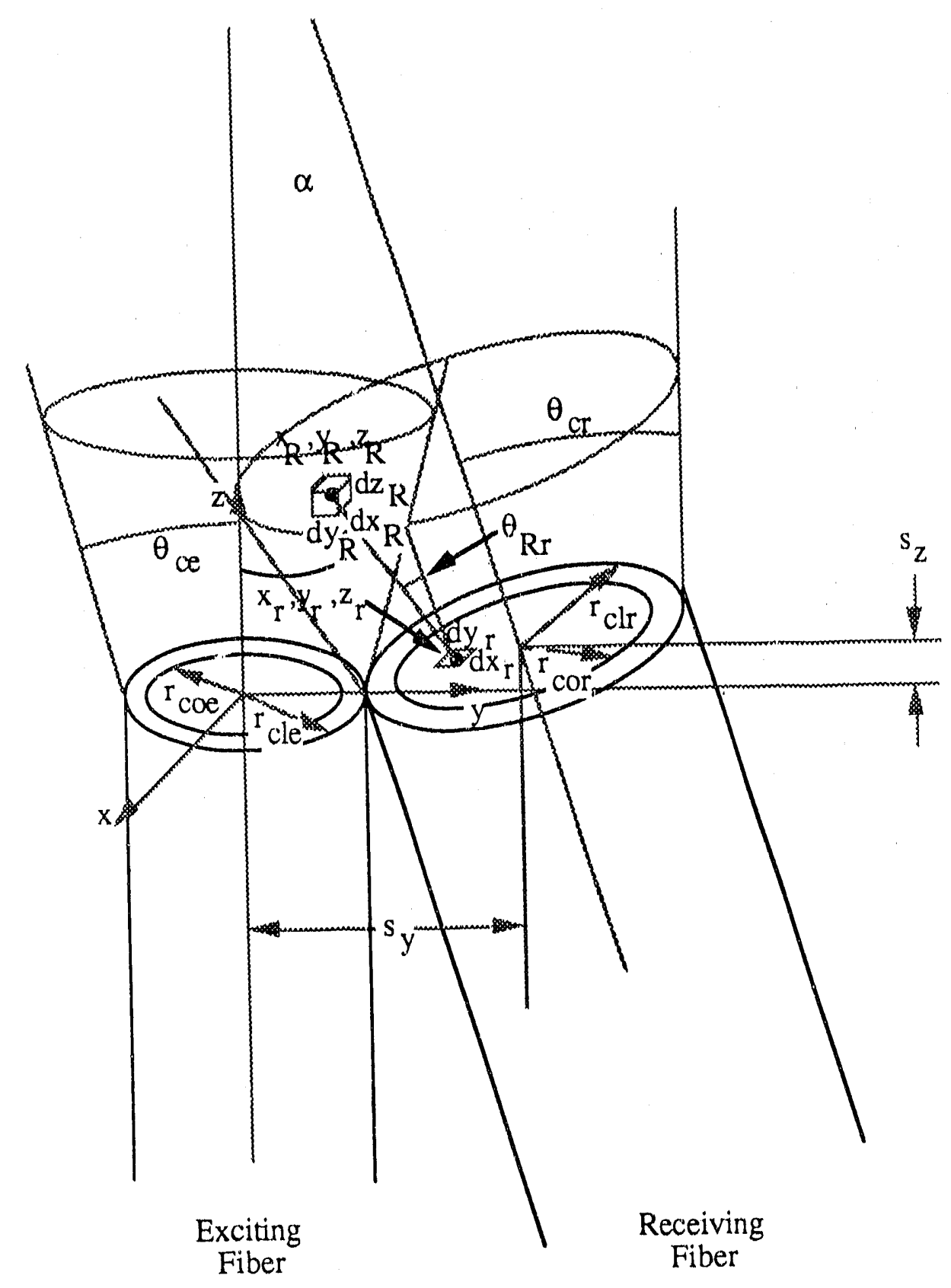

$$
P_{r}=\frac{P_{0} \beta N}{\pi_{\text {receiving fiber }}}\left\{\int_{\substack{\text { end surface } \\ \text { concing volume }}}\left[r\left(z_{R}\right)\right]^{2}\left[\left(d_{r R}\right)_{x}^{2}+\left(d_{r R}\right)_{y}^{2}+\left(d_{r R}\right)_{z_{r}}^{2}\right]^{\frac{3}{2}}\right\}
$$

Fig. 10 Mathematical model for fiber probe excitation and collection 
The overall light power gathered by this probe is roughly the same as the power gathered by a bench-top arrangement not employing optical fibers if care is taken in both cases to correctly couple the collected light into the spectrometer.

One problem with using silica fibers to guide the light is the presence of an extra Raman spectrum; that of the fiber itself [45]. There are two mechanisms by which this effect occurs:

1. On its way down the excitation fiber the excitation light causes Raman scattering in the excitation fiber. This "fiber Raman" light exits the excitation fiber with the excitation light and is Rayleigh scattered back into the collection fiber(s).

2. The excitation light at $1.064 \mu \mathrm{m}$ is Rayleigh scattered from the analyte. On its way back through the collection fibers it generates Raman scattering in the collection fibers.

This shows up as a fairly broad background interference (Fig. 12). We have shown by experiment that effect \#1 above is by far the strongest contributor of fiber Raman. This effect is typically not strong for liquid samples but is much stronger for solid samples which reflect more of the excitation light back into the collection fibers. The effect can be minimized by the use of extremely low water optical fibers [46].

Cyclohexane Spectrum through $35 \mathrm{~m}$ Fiber at $23^{\circ} \mathrm{C}$

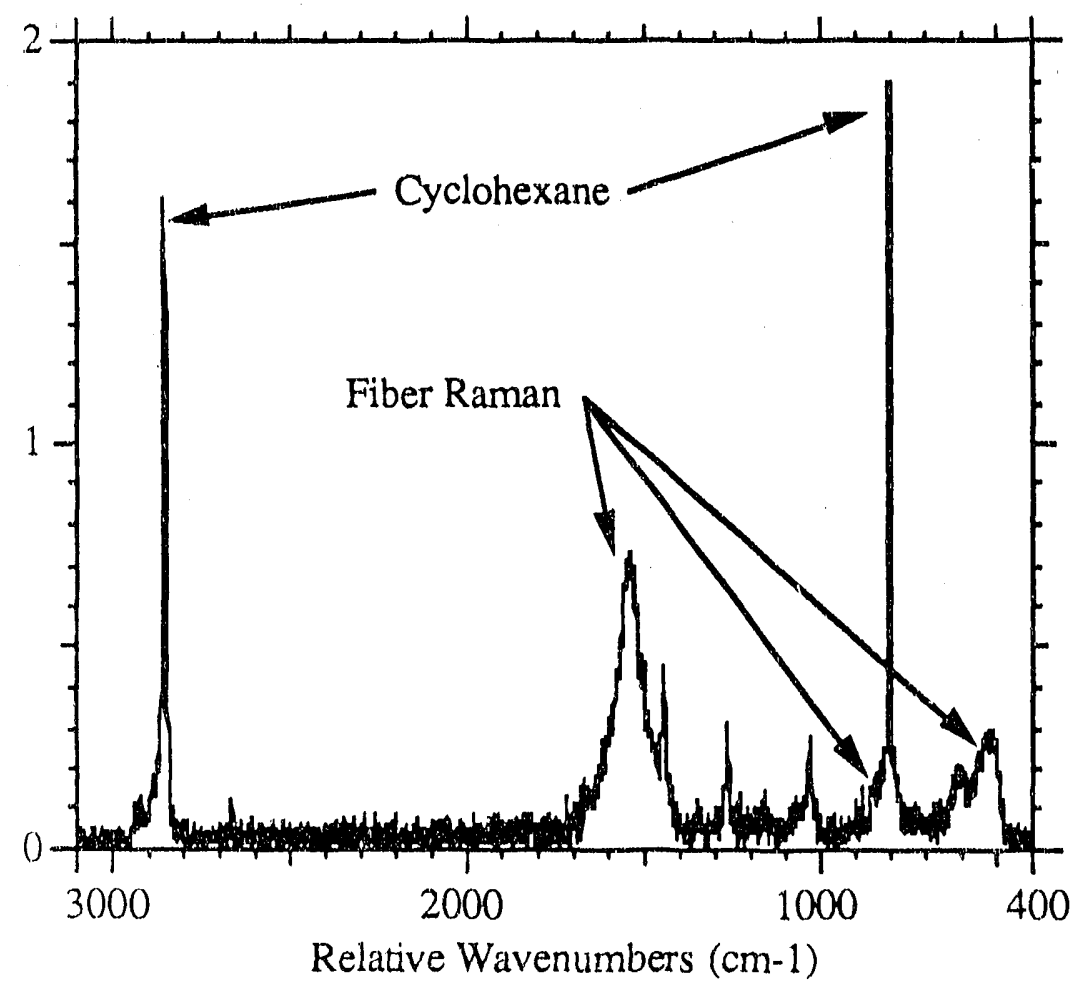

Fig. 11. Effect of "fiber Raman" on spectrum of cyclohexane.

In our tests so far, the presence of the fiber Raman background has not significantly degraded the chemometric accuracy our composition estimates for our analytes. 


\section{CONCLUDING REMARKS}

Raman spectroscopy is best suited to applications in which the concentrations of the analytes are in the percent range and not for trace concentrations. It is suitable for aqueous solutions because the Raman spectrum of water is very weak. Excitation wavelengths can be anywhere in the range of 700 to $1200 \mathrm{~nm}$ with the exact choice dependent on the magnitude of the fluorescence problem and the power available from the laser. The choice of a grating or interferometer instrument depends on the excitation wavelength, the range of wavenumbers required and the spectral resolution required. Fibers can be used to multiplex the instrument to multiple measurement points.

\section{ACKNOWLEDGMENTS}

The authors would like to acknowledge the advice and help from several sources. The Department of Energy (DOE) was the major sponsor of the Instrument development at the University of Tennessee. Chuck Mohr of EG\&G arid Mary Corrigan of DOE worked with us closely. Perkin-Elmer Corporation loaned us the interferometer and Alan Ganz and Bob Hannah have worked with us all along the way. DOW Chemical corporation helped us with probe design and loaned us one of their probes. At DOW Dick McLachlan, Ann Leugers and Ray Chrisman were very helpful. Tennessee Eastman Corporation (TEC), one of the original members of the MCEC, have been supportive from the inception and will provide a field test site for the instrument. At TEC Barry Ornitz, John Twork and Jim Doss have worked with us closely. Lois Weyer of Hercules and Ernie Baughman of Amoco have also been instrumental in the project's success.

\section{REFERENCES}

1. M. T. Riebe, and D. J. Eustace, "Process Analytical Chemistry: An Industrial Perspective", Analytical Chemistry, Vol. 62, No. 2, pp. 65A-71A, January 1990

2. M. J. Roberts, A. A. Garrison, S. W. Kercel, D. S. Trimble, C. F. Moore and E. C. Muly, "Development and Application of a Raman Spectroscopy Based Instrument for Multi-Point Composition Analysis and Control of a Distillation Column", ISA 90, New Orleans, LA, pp. 463 468, October 1990

3. A. A. Garrison, E. C. Muly, M. J. Roberts, D. S. Trimble and C. F. Moore, "Raman Spectroscopy for On-Line Distillation Process Control", ISA 89, Philadelphia, PA, pp. 357-363, October 1989

4. A. A. Garrison, D. S. Trimble, E. C. Muly, M. J. Roberts and S. W. Kercel, "On-Line Chemical Analysis Applied to Distillation Control - A Status Report", American Laboratory, pp. 19-27, February 1990

5. E. L. Wehry, "Modern Fluorescence Spectroscopy", Vols. 1 and 2, 1976, Plenum Press, New York

6. J. G. Grassel, M. K. Snavely and B. J. Bulkin, "Chemical Applications of Raman Spectroscopy", 1981, John Wiley and Sons, New York

7. B. J. Kip and R. J. Meier, "Determination of the Local Temperature at a Sample during Raman Experiments Using Stokes and Anti-Stokes Raman Bands", Applied Spectroscopy, Vol. 44, No. 4, pp. 707.711, November 1990 
8. R. Gaufrés, J. Maillols and V. Taback, "Composition of a Gaseous Mixture in Chemicinl Equilibrium as Studied by Raman Spectroscopy: Gas Phase Acetic Acid", Journal of Ramin Spectroscopy, Vol. 11, No. 6, pp. 442-448, 1981

9. E. N. Lewis, V. F. Kalasinsky and I. W. Levin, "Extending the Vibrational Limits in NearInfrared Fourier Transform Raman Spectroscopy", Applied Spectroscopy, Vol. 43, No. 1, pp. $156-159,1989$

10. M. A. Angel and M. L. Myrick, "Wavelength Selection for Fiber Optic Raman Spectroscopy. Part I", Applied Optics, Vol. 29, No. 9, pp. 11350-1352, March 1990

11. J. C. Palais, "Fiber Optic Communications", Prentice Hall, 1988, Englewood Cliffs, New Jersey

12. E. L. Dereniak and D. G. Crowe, "Optical Radiation Detectors", John Wiley and Sons, 1984, New York

13. J. E. Pernberton, R. L. Sobocinski, M. A. Bryant and D. A. Carter, "Raman Spectroscopy Using Charge.-Coupled Device Detection", Spectroscopy, Vol. 5, No. 2, pp. 26-36, 1990)

14. C. D. Allred and R. L. McCreery, "Near-Infrared Raman Spectroscopy of Liquids and Solids with a Fiber-Optic Sampler, Diode Laser, and CCD Detector", Applied Spectroscopy, Vol. 44, No. 7, pp. 1229-1231, 1990

15. Y. Wang and R. L. McCreery, "Evaluation of a Diode Laser/Charge Coupled Device Spectrometer for Near-Infrared Raman Spectroscopy", Analytical Chemistry, Vol. 61, No. 23, pp. 2647-2651, December 1989

16. J. M. Williamson, R. J. Bowling and R. L. McCreery, "Near-Infrared Raman Spectroscopy with a 783-nm Diode Laser and CCD Array Detector", Applied Spectroscopy, Vol. 43, No. 3., pp. $372-375,1989$

17. M. J. Webb, "Practical Considerations When Using Fiber Optics with Spectrometers", Spectroscopy, Vol. 4, No. 6, 1989

18. D. J. Cutler, "The Development of Fourier Transform Raman Spectroscopy", Spectrochimica Acta, Vol. 46A, No. 2, pp. 123-129, 1990

19. D. J. Cutler, "Fourier Transform Raman Instrumentation", Spectrochimica Acta, Vol, 46A, No. 2, pp. 131-151, 1990

20. N. J. Everall and J. Howard, "Signal-to-Noise Considerations in FT-Raman Spectroscopy", Applied Spectroscopy, Vol. 43, No. 5, pp. 778-781, 1989

21. P. R. Griffiths, H. J. Sloane and R. W. Hannah, "Interferometers vs Monochromators: Separating the Optical and Digital Advantages", Applied Spectroscopy, Vol. 31, No. 6, pp. 485496, 1977

22. C. J. Petty and R. Bennett, "Future Advances in Near Infrared Fourier Transform Raman Spectroscopy", Spectrochimica Acta, Vol. 46A, No. 2, pp. 331-337, 1990)

23. J. G.Radziszewski and J. Michl, "Doubled Multiplexing in Fourier Transform Raman Spectroscopy", Applied Spectroscopy, Vol, 44, No. 3, pp. 414-418, 1990 
24. M. B.Seasholtz, D, D. Archibald, A. Lorber and B, R. Kowalski, "Quantitative Analysis of Liquid Fuel Mixtures with Use of Fourier Transform Near-IR Raman Spectroscopy", Applied Spectroscopy, Vol. 43, No. 6, pp. 1067-1072, 1989

25. N.Sheppard, R. G. Greenler and P. R. Griffiths, "A Theoretical Discussion of the Comparative Performances of Dispersion and Fourier-Transform Interferometric Spectrometers for the Infrared Region", Applied Spectroscopy, Vol. 31, No. 5, pp. 448-450, 1977

26. G. M. Alber and A. G. Marshall, "Effect of Sampling Rate on Fourier Transform Spectra: Oversampling is Overrated", Applied Spectroscopy, Vol. 44, No. 7, pp. 1111-1116, 1990

27. P. Harihan, "Optical Interferometry", Academic Press, 1985, New York

28. D. D. Archibald, C. E. Miller, L. T. Lin and D. E. Honigs, "Remote Near-IR Reflectance Measurements with the Use of a Pair of Optical Fibers and a Fourier Transform Spectrometer", Applied Spectroscopy, Vol. 42, No. 8, pp. 1549-1558, 1988

29. A. Crookell and P. J. Hendra, H. M. Mould and A. J. Turner, "Fourier Transform Raman Spectroscopy in the Near-Infrared Region", Journal of Raman Spectroscopy, Vol. 21, pp. 85-90, 1990

30. S. W. Kercel, M. J. Roberts, A. A. Garrison, and D. S. Trimble, "Development of a FiberOptic Based Instrument for On-Line Raman Analysis of Process Chemical Composition", SENSORS EXPO WEST, March, 1990

31. A. E. Siegman, "Lasers", University Science Books, 1986, Mill Valley, CA

32. B. Moslehi, J. Ng, I. Kasimoff and T. Jannson, "Fiber-optic Coupling Based on Nonimaging Expanded-Beam Optics", Optics Letters, Vol. 14, No. 23, pp. 1327-1329, 1989

33. M. L. Myrick, S. M. Angel and R. Desiderio, "Comparison of Some Fiber Optic Configurations for Measurement of Luminescence and Raman Scattering", Applied Optics, Vol. 29 , No. 9, pp. 1333-1344, 1990

34. K. P. J. Williams, "Remote Sampling Using a Fibre-Optic Probe in Fourier Transform Raman Spectroscopy", Journal of Raman Spectroscopy, Vol. 21, pp. 147-151, 1990

35. R. M. Hoy and W. F. McClure, "Fourier Transform Near-Infrúred Spectrometry: Using Interferograms to Determine Chemical Composition", Applied Spectroscopy, Vol. 43, No. 6, pp. $1102-1104,1989$

36. E. V. Thomas and D. M. Haaland, "Comparison of Multivariate Calibration Methods for Quantitative Spectral Analysis", Anal. Chem. Vol. 62, pp. 1091-1099, 1990

37. P. M. Fredericks, J. B. Lee, P. R. Osborn and D. A. J. Swinkels, "Materials Characterization Using Factor Analysis of FT-IR Spectra. Part 1: Results and Part 2. Mathematical and Statistical Considerations", Applied Spectroscopy, Vol. 39, No. 2, pp. 303-316, 1985

38. E. R. Malinowski, "Theory of Error in Factor Analysis", Analytical Chemistry, Vol, 49, No. 4, pp. 606-617, 1977

39. P. C. Gillette and J, L. Koenig, "Noise Reduction via Factor Analysis in FT-IR Spectra", Applied Spectroscopy, Vol. 36, No. 5, pp. 535-539, 1982 
40. D. E. Honigs, G. M. Hieftje and T. Hirschfeld, "Number of Samples and Wavelengths Recuired for the Training Set in Near-Infrared Reflectance Spectroscopy", Applled Spectroscopy, Vol. 38, No. 6, pp. 844-847, 1984

41. R. D. McLachlan, G. L. Jewett and J. C. Evans all of the DOW Chemical Co. of Midland Michigan, "Fiber-Optic Probe for Sensitive Raman Analysis", U. S. Patent No, 4,573,761, Filed September 14, 1983, Granted March 4, 1986

42. P. J. Hendra, G. Ellis and D. J. Cutler, "Use of Optical Fibres in Raman Spectroscopy", Journal of Raman Spectroscopy, Vol. 19, pp. 413-418, 1988

43. L. A. Johnson and S. C. Jensen, "Problems and Approaches for Remote Fiber Optic Absolute Sensors", SPIE Vol. 566 Fiber Optic And Laser Sensors III, pp. 45-53, 1985

44. S. D. Schwab and R. L. McCreery, "Versatile, Efficient Raman Sampling with Fiber Optlcs", Arral. Chem. Vol. 56, pp. 2199-2204, 1984

45. M. J. Roberts, S. W. Kercel and A. A. Garrison, "Recent Advances in the Development of 4 Fiber-Optic Based Instrument for On-Line Raman Analysis, SPIE, San Diego, CA, July 1990

46. M. L. Myrick and S. M. Angel, "Elimination of Background in Fiber-Optic Raman Measurements", Applied Spectroscopy, Vol. 44, No. 4, pp. 565-570, 1990 


\section{Appendix D}

1991 Pittsburgh Conference Presentation Abstract

D-1 
Lithium has beon studied oxtonglvely, luo lo

1te arent potential na a battery nucolo imtorlul. Although one could achlove nimost $100 \%$

offledenoy for cathodloally claposiling 1 thlifum, it is difrloult to obtain $100 \%$ dlesullil loul alflotency of the 1tthtum clepositioll. Tho milll source of the problem is tho formit trill of

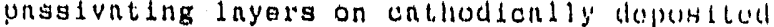
ilthium. This creates the problem for oblilludils

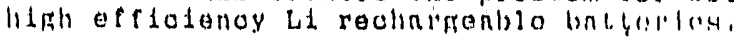

He used Hamun speotroscopy for tho uhililletolization of the passivating layers on llio

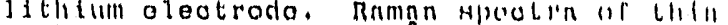

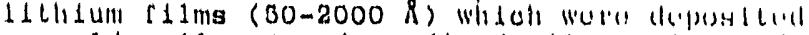
on gold, sllver, and arrodized sllver oloctrodes were recorded in severtil solute/solvont systomy such ng L1AsF $/$ propylene cnrbonnto ( $\Gamma($ i) nnd LiC1O $/$ PC, Mixed solvent systems lilclidlil? methy 1 formate (MF) + dimethyl carbonnlo (bNC:) nald mathyl neetate (AIA) + dlathyl cnelsollnto (DEC) Were algo examined. A thill-lilut. uoll 114 well as a conventional two-compnrlineil sull why used for recording the Rnmnn spoolyll. Fho berti results were obtalned when 00-100 $h$ of 111,11111 flims were deposited on elther the silval of the nnodized silver eloctrode. At lifo mmosill silver, eleotrode, strong Rnman sentholllls l rem solvelio, supporting electrolyte, nnd llnkniswll

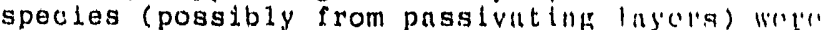
observed after depositing a thill ill fllm $(50 h)$, Intensities of Raman bands stnrted to dererenso whon thicker Li flims (moro than ouo $R$ ) 1 were depostted. The observed high lillonslly Mnmin

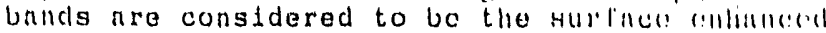

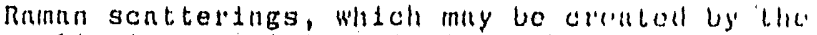
small size particles of $L 1$ on tho 4misolli HIlvol. sulfince, llowevor, this lypo of phendementim was not observed when a smooth gold sullinco whs used.

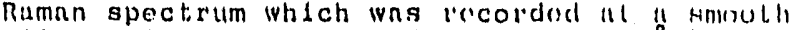
slivel electrode after dopositing $50 \&$ l. 1 li 1 mixed solvent of DMC and MF WILh LiClO 4 sholled severnl bands lnoluding 509, 730, 1008 , Ind $1215 \mathrm{~cm}^{-1}$. The mast likely specles, which ning be responsible for the observod balli, In IILhlum inethyl carbonate. The Rnman spoctium, Whloll was recorded at an anodized sliver electlocle: after depositing the LI f1Im Lin PC WLL lilClO, showed several low intonstly bands whl 'h mily be due to the formation of $\mathrm{Li}_{2} \mathrm{CO}_{3}$.

\section{0}

An Application for Surface-enhanced Raman Scallering us an Industrial Process Monitoring Technique.

DAVID BAILEY, ARLENE GARRISON, The University of Tennessec, Measurement and Control Engincering Center, Knoxville, TN 37996

Surfuce-enhanced Raman scattering (SLRS) has becn used us " liboratory analytical technique for over a decnde. Thic polential of SERS in some cases for remarkably increased sensilivity in the detection of trace amounts of Raman active chemicals suggests lis use as a process monitoring technique for industrial applicillions. Conventional Raman scattering is now being explored by lie clicmical industry as a process monitoring teclinique. However, its applicability may be limiled to the detcction of clicruicals that are gond Raman scatterers. SERS may provide a melloud for enhuncing the Raman spectra of poorly scattering chemicals that lave inclustrial significance.
Our Use of SERS is focused on the detectlon of industrial solvents stlch in toluono, honzene, and othor chemicals such as acello acid ilnd pyrlatie. The apparalus we have chosen for these experiments conislsts of a noar Infrarod FT. Raman Interferometor and a white. Ilylif punipod Nd:YAO luser emliting at 1.064 microns. Tho SERS surficos emiployed in these measurements aro electrochemically ronglienod Au wites. An SEIRS spectrum of 100 ppm by weight Ilyucous pyridine oblained in this manner is presented below. The specirll abinlned from these oxperlimonis indicate that somo thererestling hands may he brought oul through the use of this coclinicue. Such informution may then be used in the deicrmination of the concentratlon of the solution.

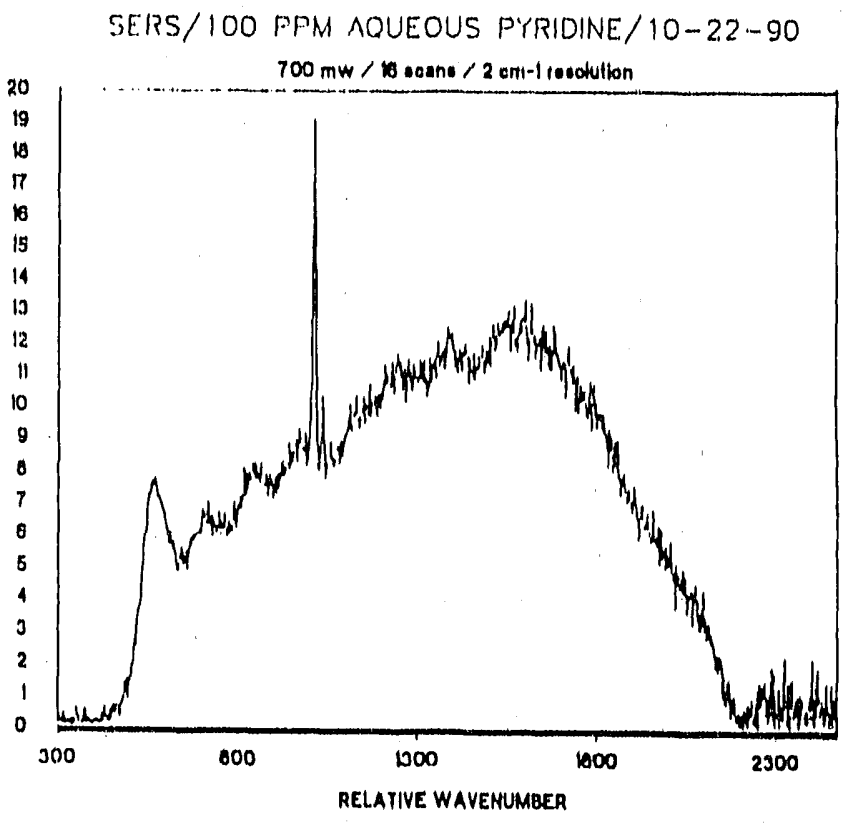

351

\section{$\triangle$ COMPARISON OF INTERFEROGRAM NOISES FROM DIODE AND PIIOTOMULTIPLIER TUBE DETECTORS.}

IVI:SLEYJ KOLAR, RON WILLIAMS

IIunier Liboratories Clemson Universily

Clanson, SC 29630

The purpose of this work was to compare the sources of nolsc in illerferograms while employing bolh germanlum dlode (ncar IR) and PMT (visible) detectors. Identical condlitions were used with each detector in order lliat differences in deicctor noises could be compared will minimal bias from other areas. The graplis below each represents the centerhurst reglon of 100 interforograms of 512 points each. Data collection was periormed employing a iungsten source and a Sirius 100 spectrometer (Mallson instruments Inc.) sel up for defection of both risible and near incrared radiation. A statistical analysis of interferogram noises will be presented along with an interpretation of their $\mathrm{D}-2$ effect on the resultant spectrn. 
Appendix E

\section{Bibliography}

E-1 


\section{BIBLIOGRAPHY}

1. Program Research and Development Announcement (PRDA No. DE-PR07-87ID12691), "Advanced Sensor Research and Development for Cement Kiln, Non-Paper Drying, and Distlllation Applications," Idaho National Engineering Laboratory, U.S. Department of Energy, Idaho Operations Office, July 25, 1987.

2. Garrison, A.A., Muly, E.C., Roberts, M.J., and Moore, C.F., On-Line Chemical Composition Analyzer Development Phase I Final Report (DOE/ID/1269-1), Idaho National Engineering Laboratory, U.S. Department of Energy, Idaho Operations Office, July 1989.

3. McLachlan, R.D., Jewett, G.L., and Evans, J.C., "Fiber-Optic Probe for Sensitive Raman Analysis," United States Patent No. 4, 573, 761, March 4, 1986.

4. Kercel, S.W., "A Sensor Using Raman Spectroscopy for On-Line Composition Monitoring of Distillation Mixtures in Real Time", Master's Thesis, August 1990, University of Tennessee, Knoxville, Tennessee.

5. Fleischmann, M, Sockalingum, D, and Musianl, M.M., "The Use of Near Infrared Fourler Transform Techniques in the Study of Surface Enhanced Raman Spectra," Spectrochim. Acta. Vol. 46A. pp 285-94. 

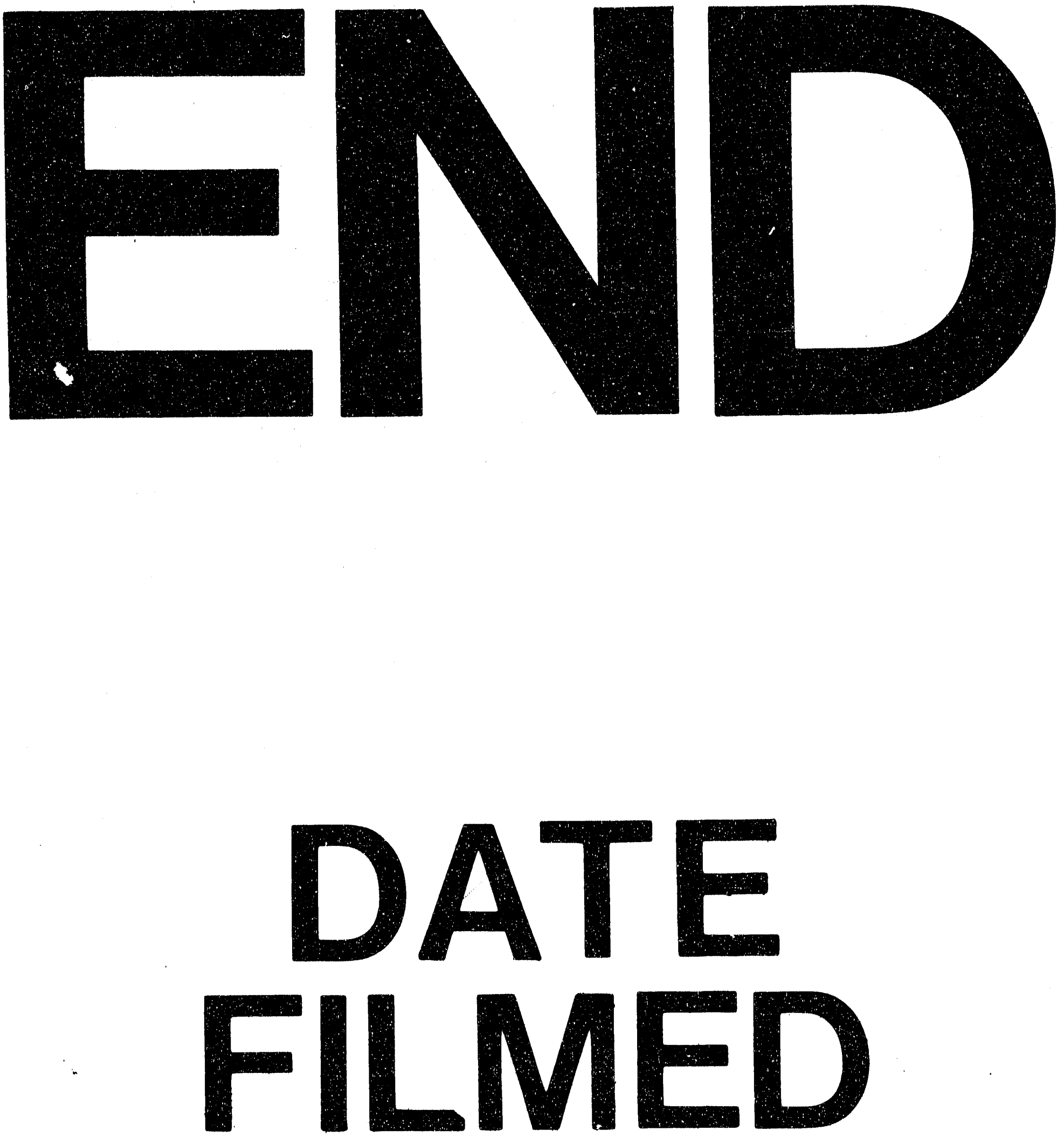

事

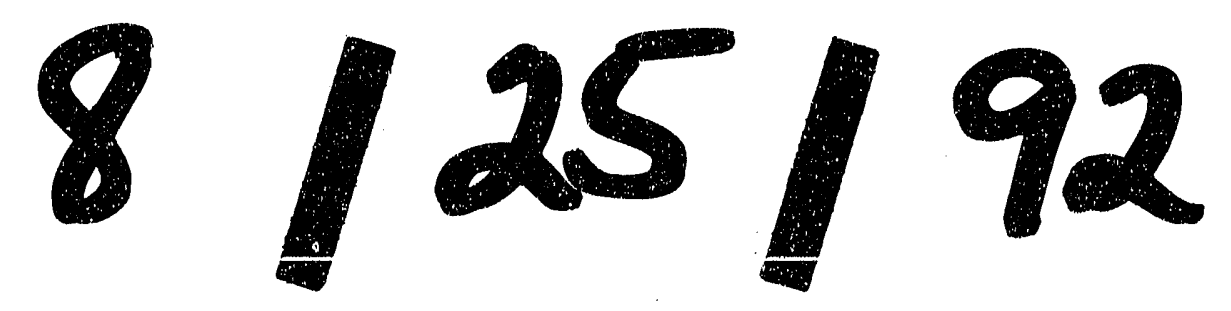


